The author(s) shown below used Federal funds provided by the U.S. Department of Justice and prepared the following final report:

Document Title: Incarcerated Women, Their Children, and the Nexus with Foster Care

Author:

Susan George, Roland Holst, Haeil Jung, Robert LaLonde, Rekha Varghese

Document No.:

234110

Date Received: April 2011

Award Number: 2004-IJ-CX-0036

This report has not been published by the U.S. Department of Justice. To provide better customer service, NCJRS has made this Federallyfunded grant final report available electronically in addition to traditional paper copies.

Opinions or points of view expressed are those of the author(s) and do not necessarily reflect the official position or policies of the U.S. Department of Justice. 
Incarcerated Women, Their Children, and the Nexus with Foster Care

Susan George, Roland Holst, Haeil Jung, Robert LaLonde, and Rekha Varghese

\section{Final Report}

November 2007

This research was supported by grant \# 2004-IJ-CX-0036 to the University of California at Berkeley and to the subcontractor, the Harris School, The University of Chicago. The views expressed in this report are those of the authors and do reflect the views of the National Institute of Justice or any agency of the state of Illinois or the U.S.Government. The authors are responsible for all errors. Send correspondence to Robert LaLonde, $\underline{\mathrm{r}-}$ lalonde@uchicago.edu or The Harris School, 1155 East 60 ${ }^{\text {th }}$ Street, Chicago, IL 60637. 
This document is a research report submitted to the U.S. Department of Justice. This report has not been published by the Department. Opinions or points of view expressed are those of the author(s) and do not necessarily reflect the official position or policies of the U.S. Department of Justice.

\title{
Incarcerated Women, Their Children, and the Nexus with Foster Care
}

\author{
Susan George, Roland Holst, Haeil Jung, Robert LaLonde, and Rekha Varghese
}

\begin{abstract}
This study shows how state administrative data can be used to assess the relationships between the criminal justice and child welfare systems. After matching corrections data on female offenders from Illinois to the state's child welfare records, we examine the incidence of childhood foster care spells among incarcerated women, the incidence of female prisoners having their own children in foster care, and how time in prison or jail is associated with different foster care outcomes, such as the loss of parental rights.
\end{abstract}




\section{Table of Contents}

1. Executive Summary

2. Introduction

3. The Childhood Foster Care Experiences of Female State Prisoners and What it Means for Reentry: Evidence from Matched Administrative Data from Illinois.

4. Incarcerated Mothers, Their Children's Placements into Foster Care, and its Consequences for Reentry and for Labor Market Outcomes.

5. Does Time in Prison Affect a Mother's Chances of Being Reunified With Her Children in Foster Care? Evidence from Cook County, Illinois.

6. Appendix: Notes on "The Value of Integrated Administrative Databases for Child and Family Research,” by Robert M. George. 


\section{Executive Summary}

This report grew out of the Incarcerated Women and Mothers Project at the Harris School at the University of Chicago. This project began with a grant from the Chicago Community Trust to examine whether it was possible to merge administrative data bases from different state agencies in Illinois to provide a fuller picture of the incarceration, employment, social and child welfare histories of women and their children.

With this new database and a few preliminary findings, we proposed to the National Institute of Justice a detailed analysis of the matched administrative database that had five broad objectives:

- First, because these is so little quantitative information available on these links, we proposed to provide an in depth description of the data.

- Second, we proposed to compare children's experiences in the foster care system in the matched data base to aggregate statistics on the experiences of all children in the foster care system.

- $\quad$ Third, we proposed to describe the timing and dynamics of foster care spells of incarcerated mothers.

- Fourth, we proposed to compare incarcerated women who were in the foster care system as children to their counterparts who did not appear in the child welfare system as children.

- Fifth, later in the project we added another objective: to improve the quality of the matches between prison spells, foster care spells, and several labor market outcomes of the women both before and after their first prison spells. These labor market outcomes were (1) quarterly earnings, (2) quarterly employment rates, and (3) earnings when women work.

\section{Own Foster Care Spells}

In Table 1, we present either our counts or our estimate of the incidence of childhood foster care spells among different cohorts of female prisoners. We define a woman's cohort by the year of her birth. As shown by the table, we find that estimates reported in the past by the Bureau of Justice Statistics that about 10 percent of women prisoners were in foster care as children are consistent with our findings from administrative data in Illinois.

There are three additional points we believe are important to highlight. First among more recent birth cohorts-those born between 1976 and 1983-this percentage is higher at about 17 percent. One possibility is that young female prison entrants are more likely to have been in foster care as children compared with older first time prisoners. A 
second factor is that the incidence of foster care rose for the general population during the 1970s. This interpretation of our findings indicates that the incidence of childhood foster care spells should be on the rise at present among current female state prisoners.

Second, our counts indicated that only a very small percentage of state prisoners likely "aged-out" of the foster care system. As shown by Table 1, among women prisoners born between 1961 and 1983, about 3 percent were in foster care after age 15. Among these women, we find that about one-half were reunited with their custodial parents or caregivers prior to their $18^{\text {th }}$ birthday. Third, coupled with our finding from earlier research that relatively few women enter prison for the first time prior to age 25, the pathway from foster care to prison at least is a relatively uncommon one for the population of incarcerated women.

Table 1

Percentage of Incarcerated Women in Foster Care As Children, by Year of Birth and Age When In FC

\begin{tabular}{llcc} 
& \multicolumn{3}{c}{ Age When in Foster care } \\
Year of Birth & $\mathbf{0 - 1 8}$ & $\mathbf{1 0}-\mathbf{1 8}$ & $\mathbf{1 5 - 1 8}$ \\
\hline $1976-1983$ & $16.9 \%$ & $13.0 \%$ & $5.8 \%$ \\
$1966-1983$ & $(9.5)$ & $7.3 \%$ & $3.7 \%$ \\
$1961-1983$ & $(9.2)$ & $(7.1)$ & $3.2 \%$ \\
\hline
\end{tabular}

Notes: Percentages indicate percentage of female state prisoners with childhood foster care experience during the indicated age category; includes spells that started during or overlapped with the indicated age category. Numbers in parentheses are estimated. Source: Figures computed by the authors from matched IDOC and DCFS administrative data bases.

\section{Labor Market Histories of Women in Foster Care as Children.}

This analysis of the labor market outcomes of female prisoners who also had been in foster care as children reveals that they were more economically disadvantaged than other female prisoners. Our findings include the following:

(a) Women who were in foster care during their late teenage years and those who were not had substantially higher earnings after prison than before entering prison for the first time.

(b) The earnings of women without late teen foster care histories grow with time since exiting their first prison spell. By contrast, the earnings of their peers who were in foster care at some point during their late teens declined during the quarters following their parole from prison.

(c) Women with childhood foster care spells earn less than other female prisoners before prison, but this gap is most pronounced after prison. During any given 
This document is a research report submitted to the U.S. Department of Justice. This report has not been published by the Department. Opinions or points of view expressed are those of the author(s) and do not necessarily reflect the official position or policies of the U.S. Department of Justice.

quarter after prison these women earned about $\$ 100$ to $\$ 400$ less than other women.

(d) This finding above in (c) results because women with childhood foster care histories earn less when they work. By contrast their quarterly employment rates are the same as their peers without these childhood foster care histories.

(e) These findings in (a) through (d) can be replicated for female prisoners in foster care at any time after age 10. After being paroled these women perform worse in the labor market than women without childhood foster care experience. The main reason is that the earnings of women with childhood foster care experience fail to grow after prison.

(f) Among women with childhood foster care experience, time in foster care is not especially good predictor of employment and earnings outcomes. This finding suggests that the foster care experience in and of itself does not "cause" poorer post-prison employment outcomes. Instead, it is likely that having been in foster care as a child is associated with a set of (unobserved) characteristics likely to be linked to poor prospects for reentry.

(g) Among female inmates with childhood foster care experience whether she "agedout” or was reunified with a parent has little bearing on her labor market skills, productivity or reentry prospects.

To illustrate the ways that we illuminate these findings in this report, below is an example of the many figures that shows the relationship between women's quarterly earnings histories relative to the quarter that they enter or exit prison and their own foster care experiences as children.

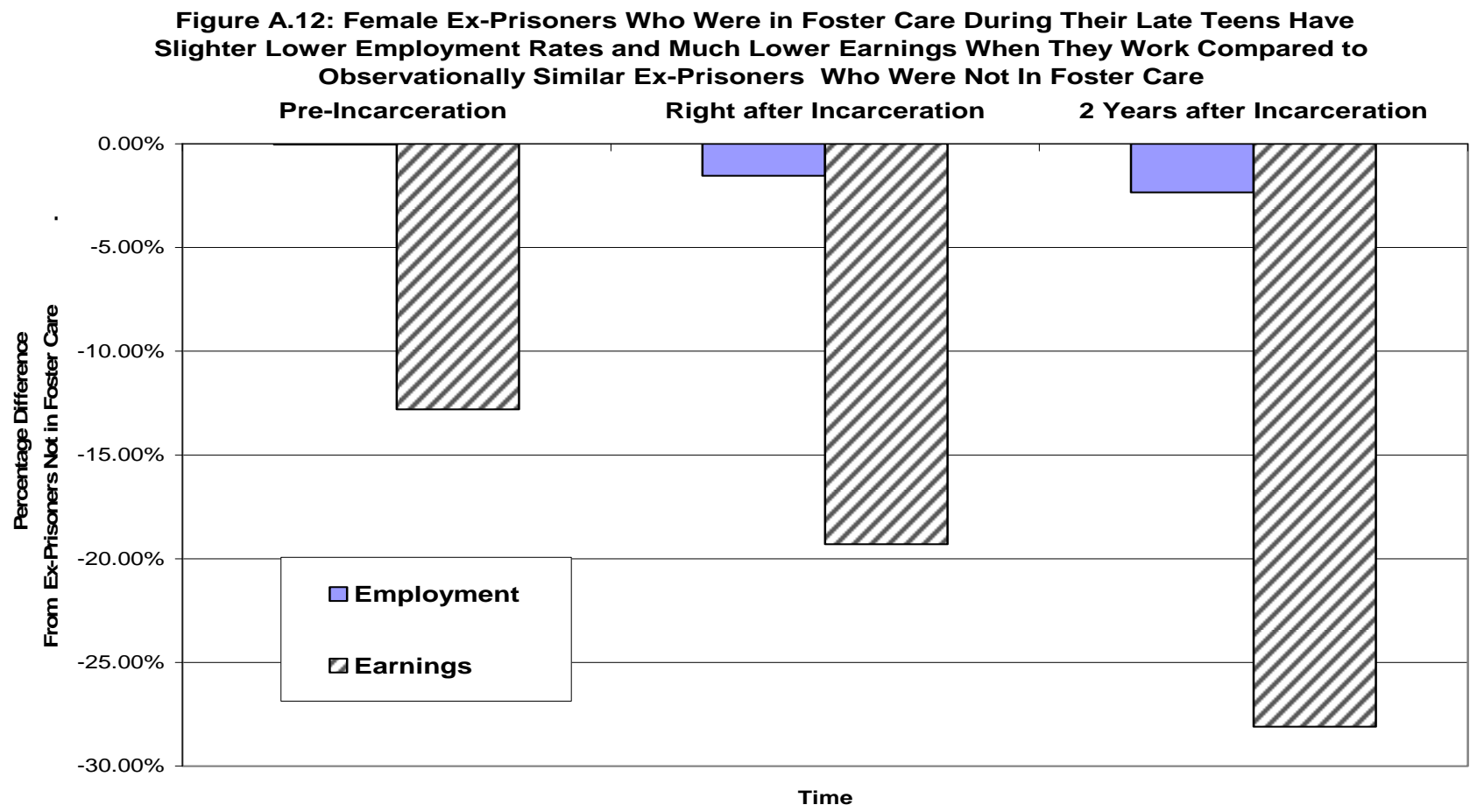




\section{Foster Care Spells of the Children of Incarcerated Mothers}

We also examined the labor market histories of women whose children had been in foster care. We find that about 26 percent of women in prison had children in foster care at some point between 1976 and 2001. Because those women prisoners with many children are more likely to have had their children spend time in foster care, at least 33 percent of Illinois children whose mothers spent time in prison also were in foster care at some point during their childhood.

One of our most interesting findings in our report is that many of these foster care spells begin and end prior to women's first prison spell. An accounting of these spells is presented below in Table 2. In the first row of the table, we observe that 74 percent of women who entered prison between July 1989 and June 2001 had children who had no apparent contact with the foster care system. (The percentage of mothers is lower, because only they can have their own children in foster care.)

Among women whose children spent time in foster care, about one-third (i.e. 5\% + 4\% / $26 \%$ ) of the spells had ended prior to their first prison spell. In nearly one-sixth (i.e. $4 \%$ / $26 \%$ ) of them the affected women had lost custody to at least one of their children prior to going to prison for the first time.

Most of the remaining foster care spells over lapped with time in prison. Given that these women's prison spells were short-about 9 months on average-the concentration of the foster care spells during this period suggests that prison may lead to more foster care stays among children of prisoners. However, we find that relatively few of these overlapping spells started within one year of entering prison.

As shown by Table 2, only a small percentage of the overlapping spells are resolved with the affected child being reunited with her mother. We are especially interested in the post-prison employment histories of women who are losing parental rights during or after prison.

Table 2

Foster care and Prison Spells of Women and Their Children

1) No Children Ever In Foster Care: 74\%

2) At least One Child Foster Care Spell Begins and Ends Prior to First Prison Spell:

Ends With Reunification with Mother: 5\%

Ends With Another Outcome, Including Adoption: 4\%

3) Children’s Foster Care Spells Overlap with Prison Spell: 
This document is a research report submitted to the U.S. Department of Justice. This report has not been published by the Department. Opinions or points of view expressed are those of the author(s) and do not necessarily reflect the official position or policies of the U.S. Department of Justice.

Ends With Reunification with Mother: 2\%

Ends With Another Outcome, Including Adoption: 13\%

4) Children's First Child Foster Care Spell Begins after First Prison Spell Ends: 2\% Source: Authors calculations from the merged data base.

\section{Labor Market Histories of Incarcerated Women with Children in Foster Care}

(a) Like other women who spent time in prison, women whose children spent time in foster care, also have more success in the labor market after prison compared to before prison. Prison does not appear to impair their labor market outcomes.

(b) Women without child foster care records have earnings that appear to be growing more rapidly after prison than are the earnings of women whose children were in foster care while they were in prison.

(c) The pre-prison earnings histories indicate that women who never have a child of theirs in foster care were more employable to start with than their counterparts who had children in foster care while in prison.

(d) The earnings histories of women who were reunified with their children are better than those of women who lost their parental rights or their children "aged-out" of foster care. Neither group does as well in the labor market, especially after prison, as women whose children had no apparent contact with the child welfare system.

(e) The reason that women who are reunited with their children earn more is because they were more likely to be employed during any given quarter than other women. But when they work they do not earn more than other women whose children spent time in foster care.

(f) Our findings indicate that having children in the child welfare system is an indicator of poor labor market outcomes. It does not matter much whether these foster care spells ended prior to, during, or after these women where incarcerated in prison.

(g) Women who were reunified with their children were more likely to be employed than their counterparts who lost parental rights. But, it is important to recognize that our data indicate that women who were reunified with their children have consistently had higher employment rates and not simply higher employment rates around the time that they were reunified with their children.

One implication of these findings is that having a child in FC does not appear to encourage women to work more after getting out of prison in order to try to get their kids back. Ever having a kid in FC is associated with poorer labor market outcomes no matter when the FC spell started or ended. Not surprisingly, losing parental rights is associated with especially bad and seemingly permanently bad labor market outcomes. Again it does not matter much whether lost parental rights before, during, or after prison. Just knowing this is a good indicator of especially poor labor market performance. But if officials know a women has a link to the child welfare system not only does this mean that she will do poorly in the labor market after (as well as before) prison but her earnings won't 
grow much either. Without intervention these women's prospects for reentry appear to be especially poor.

\section{Determinants of Reunification with Children in Foster Care}

The Adoption and Safe Families Act of 1997 appears to create barriers for incarcerated mothers whose children also were in foster care. Many advocates for this population have expressed concerns that this legislation would inadvertently lead to the "break-up" of families. Accordingly, in this part of the report we examine whether prison and time in prison is associated with lower reunification rates.

Our approach in this analysis is to compare two groups of incarcerated mothers who had children in child welfare system: (1) women who had only 1 jail spell and spent less than 1 week in jail after 1995; (2) women who had a prison spell after 1995. Among women in our prison sample, we focus on her first prison stay. The short jail sample serves as our comparison group.

Our key findings are the following:

(a) Few foster care spells start around the time a mother is incarcerated. About 75 percent are in progress for more than one year prior to a mother's first prison stay.

(b) Reunification unlikely if child's FC “overlaps” with mother's prison spell.

(c) This finding holds in both Pre- \& Post-ASFA, but the gaps are most pronounced prior to ASFA taking effect.

(d) Lower reunification rates for "overlapping” foster care/prison spells can partly explained by other variables.

(e) One factor is that FC spells have been ongoing for some time prior to entering prison for the first time and longer foster care spells are associated with lower reunification rates.

(f) Time served in prison not strongly associated with reunification rates.

(g) Time served in prison is very short for the median female prisoner.

(h) Post-ASFA era developments not consistent with time in prison "causing” lower reunification rates. 


\section{Introduction}

This report grew out of the Incarcerated Women and Mothers Project at the Harris School at the University of Chicago. This project began with a grant from the Chicago Community Trust to examine whether it was possible to merge administrative data bases from different state agencies in Illinois to provide a fuller picture of the incarceration, employment, social and child welfare histories of women and their children.

Accordingly, one of the subcontractors to this project the Chapin Hall Center for Children at the University of Chicago devised an algorithm to "probabilistically" match records from the from the following sources:

2. Admission and exit records for women admitted to state prison (1990 - 2003:II).

3. Admission and exit records for women admitted to Cook County Jail (October 1992 - November 2002).

4. The IRB data base maintained Chapin Hall. The IRB data base includes child welfare records include a foster care stays starting in January 1975 through 2002.

Notes summarizing this process and the potentially available data bases are in the appendix to this report. The data bases were merged successfully by Chapin Hall. Match rates with the prison records for the state of Illinois were 82 percent. Among approximately 52,000 women admitted to Cook county jail approximately 7,000 had children in foster care at some point during the period from 1975 through 2002.

Preliminary analysis of the merged child welfare data indicated that (i) that, among children whose mothers are admitted to state prison, as many as $30 \%$ have been in foster care system at some time during their childhoods; (ii) between 1990 and 2000 an estimated 14,000 women in Illinois spend time in state prison and were mothers to an estimated 35,000 children. Preliminary results indicated that between $20 \%$ and $40 \%$ of these families has had contact with child welfare services; and (iii) there were nearly 1,000 prisoners who had spend time in foster care children.

With these preliminary findings in hand we proposed to the National Institute of Justice a detailed analysis of the matched administrative that had four broad objectives:

- First, because these is so little quantitative information available on these links, we propose to provide an in depth description of the data.

- Second, we propose to compare children experiences in the foster care system in the matched data base to aggregate statistics on the experiences of all children in the foster care system.

- $\quad$ Third, we propose to model the dynamics of foster care spells of incarcerated mothers. 
- Fourth objective we proposed to compare incarcerated women who were in the foster care system as children to their counterparts who did not appear in the child welfare system as children.

Later in the project we added a fifth objective: to improved the quality of the matches between prison spells, foster care spells, and several labor market outcomes of the women both before and after their first prison spells. These labor market outcomes were (1) quarterly earnings, (2) quarterly employment rates, and (3) earnings when women work. The difference between employment outcome (1) and (3) is that for outcome (1) we include women who were not working during the quarter and thus whose earnings equaled zero. Given the limited information about women’s demographic characteristics in her prison records, we decided it would be worthwhile to do more to better understand the differences among incarcerated women's employment histories and how these differences were associated with the mother's contacts with the state's child welfare system.

Our rationale for pursing this objective as part of the NIJ project is that the employment histories of these women-before and after prison-would provide the best indication possible of their underlying skills and their likely prospects for reentry after parole from prison. Do women with contacts with the state child welfare system perform worse or better in the labor market after prison? How do these women's post-prison employment outcomes compare with their pre-prison employment outcomes? As shown in this report, we now have a very detailed understanding of the timing of children's foster care stays, how these stays are resolved, the timing of prison, and labor market outcomes.

The support that we received from the NIJ has enabled use to build on our preliminary work - work that was not possible to do otherwise, but we believe adds significantly to our understanding of the intersection of these criminal justice and child welfare systems.

The remainder of this report has three sections:

1. The Childhood Foster Care Experiences of Female State Prisoners and What it Means for Reentry: Evidence from Matched Administrative Data from Illinois.

2. Incarcerated Mothers, Their Children's Placements into Foster Care, and its Consequences for Reentry and Labor Market Outcomes.

3. Does Time in Prison Affect a Mother's Chances of Being Reunified With Her Children in Foster Care? Evidence from Cook County, Illinois. 


\title{
The Childhood Foster Care Experiences of Female State Prisoners and What it Means for Reentry: Evidence from Matched Administrative Data from Illinois
}

\author{
Haeil Jung \\ Robert LaLonde \\ Rekha Varghese \\ The Irving B. Harris Graduate School of Public Policy Studies \\ The University of Chicago \\ 1155 East $60^{\text {th }}$ Street \\ Chicago, IL 60637
}

November 2007

This research was supported by the Chicago Community Trust and the National Institute of Justice. We have benefited from comments by Henry Brady, Robert George, Susan George, Marilyn Moses, and Anne Powell, and participants in the Center for Human Potential and Public Policy and the Incarcerated Women and Their Children workshops at the University of Chicago, and participants at the National Institute of Justice Conference, July 17 to 19, 2006 in Washington D.C. The views expressed in this paper are those of the authors and do not reflect the views of the National Institute of Justice or any agency of the State of Illinois. The authors are responsible for all errors. Send correspondence to Robert LaLonde, r-lalonde@uchicago.edu or The Harris School, 1155 East $60^{\text {th }}$ Street, Chicago, IL 60637. 


\section{Introduction}

Female offenders have been shown to be a very disadvantaged population.(cite) One predictor of individuals' economic and social well-being as adults is the characteristics of their family background as a child. Children with contacts with their state's child welfare system have been shown to be especially disadvantaged both as children and as adults.(cites)

Our interest in this study is to understand the extent of contacts of female state prisoners with the child welfare system when they were children. The primary purpose of this research is descriptive. We document to the extent that we can identify from matched state administrative records whether women in the Illinois state prison system also spent time the state's child welfare system as children.

In this paper we address the following four questions:

(i) What percentage of women prisoners were in foster care as children?

(ii) Does this percentage vary by these women's personnel characteristics and by the criminal offenses that lead to their incarcerations?

(iii) Are female offenders with foster care histories distinguishable from other female offenders who do not have these histories?

(iv) Do the answers to the forgoing questions depend on women's foster care placements as children such as type of care (i.e. kin care, foster care boarder, institutional care etc.), on how the foster care spell was resolved, (i.e. through reunification, adoption, or aging out of the system) and on the amount of time these women spent in foster care?

Rather than relying on survey data to address these questions, we rely on less costly to obtain state administrative data from Illinois. One goal of this project is to 
demonstrate the utility of these available data for examining the linkages between state criminal justice and child welfare systems.

In this study, individual records from two state agencies were matched. The first source was the admission and exit records from the Illinois Department of Corrections (IDOC). Our sample of female prisoners consists of approximately 14,000 women admitted to Illinois state prisons from between July 1, 1989 through April 30, 2001. The second source is out-of-home placements from the Illinois Department Children and Family Services (DCFS. These DCFS foster care records date back to spells in progress as of January 1, 1975).

As we explain below, we can not study the potential foster care history of all female prisoners, because most incarcerated women in our sample were born prior to 1975. However, we can use most of the data base to study alternatively the incidence and time in foster care during different phases of childhood for the Illinois female prison population.

We have organized this paper as follows. In the next section, we summarize the limited literature on the childhood foster care spells of female offenders. We also provide some general statistics on the population in foster care starting in the 1960s and continuing through the present. This information is important for understanding how much more frequent are childhood foster care experiences among the population of female state prisoners than for the population of similarly aged adults.

In section three, we describe the three matched samples of female prisoners that we construct from the matched administrative data. These matched samples are defined based on the first age that we can potentially observe foster care spells for each woman in 
the IDOC data. In the fourth section, we document the childhood foster care experiences of female state prisoners. In section five, we examine whether these histories vary by prisoners characteristics, such as their educational attainment, labor market outcomes, and number of children. Some concluding remarks follow in section six.

\section{Literature Review.}

To better understand the context of childhood foster care spells among the female prisoners, it is important to compare its incidence among this population to its incidence among the general population. During each of the last 10 years, approximately 500,000 to 600,000 children per year are in foster care. About one-half of these children start new foster care spells, some for the first time, and the rest are in spells that have continued over from the previous year. This number of children constitutes roughly $0.7 \%$ of the population of children, 18 years and under in the United States. ${ }^{1}$

The foregoing statistics are for children in foster care during the last decade. But how well do they describe the incidence and characteristics of the foster care population during the 1960s through the 1980s? This information is certainly more relevant interpreting the incidence of childhood foster care among the female prison population. As shown by figure 1, the population in foster grew starting in the 1950s through the 1980s as a result of several policy changes, including the closing of many orphanages during the middle part of the $20^{\text {th }}$ century and the Child Abuse Prevention and Treatment Act (CAPTA) of 1974 (and Amended in 1978). This legislation is associated with a sharp increase in out-of-home placements. Policy changes during the 1990s associated with

\footnotetext{
${ }^{1}$ See http://nccanch.acf.hhs.gov/pubs/factsheets/fosterdlinks.cfm.cfm. These figures are based on statistics from the Adoption and Foster Care Analysis and Reporting System (AFCARS). AFCARS data include all children in foster care, regardless of their eligibility for Title IV-E reimbursement.
} 
increased loss of parental rights and adoptions came too late to have any effect on prisoners.

\section{The Samples of Matched Administrative Records}

\section{A. Birth Cohorts Analyzed in this Paper}

We can not examine the complete foster care histories of most female prisoners going back to their birth, because the state foster care records start in 1976. Since the average age of women when they were admitted into state prison between 1989 and 2001 was about 31, we can follow the entire potential foster care history from birth through age 18 for prisoners born between 1976 and $1983 .{ }^{2}$ This sample of female offenders consists of 944 women.

For prisoners born prior to 1976, we can follow only a portion of their potential foster care histories. To study this group as systematically as we can, we organized our matched administrative data into two additional samples. The second sample we study consists of female offenders born between 1966 and 1983. For these women we can follow their entire potential foster care history starting from age 10 . We refer to this group of women as the tween/teen sample. This sample of prisoners consists of 6,247 women. Among women prisoners in the tween/teen sample, we can estimate the percentage of female inmates who were in foster care during their teen years.

We use the tween/teen sample to construct a rough estimate of percentage of these women who also may have had foster care experiences prior to age 10 . To estimate this percentage, we use the percentage of women in the 1976 to 1983 birth cohort who were

\footnotetext{
${ }^{2}$ In Illinois, as in some other states, the cases of children in foster care are not automatically closed at age 18. Some children especially if they are enrolled in college stay in foster care beyond age 20 .
} 
in foster care prior to age 10, but never in foster care after age 10. This percentage turns out to be about 4 percent. We can calculate this percentage for the 1976 to 1983 birth cohort because we can follow their entire potential foster care history. Using the percentage of offenders in this birth cohort who spent time in foster care prior to age 10, we extrapolate a corresponding percentage for women in tween/teens sample.

The third sample we study consists of female prisoners born between 1961 and 1983. We can observe all of their potential foster experiences starting at age of 15 . We refer to this group of prisoners as the late teen sample. This sample of prisoners consists of 9,956 women. We use the same approach as described in the previous paragraph to estimate the percentage of these women who were in foster care at younger ages.

Despite its limitations, by studying the late teen sample, we can address two policy-related questions:

(i) What percentage of female state prison inmates during the 1990s was in foster care during their later teen years;

(ii) What percentage of inmates likely "aged-out" of the foster care system as children.

These percentages and how they have changed across successive birth cohorts will provide a strong indication of the past frequency of this phenomena and whether such women are likely to constitute an increased percentage woman in prison. ${ }^{3}$

In the Appendix, we present the same demographic statistics as we do in Table 2 for our full sample of nearly 14,000 female offenders. There we observe that the

\footnotetext{
${ }^{3}$ We can not estimate this percentage for first time offenders because women born earlier during this time period reached age 18 many years prior to the start of our prison data in 1989. But for women born after 1970 in this sample, we can be sure that the first prison spell we observe in our data is in fact their first prison spell.
} 
percentage of women who served time for drug-related crimes is 44.4 percent; the percentage serving time for person-related crimes is 15 percent.

\section{Incidence of Childhood Foster Care among Female State Prisoners}

Our matched administrative records suggest that roughly 10 percent of women in state prison were in foster care sometime as a child. As shown by Table 2, among prisoners from the most recent birth cohort of prisoners in our sample, women born between 1976 and 1983, about 17 percent had spent time in foster care as a child. This birth cohort of prisoners is the only one for whom we can track all potential foster care spells from birth through age 18.

\section{A. Estimating the Incidence of Childhood Foster Care Spells among Female Prisoners}

To estimate the percentage of all female prisoners who spent time in foster care as children we used information from the tween/teen and late teen samples. As shown by column 2 of Table 2, 7.3 percent of female prisoners born after 1966 spent time in foster care after age 10. In the first row of this column we observe that nearly 13 percent of prisoners in 1976 to 1983 birth cohort also spent time in foster care after age 10. This percentage implies that about 56 percent of the women in this birth cohort who spent time in foster care as children spent some of that time in foster case after age 10. We use this 56 percent figure to infer that 9.5 percent of female prisoners from the 1966 to 1983 birth cohort that ever spent time in foster care. ${ }^{4}$

\footnotetext{
${ }^{4}$ This 9.5 percent figure was chosen so that its ratio with the percentage of prisoners from the 1976 to 1983 birth cohort who were in foster care as children, 16.9 percent also was 0.56.
} 
This document is a research report submitted to the U.S. Department of Justice. This report has not been published by the Department. Opinions or points of view expressed are those of the author(s) and do not necessarily reflect the official position or policies of the U.S. Department of Justice.

The information from the third sample indicates that about 3 percent of prisoners were in foster care during their late teenage years (i.e. beyond age 15). For the 1976 to 1983 birth cohort this figure is about 6 percent. This 6 percent figure is about one third of the percentage of these women having been in foster care at any time during their childhood. We use the one-third fraction to infer that the percentage of women from the 1961 to 1983 birth cohort that spent time in prison is about 9.2 percent.

\section{B. Will the Incidence of Childhood Foster Care Experience Rise among Female}

\section{Prisoners?}

We also see from Table 2, that the incidence of childhood foster care spells among female prisoners has likely risen among recent cohorts of prisoners. Our figures suggest that incidence of time in foster care was the highest for the 1976 to 1983 birth cohort and loses for birth cohorts born during the 1960s.

The apparent rise in childhood foster care experiences is consistent with the general rise in foster care cases during the 1970s and 1980s. The rise also suggest that during the current decade the percentage of incarcerated women with childhood foster care spells will be rising as more recent birth cohorts constitute larger fractions of the prison population. This change occurs because women from earlier birth cohorts with lower incidences of childhood foster care experiences increasingly leave the corrections system and are replaced by offenders from more recent birth cohorts with apparently higher incidences of childhood foster care experience.

\section{Is it Birth Cohort or Age at First Prison Spell that Matters?}


An alternative way to interpret the evidence in Table 2 is that the more recent birth cohorts have higher incidences of childhood foster care spells not because of policy changes in the child welfare system, but because they entered prison at a young age. Women entering prison from the 1976 to 1983 birth cohort were 17 to 24 years old when they first went to prison. As discussed in the previous section the average age of a woman when she first goes to prison is about 31. So the women in this birth cohort are substantially younger than the typical new inmate. We observe in Table 1 that another way that they are different from other women is that they were more likely incarcerated for a person related offense than other incarcerated women and less likely to have been incarcerated for a drug law violation.

The evidence from Table 1 suggests that the age that a woman first enters prison may be more important than her birth cohort in predicting whether she was in foster care as a child. To explore this issue further we examine the incidence of:

(i) late teen foster care spells among women in different birth cohorts, by age of first entry into state prison;

(ii) childhood foster care spells among women in the 1976 to 1983 birth cohort, by age of first entry into state prison.

To address the first of the foregoing questions we examine the incidence of late teen foster care spells by birth cohort and age of first prison spell (c.f. Table 3A) and the incidence of tween/teen foster care spells by birth cohort and age of first prison spell (c.f. table 3B). Because our administrative data on prison admissions begin in July 1989 we can have no information about late teen foster care spells among women from the 1961 to 
1965 birth cohort who entered prison between the ages of 18 and 24. We have incomplete data on admissions for this age group for the 1966 to 1970 cohort.

A significant part of the rise in the incidence of childhood foster care spells across successive birth cohorts appears to result because of the changing composition of age-atfirst entry among these cohorts. In the first row of Table 3 we observe that the incidence of late teen foster care spells is highest among women form the most recent birth cohort and lowest among women form the earliest birth cohort. In the third row we observe, that incidence of late teen foster care spells among the 18 to 24 year old entrants is about 4 or 5 percent for the 1966 to 1970,1971 to 1975 and 1976 to 1983 birth cohorts, although this percentage is highest for the more recent cohort. Turning to the third row of the table, we observe that the incidence of late teen foster care spells among 25 to 29 year olds is about 2 or 3 percent for the 1961 to 1965, 1966 to 1970, and 1971 to 1975 birth cohorts. This percentage does not tend to rise for the most recent birth cohorts. Taken together the evidence indicates that age at first entry is associated with whether she was in foster care as a child.

As shown by Table 3B, our analysis of tween/teen foster care spells are consistent with our finding in the previous paragraph that age at first entry into prison is associated with having been in foster care as a child. Where comparisons can be made (i.e for the 1966 to 1970 and 1971 to 1975 birth cohorts) the incidence is roughly 75 percent larger for women who entered prison for the first time between the ages of 18 to 24 than it is for women who entered between the ages of 25 to 29 . At the same time it also appears that a women's birth cohort also is associated with the incidence of tween/teen foster care spells. As shown by row 3 of Table 3B, the incidence of foster care among 18 to 24 year 
old prison entrants is 3 to 4 percentage points higher among the 1976 to 1983 birth cohort than it is among the two earlier birth cohorts.

We next take a closer look at the relationship between age at first prison spell and the incidence of foster care among the youngest first time prisoners who appear to have the highest incidence of childhood foster care spells. Within the relatively narrow age range of 17 to 24 year old prisoners, age at first entry is not associated with higher rates of childhood foster care as it was in Figures 3A and 3B. As shown by the first row and first column of Table 4, among young first time prisoners in Illinois state prisons-those entering prison for the first time between the ages of 17 and 24--about 17 percent were in foster care as children. Looking across the first row of the table, we see that this percentage is within 3 percentage points of the corresponding percentage for each of the five birth years from 1976 through 1980. We make a point of highlighting these individual birth years, because these women are born early enough for us to observe them entering prison for the first time after their teenage years. We also find that this percentage is fairly stable by age at first entry to prison, except for first time entrants who entered prison prior to their $18^{\text {th }}$ birthday.

Starting with age 18, we find that about 16 percent of all first time teenage and young adult prison entrants were in foster care as children. In the subsequent rows of the table, we observe that this percentage does not appear to be systematically higher or lower for older first time prison entrants. The age with the highest percentage of women with childhood foster care experience was 24 year old first time prison entrants who were born in 1976. In addition, the remaining columns of the table suggest that this pattern holds for women in the specific birth years listed in the table. The figures in these other 
This document is a research report submitted to the U.S. Department of Justice. This report has not been published by the Department. Opinions or points of view expressed are those of the author(s) and do not necessarily reflect the official position or policies of the U.S. Department of Justice.

columns exhibit more variation in the percentage of women in foster care as children, but the sample sizes of these “cells” also are small.

The one exception to our finding that among the youngest prison entrants age of first prison spell is not systematically related whether female prisoners were in foster care as children are those women who entered state prison prior to their $18^{\text {th }}$ birthday. As shown by the second row of Table $1,27.5$ percent of these women were in foster care as children. ${ }^{5}$ To be sure, as shown in the second and third columns of the table, this pattern is not readily apparent among women in the 1976 and 1977 birth cohorts, but it emerges in the later birth cohorts in the sample. Among women born in 1979, who entered prison prior to age 18, 37.5 percent had been in foster care as children; among women born in 1980, the figure is 41.7 percent. $^{6}$ It is important, however, not to overemphasize this finding because 17 year old female entrants are a relatively rare among female state prison population.

\section{Time Spent in Foster Care}

So far we have characterized prisoners’ childhood foster care experience simply by whether or not it occurred. But, foster care experiences for the general population in foster care differ markedly. Many spells last only a few days. Some spells result in placement with a relative, while other spells result in placement in a Hospital or Health facility. Foster care spells also are resolved in dramatically different ways. Many children

\footnotetext{
${ }^{5}$ The "p value" for the difference between these percentages of women with childhood foster care experience for 17 year olds and 18 to 24 year olds is less than 0.005 .

${ }^{6}$ To test whether the apparent larger percentage of foster care histories among very young entrants was statistically meaningful, we compared the percentage of first-time prison entrants who were in foster care as children among women who were (i) under 18 years or (ii) 18 years or less when admitted to prison to all other women in the 1976 to 1983 birth cohort. In the first case the difference is highly statistically significant (the p value is less than 0.005) and in the second case the difference in percentages is marginally statistically significant (the p-value is 0.08 ).
} 
are reunified with their custodial parents, but others result in adoption by a new family or in the child aging out of the system at age 18. The type of foster care experience might affect children's later functioning as adults and be important for understanding how such women would fare after making contact with the criminal justice system.

It is possible that it is more important to know how long these women spent in foster care, how their foster care cases resolved, and where they were placed than simply whether or not they were in foster care as children. Therefore we first document that these measures of their foster care experiences vary considerably among incarcerated women with foster care spells. We examine three measures of female prisoners’ foster care experiences as children: (1) the length and number of their spells in foster care; (2) the resolution of their spells; and (3) their placements.

We first address the question of how much time in days did these women spend in foster care as children. Our analysis reveals that there is considerable heterogeneity in time spent in foster care among female prisoners. Some spent a few days while others spent most of their childhood or teen years removed from their parent's or primary caregiver’s custody. As shown by Table 5, among prisoners born between 1976 and 1983 with childhood foster care experience, the median woman spent 971 days or about 2 years and 8 months in foster care. However, 25 percent of these women spent 241 (8 months) or fewer days in foster care while another 25 percent of these women spent more than 2,158 days or 5 years and 11 months in foster care as children. The mean number of days in foster care exceeds the median number of days in foster care by more than one year because the distribution of days is skewed toward a few women spending many years in foster care as children. 
To see whether the wide variation in time spent in foster care holds for a wider population of state prisons, we calculated the number of days in spent in foster care between the ages of 10 and 18 among women from the 1966 to 1983 birth cohort. As shown by the middle column, there also is wide variation in time spent in foster care among women in this sample as well. Twenty five percent spend less than 4 months during their tween/teen years, but another 25 percent spent more than 1,828 days or 5 years in foster care during these 8 years of their childhood. ${ }^{7}$

Finally, we consider the number of days spend in foster care during these women's late teen years. This group isolates those prisoners who were most likely to “aged-out” of the child welfare system. As shown by the last column in Table 5, among women in the 1961 to 1983 birth cohort, ....

\section{E. How Were the Childhood Foster Care Cases Resolved?}

Another way to characterize state prisoners' childhood foster care spells is based on how their cases were resolved. Two important questions are as follows:

(i) How often were the women reunified with their mothers?

(ii) How often does she appear to have "aged-out” of the child welfare system and what percentage of female inmates likely aged-out of foster care as children?

The figures above in Table 2 reveal that 3.2 percent of all state prisoners, born after 1961, were in foster care during their late teenage years. This percentage puts an upper bound on the percentage of the female prison population that "aged-out" of child

\footnotetext{
${ }^{7}$ Most of these days likely accumulated during one or two spells. As shown by Appendix Table 4, approximately 70 percent of these women had only one foster care spell during this period; approximately 20 percent had two spells.
} 
This document is a research report submitted to the U.S. Department of Justice. This report has not been published by the Department. Opinions or points of view expressed are those of the author(s) and do not necessarily reflect the official position or policies of the U.S. Department of Justice.

welfare system as children. The actual percentage must be lower because some of these women could have been reunified with their mothers, adopted, placed into a subsidized guardianship, or left the system in some other way such as being a runaway child.

As shown by Table 6, the childhood foster care spells of female state prisoners ended essentially in two ways: Either, these women were reunited with their custodial parent or they most likely aged out of foster care. About 40 to 45 percent of spells regardless of what age that they occurred, resulted in these women having been reunified most likely with their mothers. As shown by the fourth row of Table 6, more than onehalf of all of these women's foster care spells ended when these women aged-out of foster care. Such women are of particular interest, because they spent so much of their childhood in the child warfare system.

One of our most striking findings is how unusual it was for a childhood foster care spell end with an adoption or a subsidized guardianship. ${ }^{8}$ As shown by the second and third rows of the table, during the period covered by our sample only a very small percentage of incarcerated women's childhood foster care spells resulted in their being adopted or placed in a subsidized guardianship. ${ }^{9}$ In other work we have done, we find that adoption or subsidized guardianships is the most common resolution of the foster care spells of the children of state prisoners. This difference seems likely to have resulted from changes in public policy during the 1990s on the adoption of children in foster care.

\footnotetext{
${ }^{8}$ Subsidized guardianships differ from adoptions in several ways. When child welfare case workers determine that adoption is not an option for a child in foster care who is 12 or over, they may eligible to be placed in subsidized guardianship. Guardians have many similar rights and responsibilities as adoptive parents and receive subsidies from the state including a Medicaid care for the child. But unlike an adoption, a guardianship ends when the child turns 18 . Furthermore, the birth parents retain visitation rights and other rights including the right to determine the child's religion. See Illinois Department of Children and Family Services web site: $\underline{\text { www.state.il.us/dcfs/docs/chapter7.pdf: }}$

${ }^{9}$ Note that the possibility of adoption or placement in a subsidized guardianship does not explain why these women who in foster care prior to age 10 where not in such care after age 10. See Table 6.
} 
This document is a research report submitted to the U.S. Department of Justice. This report has not been published by the Department. Opinions or points of view expressed are those of the author(s) and do not necessarily reflect the official position or policies of the U.S. Department of Justice.

To better understand why the childhood foster care spells ended the way that we did, we examined the differences between the demographic characteristic of women with these different types of spells. We find that women whose childhood foster care spells ended when they were reunified with their mothers or primary caregivers were much less likely to be from Cook County, Illinois, less likely to be African-American, more likely to have served time for a property-related offense and more likely to be a mother. (See Appendix Table E.)

Women with childhood foster care spells who aged out of the system were comprised of a relatively large share of women who served time for person-related crimes and who were African-American. This higher share of African-Americans among state prisoners who aged-out of foster care as children does not result because a higher than expected share of these women were from Cook County. Although these findings are suggestive of important differences between women with these two types of foster care spells, the small samples involved make it inappropriate to put too much weight on these findings.

Women who were reunified with their mothers and women who likely "aged-out" of the child welfare system were similar in one important respect: both groups had similarly low levels of schooling. Among women from the 1976 and 1983 birth cohort, only about 15 percent of both childhood foster care groups had a high school degree. This low percentage indicates that both groups of women child foster care experiences are equally unskilled and should have very poor labor market histories. Reentry programs targeted toward these populations likely will have a challenging time helping these women become self-sufficient. 


\section{F. Where Were These Women Placed When in Foster Care?}

Our merged IDOC-DCFS data also provide information on where women with childhood foster care spells were placed. Some spells resulted in placement with a relative, others with a foster family. Still others result in placement in a hospital or health facility or in a group institution. Our analysis of the matched IDOC/DCFS records indicates that these women’s foster care experiences differed markedly. These different placements likely reflect their condition as well as the circumstances that lead to their foster care spells. It also may reflect the effects that the foster care experience had on these women as children that could have carried over into adulthood. ${ }^{10}$ The type of foster care experience might affect children's later functioning as adults and be important for understanding how such women would fare after making contact with the criminal justice system. Starting with incarcerated women in the 1976 to 1983 birth cohort, we find that the foster care placements of these women were varied. As shown by the first column of Table 7, female offenders with childhood foster care histories were placed in roughly equal proportions in foster care families, with relatives, and in private or public institutions. Each accounted for about one-fifth of placements. An additional 10 percent of women were placed into a hospital or health facility.

Turning to the sample of incarcerated women from the 1966 to 1983 birth cohort, those placements for this group were similarly varied while they were in foster care during their tween/teen years. This distribution of placements is similar to those women from the 1976 to 1983 cohort who were in foster care between the ages of 10 and 18. This evidence indicates that the distribution of foster care placements for these women

\footnotetext{
${ }^{10}$ However, a factor mitigating this effect is to the extent that possible authorities place children with the objective of improving their welfare. This consideration would tend to reduce the variation in outcomes associated with having any particular foster care placement.
} 
for whom we can observe all possible spells from birth is likely representative of the childhood foster care experience of other incarcerated women. Consistent with this conclusion is the distribution of foster care placements for women who were in foster care during their late teenage years (c.f., Column 4 of Table 7).

\section{Demographic Characteristics and Criminal Offenses of Incarcerated Women}

Having established the incidence and characteristics of childhood foster care experiences among incarcerated women in Illinois, we next explore whether women with these histories differ from other prisoners in ways that might otherwise be apparent to prison officials or to reentry program operators. The purpose of this analysis is to see whether women with prior foster care histories are even more disadvantaged than other female prisoners or at least among women in prison those with childhood foster care histories are otherwise indistinguishable from other prisoner.

We begin our analysis with the 1976 to 1983 birth cohort summarized in Table 8. For these women, we observe their entire potential foster care history from birth to age 18. The first column reports demographic and criminal offense information for female offenders who had at least one tween/teen foster care spells. This means that they were in foster care at some point after the age of 10. The second column reports this information for all women who were in foster care between birth and age 18. This column adds women who were in foster between birth and age 10, but were never in foster care after age 10. Finally, column three reports means for all other women in the 1976 to 1983 birth cohort who never had childhood foster care spells. 
This document is a research report submitted to the U.S. Department of Justice. This report has not been published by the Department. Opinions or points of view expressed are those of the author(s) and do not necessarily reflect the official position or policies of the U.S. Department of Justice.

Comparisons among the three columns indicate modest differences in some of the characteristics and criminal offenses between women with foster care spells and those without. The timing of these spells during childhood appears to matter less. For the youngest women in the state prison sample, childhood foster care spells are associated with being African-American, being committed to prison from outside Cook County, and having more children than their counterparts without childhood foster care experiences. Women with childhood foster care spells are less likely to have been held for drug-law violations. $^{11}$

The higher rates of African-American women offenders with child foster care histories are apparently not the result of higher childhood foster care rates among inmates admitted from Cook County. This result is somewhat unexpected, because both the state’s African-American population and the state’s female population of AfricanAmerican offenders are disproportionately from Cook County. ${ }^{12}$ Among inmates with childhood foster care histories, the percentage of woman from Cook County is actually about 6 percentage points lower than it is among offenders without such histories. ${ }^{13}$

One important demographic characteristic is similar for women with and without childhood foster care spells. Educational attainment is very low for both groups. Only

\footnotetext{
${ }^{11}$ The greater representation of African-Americans among women in the two foster care samples of offenders and the smaller representation of Hispanics is statistically meaningful despite the relatively small numbers of women in the two foster care samples. The difference between these two groups' representation in the child foster care sample and in the sample of women with no foster care histories is statistically significant at the 5 percent level.

${ }^{12}$ In this paper we use the expression "that inmates were from Cook County." This expression does not mean that these offenders were Cook County residents, but instead that they were committed to state prison from Cook County. We believe that it is usually the case that women committed to state prison from Cook Country also are Cook County residents. Because of the sample sizes, the 6 percentage point gap is not statistically significant at conventional levels of statistical significance.

${ }^{13}$ Not shown in the table is that state prisoners from the 1976 to 1983 birth cohort are less likely to be from Cook County than are other state prisoners from earlier birth cohorts. During the period studied here, 58.4 percent of all incarcerated women were from Cook County. This percentage is 12 percentage points greater than the corresponding percentage of women in the 1976-1983 birth cohort who were from Cook County.
} 
about 15 percent of offenders in the 1976 to 1983 birth cohort report having a high school degree. This evidence of low high school graduation rates among young ex-prisoners suggests that they will have difficulty transitioning into the labor market after being paroled. But the similarity in graduation rates also suggests that women without childhood foster care experience will be as economically disadvantaged as their peers who were in foster care at some point during their childhood. In the next section of this paper, we explore this hypothesis in detail.

These findings on educational attainment appear to be related to a woman's age when she first enters prison. As shown by Table 9, when we turn to examine tween/teen foster care spells using women in the 1966 to 1983 birth cohort we find that women with some tween/teen foster care experience have lower high school graduation rates that average 19 percent (column 1). As already observed women in the 1976 to 1983 birth cohort have graduation rates that are on average about 15 percent (column 4). By contrast the high school graduation rate of women who have no tween/teen foster care experience were nearly 27 percent.

The foregoing observation about the general skill levels of women with childhood foster care spells does not depend on how their foster care cases where resolved. As shown by columns 2 and 3 of the table, we find that the high school graduation rates of women were reunified with their mother or primary caregiver were about 1.5 percentage points greater than the graduation rate of women who aged-out of the child welfare system. 
More striking differences between these two groups of women with childhood foster care experience are their ethnicity, being from Cook County, and the likelihood of being held for person-related or property-related law violations.

The foregoing results are potentially important, for while they again underscore the low general skill levels of incarcerated women, they suggest that women with childhood foster care experience are more economically disadvantaged than their peers who did not have such experience. To measure the economic importance of this gap and whether knowing a women's childhood foster status is a useful indicator of her labor market skills, in the next section we compare these women's employment related outcomes.

\section{Late Teenage Foster Care and Adult Labor Market Outcomes}

Comparisons between the limited demographic characteristics suggests that a prisoner's childhood foster care history is not an especially important attribute for predicting (i) a variety of their socio-economic outcomes and (ii) the effects of prison on these outcomes. One of the most important of these outcomes is their labor market outcomes. We measure women’s quarterly earnings during the quarters leading up to prison and during the quarters after prison. We look for evidence that women with childhood foster care spells perform differently in the labor market than their counterparts without such spells, both prior to and after exiting their first prison spell.

In addition to quarterly earnings, we also study two other labor market outcomes. We can decompose quarterly earnings into quarterly employment rates and earnings when women are working. These two additional labor market outcomes enable use to 
determine whether differences in earnings result from differences in employment rates, differences in earnings when working or both. The earnings when working outcome is more closely associated with a workers' skill level or productivity than are the other two outcomes.

We consider separately the three samples of prisoners. To study late teenage foster care spells we analyze the foregoing outcomes for women born between 1961 and 1983. To study tween/teen foster care spells we limit our sample to women born between 1966 and 1983. Finally, to analyze the potential consequences of being in foster care at anytime during childhood, we further limit our sample to women born between 1976 and 1983.

In Figure 1 we present quarterly earnings for two groups of incarcerated women relative to the quarter that they entered and exited prison. We designate quarters in prison as 0 . It is possible to have reported earnings during these quarters, because employers report earnings for these women after they are incarcerated. It also is possible to work in a regular job while in prison, or these reported earnings result from matching errors. The two lines in the table are for women who were in foster care after age 15 (the diamonds) and women without such spells (the squares).

The pattern of earnings in the figure reveals that incarceration in prison is not associated with lower earnings or impaired labor market performance for either group of women. Both women who were in foster care during their late teenage years and those who were not had substantially higher earnings after prison than before. Further, the earnings of women without late teen foster care histories grow with time since exiting their first prison spell. By contrast, the earnings of their peers who were in foster care at 
This document is a research report submitted to the U.S. Department of Justice. This report has not been published by the Department. Opinions or points of view expressed are those of the author(s) and do not necessarily reflect the official position or policies of the U.S. Department of Justice.

some point during their late teens slowly decline during the quarters following their parole from prison.

\section{A. Late Teen Foster Care and Labor Market Outcomes}

The pattern of earnings in Figure 1 reveals that childhood foster care spells are associated with poorer labor market outcomes, especially after these women exit from prison. Women with childhood foster care spells earn less before prison, but the gap is most pronounced after prison. During any given quarter after prison these women earned about \$100 to \$400 less than other women. This finding results because women with childhood foster care histories earn less when they work. As shown by Figure 2, both groups of women are equally likely to have been employed.

The patterns in Figure 3 indicate that women who were in foster care during their late teens were less skilled or productive as adults compared with other incarcerated women. When these more disadvantaged women work they earn about \$500 per quarter less than women who were never in foster care as children. On a full-time hourly basis this gap in earnings implies a difference of about $\$ 1$ in hourly wages. This shortfall amounts to an approximately 20 percent of the earnings when working of women with no late teen foster care experience.

The foregoing evidence indicates the women who spend time in foster care during their late teenage years do have more difficulty in the labor market than other female prisoners after their paroles. We explore this finding further by asking whether this result more likely reflects the consequences of foster care itself or the tendency for children 
who have been in foster care to be more economically disadvantaged than other people.

To address this question we formulated a statistical model that ...

\section{B. Tween/Teen Foster Care and Labor Market Outcomes}

It is possible that the foregoing findings for late teen foster care spells do not result from being in foster care per se but from being in foster care late in childhood. Foster care spells that start and end earlier during a women's childhood may not be associated with as adverse labor market outcomes as adults. We next consider the same labor market outcomes as above but for all tween/teen foster care spells (i.e. those starting after age 10).

Although the percentage of women in the tween/teen sample with foster care spells is about twice as large as the percentage of women in the late teen sample with such late teen foster care spells, the earnings patterns appear to be similar. As shown by Figure 4, the gap in earnings after prison is about \$100 to \$200 per quarter and growing. Prior to prison the difference between these two groups' earnings is statistically insignificant. After prison women with tween/teen foster care spells perform worse in the labor market than women without these experiences. Further, among women with foster care histories prison is not associated with as large and growing earnings gains.

Turning to Figures 5 and 6, we find that the differences in earnings patterns documented in Figure 4 result entirely from difference in earnings when these women work. As shown by Figure 5, both groups have nearly the same quarter employment rates both before and after prison. But, as shown by Figure 6, within a year or two of being paroled from prison, when women with tween/teen foster care spells work, their earnings 
lag behind those of other women. Moreover, the earnings gap appears to widen. This evidence indicates that after exiting prison, women with childhood foster care spells do not earn as much when they work as other women or appear to make the transition from prison as well as other former prisoners.

\section{Childhood Foster Care and Young Female Prisoners}

Finally, we consider the sample of female prisoners who were born between 1976 and 1983. In this sub-sample, we can track all foster care spells during a woman’s entire childhood. These women however are very young when admitted to prison for the first time.

As shown by Figure 7, these women's employment rates follow a similar pattern as other female prisoners. Further the earnings of women who were in foster care at some point between birth and age 18 are consistently below those of other women. The gap is larger during the post-prison period than during the pre-prison period. But overall, the earnings gap averages about $\$ 150$ per quarter during the post-prison period, smaller than in the previous figures.

A different wrinkle on the determinants of the earnings patterns observed in Figure 7 is that the quarterly employment rates are lower among women with any childhood foster care experience (c.f. Figure 8). By contrast, as shown in Figure 9, there is no systematic difference between these two groups' quarterly earnings when working. Whether this patterns result from a women being a young prison entrant or from foster care experiences especially as a young child is a topic for future research.

\section{Does Time in Foster Care Matter?}


Childhood foster care spells may have varying effects on the lives of adults depending on how long women spent on foster care and how their foster care spells were resolved. Instead of comparing labor market outcomes between women who had childhood foster care experiences and those who did not, we compare these outcomes among women with different childhood foster care experiences.

Childhood foster care experiences differ both in terms of time spent in foster care as a child and how their foster care spells were resolved. As discussed above, among women with childhood foster care experiences there is considerable variation in the amount of time spent in foster care. Likewise, about one-half of the time these women were reunified with their mothers, while the other half of the time these women likely “aged-out” of the system. If childhood fosters care affect adult labor market outcomes of female state prisoners we expect to find some association between time in foster care and how the foster care spells were resolved and employment and earnings.

We find that although childhood foster care is associated with poorer labor market outcomes as an adult, time in foster care is not especially good predictor of these outcomes. Women who spent less than 30 days in foster care as children have approximately the same, if not somewhat lower, quarterly earnings as women who spent more than 2 years in foster care as children. To be sure both groups' earnings are low, averaging about $\$ 500$ per quarter. It also is the case that the earnings of both groups of women are greater during their post-prison years than they were during their pre-prison years.

The similarly in earnings outcomes between women who spent little time compared to significant time in foster care as children results form the similarity in their 
post-prison quarterly employment rates and their earnings during those quarters when they worked. We find that the post-prison quarterly employment rates of both groups average about 33 percent during the year after prison and decline slowly during the following years. (C.f., Figure 14.) Prior to prison the quarterly employment rates of the less than 30 days group exceeded the earnings of the 2 year plus group by about 5 percentage points. This means that employment gains associated with prison are concentrated among those women with more childhood foster care experience as opposed to their counterparts with little such experience.

Finally, we find that the high and low foster care women are likely to be equally productive when they work. Average quarterly earnings among those who are working are approximately the same for both groups. When they work, they earn on average about $\$ 1,500$ per quarter or less than the equivalent of working full time at the minimum wage.

\section{E. Resolution of Late Teenage Foster Care Spells}

Turning from time spent in foster care as a child to how foster care spells were resolved we find that women who were reunified with their mothers or primary care taker performed about as well in the labor market as adults as their counterparts who most likely "aged-out" of the child welfare system. We find that the earnings for both groups are higher during the post-prison period than they were prior to prison. As shown by Figure 13, women who were reunited with their mothers appear to have been more likely to have been employed during the post-prison period, though these differences are not large. But, when they work, both groups of women earn approximately the same amount. This result suggests that among female inmates with foster care experiences whether one 
aged-out or was reunified with a parent has little bearing on their labor market skills and productivity.

\section{F. Discussion of Findings on Labor Market Outcomes}

Another way of understanding these findings is in combination with our findings reported in the previous subsection. Whether a woman had a child foster care spell is associated with labor market outcomes as adult. This association is seen during both the pre- and post-prison periods, but it is especially marked during the post-prison period. However, among women with childhood foster care spells, time in foster care or how their foster care spells were resolved does not seem to be associated their success in the job market.

Comparison of outcomes among women with differing childhood foster care experiences does not suggest that these experiences adversely affect women's labor market outcomes. If they did we expect that those with more such experiences would have worse labor market outcomes. Instead, our finding indicate that having had a child foster care spells is marker for adverse economic outcomes as an adult both before and especially after prison.

In particular, our results indicate that female prisoners who "aged-out" of the child welfare system are not any greater risk of adverse labor market outcomes than their counterparts who had late teenage foster care spells, but were reunified with their mothers or primary caregivers. Above we observed that only about 2 percent of female state prisoners likely "aged-out" of child welfare as children. Hence not only are such women relatively uncommon among the female prison population, their outcomes are similar to other women whose foster care experiences were resolved differently. 
One potential explanation for the foregoing finding is that women who had childhood foster care experiences have a long history of less productive family support. This family attribute contributes to their being in foster care during their childhood and to their finding little support when leaving prison. One way this lack of productive family networks reveals itself is in poorer labor market outcomes, especially after prison. We can not address this explanation directly with our data, but we raise it because it appears consistent with our data. 


\section{References}

Allard, Patricia (2002). “Life Sentences: Denying Welfare Benefit To Women Convicted Of Drug Offenses,” A Report of the Sentencing Project, Washington, D.C., February 2002.

Barr, Bernadine, "Estimates of Numbers of Children in Institutions, Foster Family Care, and Adoptive Homes, 1910-1960”

Crosby-Currie C. and N.D. Reppucci (1999). “The Missing Child in Child Protection: The Constitutional Context of Child Maltreatment From Meyer to DeShaney.” Law \& Policy, Volume 21, Number 2, April 1999, pp. 129-159(31).

CRS Report for Congress, Congressional Research Service, The Library of Congress Prepared at the request of the House Subcommittee on Human Resources, January 15, 1997 Karen Spar, Specialist in Social Legislation Education and Public Welfare Division Foster Care And Adoption Statistics: Summary, www.casanet.org/library/fostercare/fost.htm

Goerge, Robert M., Fred H. Wulczyn, and Allen W. Harden. An Update from the Multistate Foster Care Data Archive, Foster Care Dynamics, 1983-1993, Chapin Hall Center for Children, University of Chicago, Illinois, undated.

Hagan, John and Juleigh Petty Coleman, (2001). "Returning Captives of the American War on Drugs: Issues of Community and Family Reentry.” Crime \& Delinquency, Vol. 47, No. 3, 352-367 (2001)

The adoption history project. darkwing.uoregon.edu/ adoption/archive/Barrstats.htm From Source: Bernadine Barr, "Spare Children, 1900-1945: Inmates of Orphanages as Subjects of Research in Medicine and in the Social Sciences in America” (Ph.D. diss., Stanford University, 1992), p. 32, Figure 2.2.

Human Rights Watch (2002). Collateral Casualties: Children of Incarcerated Drug Offenders in New York.

Mauer, Marc, Cathy Potler, and Richard Wolf (1999).“Gender And Justice: Women, Drugs, And Sentencing Policy,” Report of the Sentencing Project, Washington D.C, November 1999 - Lack of data on timing of foster care relative to start of prison spell.

Mumola, Christopher J. (2000). “Incarcerated Parents and Their Children,” The U.S. Department of Justice, Office of Justice Programs, Bureau of Justice Statistics, NCJ 182335, August 2000. - Nearly 17\% of incarcerated women report having been in foster care themselves as children. 
Perez, Alfred, Kasia O’Neil, and Sarah Gesiriech (2003).’Demographics of Children in Foster Care.” Pew Foster Care Project, http://pewfostercare.org/research/docs/Demographics0903.pdf

Reed, Diane, and Edward Reed, (1997), “Children of Incarcerated Parents,” Social Justice, Vol. 24.

Richie, Beth, Nicholas Freudenberg' and Joanne Page (2001). "Reintegrating women leaving jail into urban communities: A description of a model program,” Journal of Urban Health, Volume 78, Number 2 / June, 1099-3460 (Print) 1468-2869 (Online) Pushing kids into foster care

Ruiz, Dorothy S. (2002). The Increase in Incarcerations among Women and Its Impact on the Grandmother Caregiver: Some Racial Considerations.” Journal of Sociology \& Social Welfare, Vol. 29.

Sinden, Amy (1990). "In Search of Affirmative Duties toward Children under a PostDeShaney Constitution.” University of Pennsylvania Law Review, Vol. 139, No. 1 (Nov., 1990), pp. 227-270. 


\section{Appendix Table A}

Sample Size for Analysis of Women with Childhood Foster Care Spells

\begin{tabular}{|l|l|}
\hline $\begin{array}{l}\text { Number of women in merged IDOC - DCFS } \\
\text { data with record of childhood foster care spells }\end{array}$ & 932 \\
\hline Number born after January 1, 1961 & 801 \\
\hline $\begin{array}{l}\text { Number that exited state prison for the first } \\
\text { time after January } 1,1995\end{array}$ & 605 - Late Teen Sample \\
\hline Number born after January 1, 1966 & 494 - Tween/Teen Sample \\
\hline Number born after January 1, 1976 & 168 - Childhood Sample \\
\hline $\begin{array}{l}\text { Number born after January } 1,1961 \text { and who } \\
\text { report having at least } 1 \text { child when admitted to } \\
\text { state prison for the first time after } 1 / 1 / 95 .\end{array}$ & 459 \\
\hline $\begin{array}{l}\text { Number born after January } 1,1966 \text { and who } \\
\text { report having at least } 1 \text { child when admitted to } \\
\text { state prison for the first time after } 1 / 1 / 95 .\end{array}$ & 368 \\
\hline $\begin{array}{l}\text { Number born after January } 1,1976 \text { and who } \\
\text { report having at least } 1 \text { child when admitted to } \\
\text { state prison for the first time after } 1 / 1 / 95 .\end{array}$ & 89 \\
\hline
\end{tabular}




\section{Appendix Table B \\ Demographic Profile of Incarcerated Women, by Childhood Foster Care Status}

(Incarcerated in Illinois State Prisons between July 1989 and June 2001,)

\begin{tabular}{|c|c|c|c|c|c|c|c|c|}
\hline & $\begin{array}{l}\text { Full } \\
\text { Sampl }\end{array}$ & & $\begin{array}{l}\text { With I } \\
\text { Histor }\end{array}$ & & $\begin{array}{l}\text { If Twe } \\
\text { teen F } \\
\text { Histor }\end{array}$ & & $\begin{array}{l}\text { No FC } \\
\text { History }\end{array}$ & \\
\hline & No. & $\%$ & No. & $\%$ & No. & $\%$ & No. & $\%$ \\
\hline African-American & 9511 & 66.4 & 582 & 62.9 & 411 & 60.6 & 8929 & $66.7^{* *}$ \\
\hline White & 3964 & 27.7 & 293 & 31.7 & 226 & 33.3 & 3671 & $27.4^{* * *}$ \\
\hline Hispanic & 744 & 5.2 & 34 & 3.7 & 30 & 4.4 & 710 & $5.3^{* *}$ \\
\hline High School Graduate & 4859 & 33.9 & 202 & 21.8 & 138 & 20.4 & 4657 & $34.8^{* * *}$ \\
\hline Cook County Resident & 8368 & 58.4 & 448 & 48.4 & 319 & 47.1 & 7920 & $59.1^{* * *}$ \\
\hline Married & 1994 & 13.9 & 87 & 9.4 & 65 & 9.6 & 1907 & $14.2^{* * *}$ \\
\hline Mother & 11845 & 82.7 & 720 & 77.8 & 528 & 77.9 & 11125 & $83.1^{* * *}$ \\
\hline Substance Abuse $<1>$ & 8602 & 60.1 & 565 & 61.1 & 417 & 61.5 & 8037 & 60.0 \\
\hline Person Crimes & 1840 & 15.7 & 176 & 22.9 & 130 & 23.2 & 1664 & $15.2^{* * *}$ \\
\hline Property Crimes & 3898 & 33.3 & 268 & 34.9 & 197 & 35.2 & 3630 & 33.2 \\
\hline Drug Crimes & 5200 & 44.4 & 253 & 32.9 & 180 & 32.1 & 4947 & $45.2^{* * *}$ \\
\hline Sex Crimes & 230 & 2.0 & 30 & 3.9 & 25 & 4.5 & 200 & $1.8^{* * *}$ \\
\hline Other Crimes & 541 & 4.6 & 42 & 5.5 & 28 & 5.0 & 499 & 4.6 \\
\hline Av. No. of kids & 2.43 & & 2.20 & & 2.15 & & $2.45^{* * *}$ & \\
\hline Av. Age at imprisonment & 31.53 & & 26.74 & & 26.38 & & $31.86^{* *}$ & \\
\hline Number of Observations & 14321 & 100.0 & 925 & 100.0 & 678 & 100.0 & 13396 & 100.0 \\
\hline
\end{tabular}

Notes: Asterisks indicate the level of statistical significance for the difference between the percentages in FC history samples and the NO FC history samples: * $10 \%$ level of significance, ** $5 \%$ level of significance; $* * * 1 \%$ level of significance. $<1>$ This measure is self-reported when women are admitted into prison. The measure reported here refers to both drug and alcohol abuse or additions. Source: Authors calculations from IDOC and DCFS administrative data. 


\section{Appendix Table C}

\section{The Number of Childhood Foster Care Spells Female State Prisoners}

\section{Total Time In FC}

Birth Cohort

Number Spells (\%):

1 FC spell

2 FC spells

3 FC spells

4 or more FC spells
Distribution of Foster Care Spells During Age Period:

Age 0-18

$10-18$

15-18+

1976-1983

1966-1983

1961-1983

$59.5 \%$

27.0

$69.1 \%$

19.9

$65.2 \%$

6.8

6.0

21.7

6.8

5.3

Notes: The numbers of spells that include right and left censored spells as well as spells that start and end during the indicated period. Source: Authors calculations from matched IDOC and DCFS administrative data. 


\begin{tabular}{|c|c|c|c|c|c|c|}
\hline African-American & $\frac{\text { No. }}{39}$ & $\frac{\%}{52.7^{*}}$ & $\frac{\text { No. }}{56}$ & $\begin{array}{l}\% \\
63.0\end{array}$ & $\frac{\text { No. }}{410}$ & $\frac{\%}{49.6}$ \\
\hline White & 32 & 43.2 & 27 & 30.3 & 314 & 38.0 \\
\hline Hispanic & 3 & 4.1 & 3 & 3.4 & 92 & 11.1 \\
\hline High School Graduate & 9 & 12.2 & 14 & 15.7 & 130 & 15.7 \\
\hline Cook County Resident & 21 & $28.4^{* * * *}$ & 44 & 49.4 & 391 & 47.3 \\
\hline Married & 5 & 6.8 & 7 & 7.9 & 45 & 5.5 \\
\hline Mother & 47 & 63.5 & 45 & 50.6 & 432 & 52.3 \\
\hline Substance Abuse $<1>$ & 42 & 56.8 & 36 & 40.5 & 341 & 41.3 \\
\hline Person Crimes & 16 & 21.6 & 36 & 40.5 & 248 & 30.0 \\
\hline Property Crimes & 37 & $50.0^{* *}$ & 27 & 30.3 & 271 & 32.8 \\
\hline Drug Crimes & 13 & $17.6^{*}$ & 24 & 27.0 & 262 & 31.7 \\
\hline Sex Crimes & 4 & $5.4^{*}$ & 0 & 0.0 & 11 & 1.3 \\
\hline Other Crimes & 4 & 5.4 & 2 & 2.3 & 34 & 4.1 \\
\hline Number of children & 1.28 & & 0.92 & & 0.91 & \\
\hline Av. Age at imprisonment & 20.3 & & 20.1 & & 20.3 & \\
\hline Number of Observations & 74 & 100.0 & 89 & 100.0 & 826 & 100.0 \\
\hline
\end{tabular}


Appendix Table E

\section{Use of Food Stamps and TANF/AFDC Among Female Prisoners With Childhood Foster Care Experience}

Foster Care Experience

Own Childhood Foster Care

Own Tween/Teen Foster Care

Own Tween/Teen Foster Care

Own and Children in Foster Care

Only Children in Foster Care

Percentage Received Benefit
Birth Cohort

$1976-1983$

$1976-1983$

$1966-1983$

$1976-1983$

$1976-1983$

Prior to $1^{\text {st }}$ Child FC Spell $<1>$
Percentage Received Social Welfare Benefits Between and 1990 and 2001? Food Stamps TANF/AFDC $81.6 \%$ $58.9 \%$

83.0

59.7

81.0

52.4

83.3

66.7

84.3

Notes: $<1>$ Sample limited women with children in foster care-includes women with childhood foster care spells. Source: Authors calculations from matched IDOC and DCFS administrative data. 
This document is a research report submitted to the U.S. Department of Justice. This report has not been published by the Department. Opinions or points of view expressed are those of the author(s) and do not necessarily reflect the official position or policies of the U.S. Department of Justice.

Figure 1: Quarterly Earnings of Female Ex-Prisoners Born Between 1961 and 1983

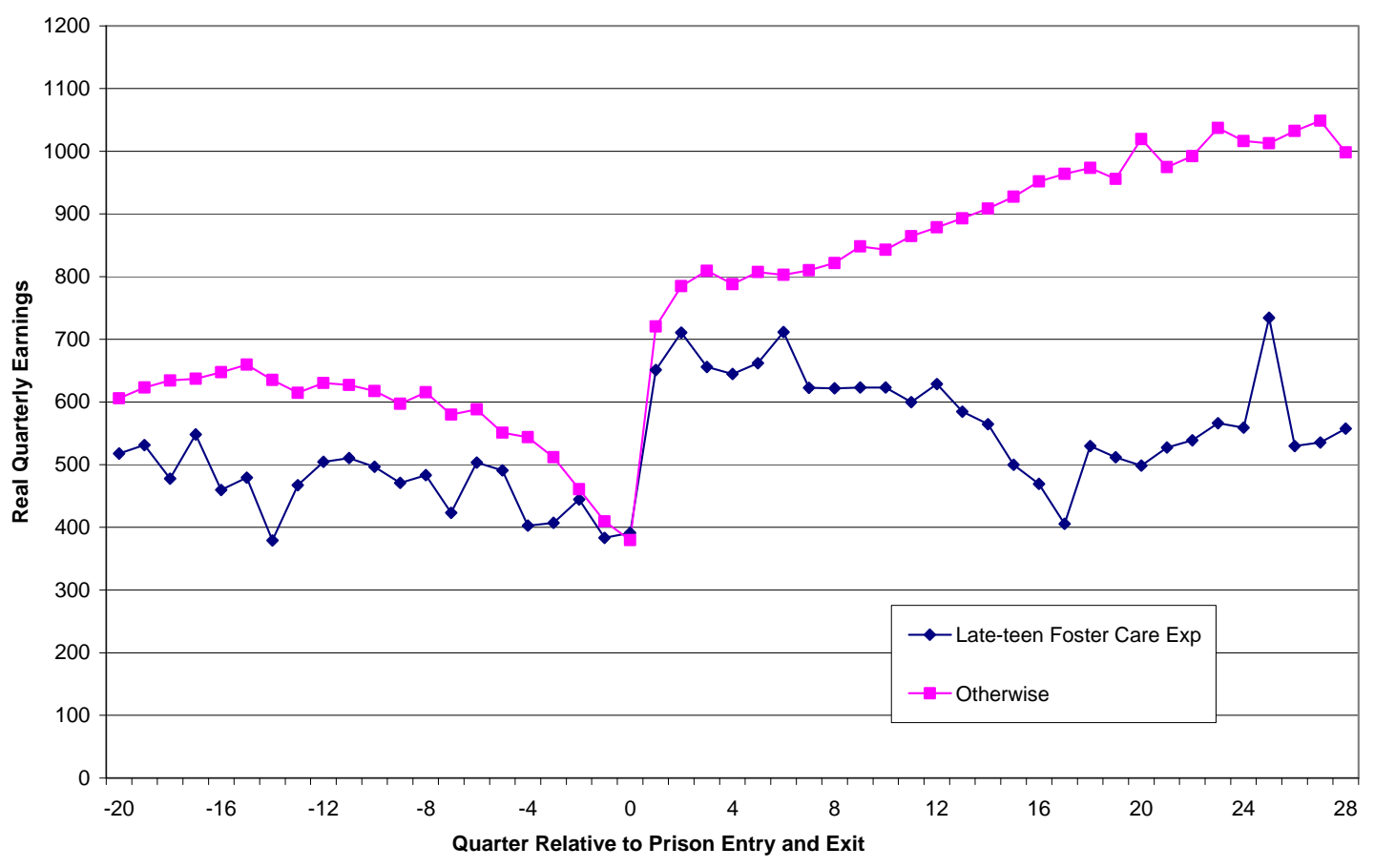

Figure 2: Employment Rates of Female Ex-Prisoners Born Between 1961 and 1983

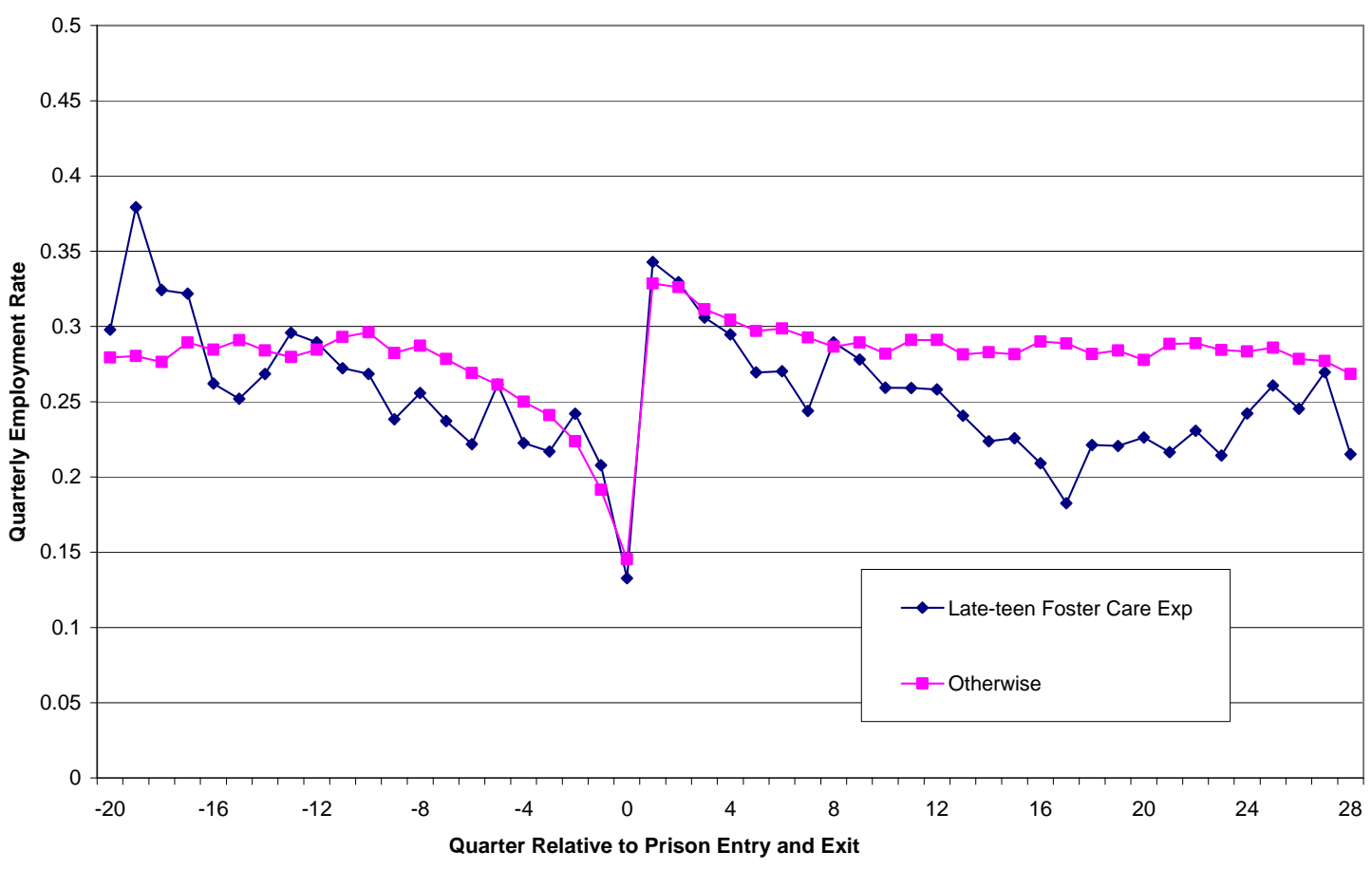


This document is a research report submitted to the U.S. Department of Justice. This report has not been published by the Department. Opinions or points of view expressed are those of the author(s) and do not necessarily reflect the official position or policies of the U.S. Department of Justice.

Figure 3: Quarterly Earnings When Working of Female Ex-Prisoners Born Between 1961 and 1983

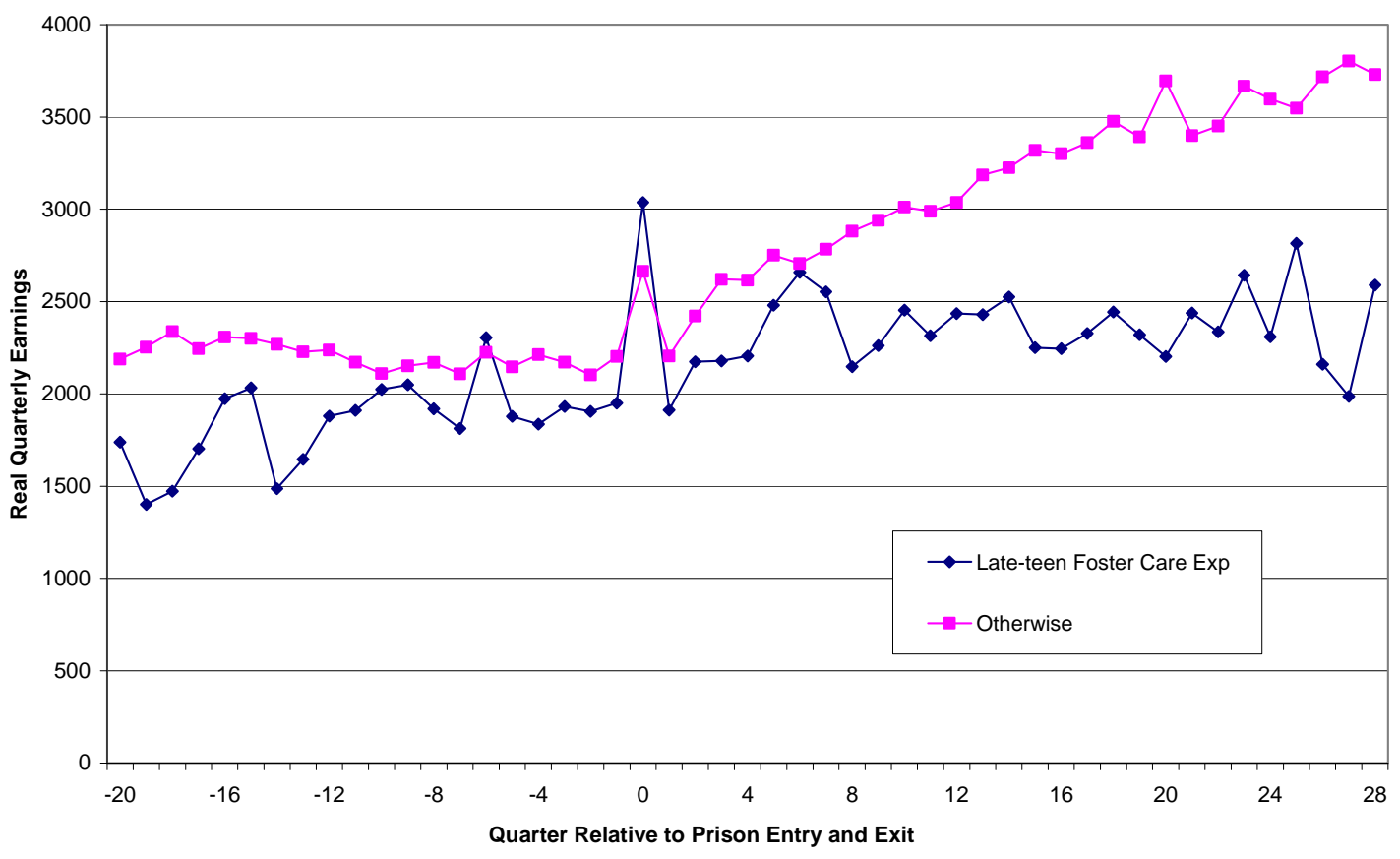

Figure 4: Quarterly Earnings of Female Ex-Prisoners Born Between 1966 and 1983

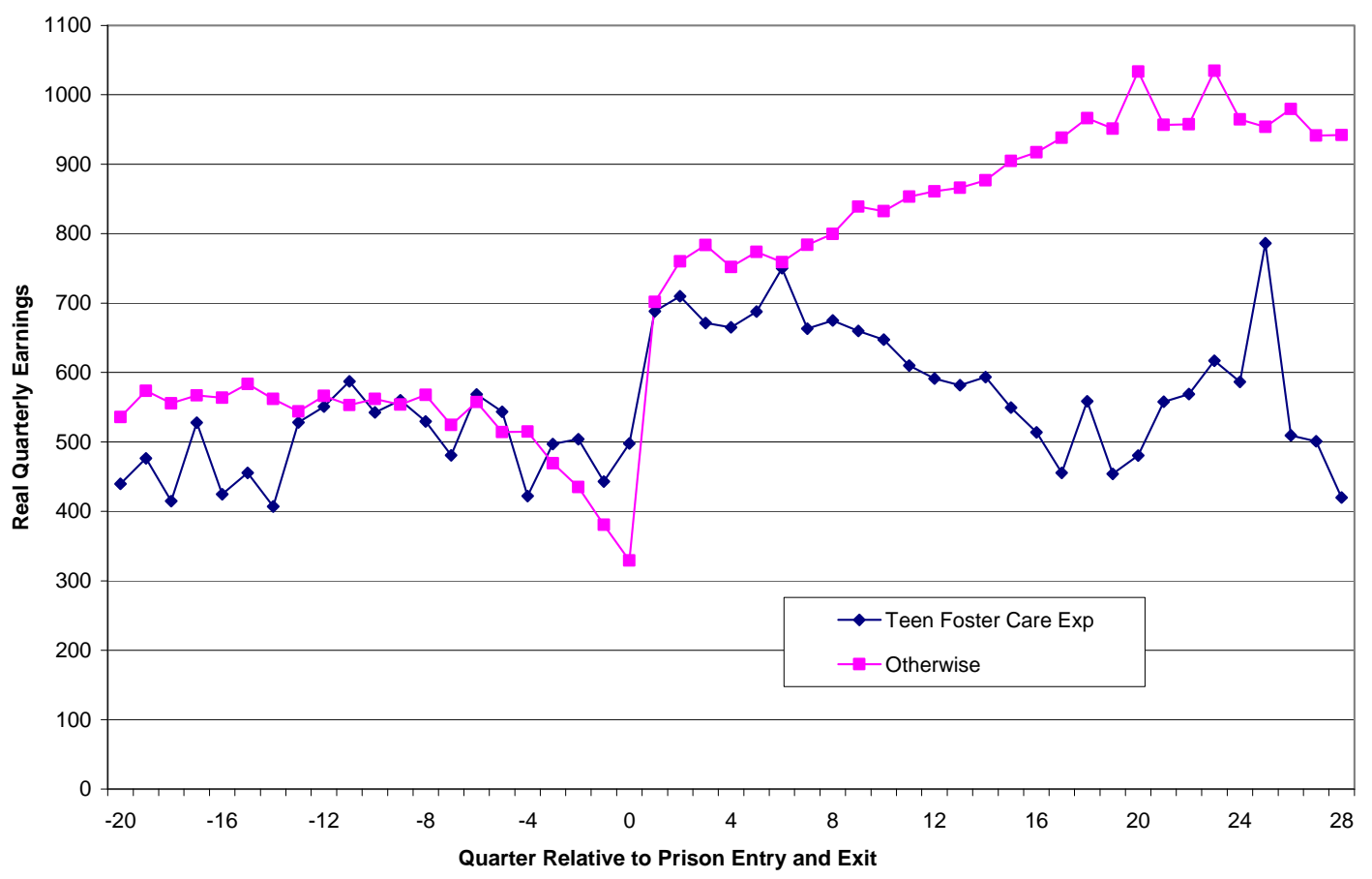


This document is a research report submitted to the U.S. Department of Justice. This report has not been published by the Department. Opinions or points of view expressed are those of the author(s) and do not necessarily reflect the official position or policies of the U.S. Department of Justice.

Figure 5: Employment Rates of Female Ex-Prisoners Born Between 1966 and 1983

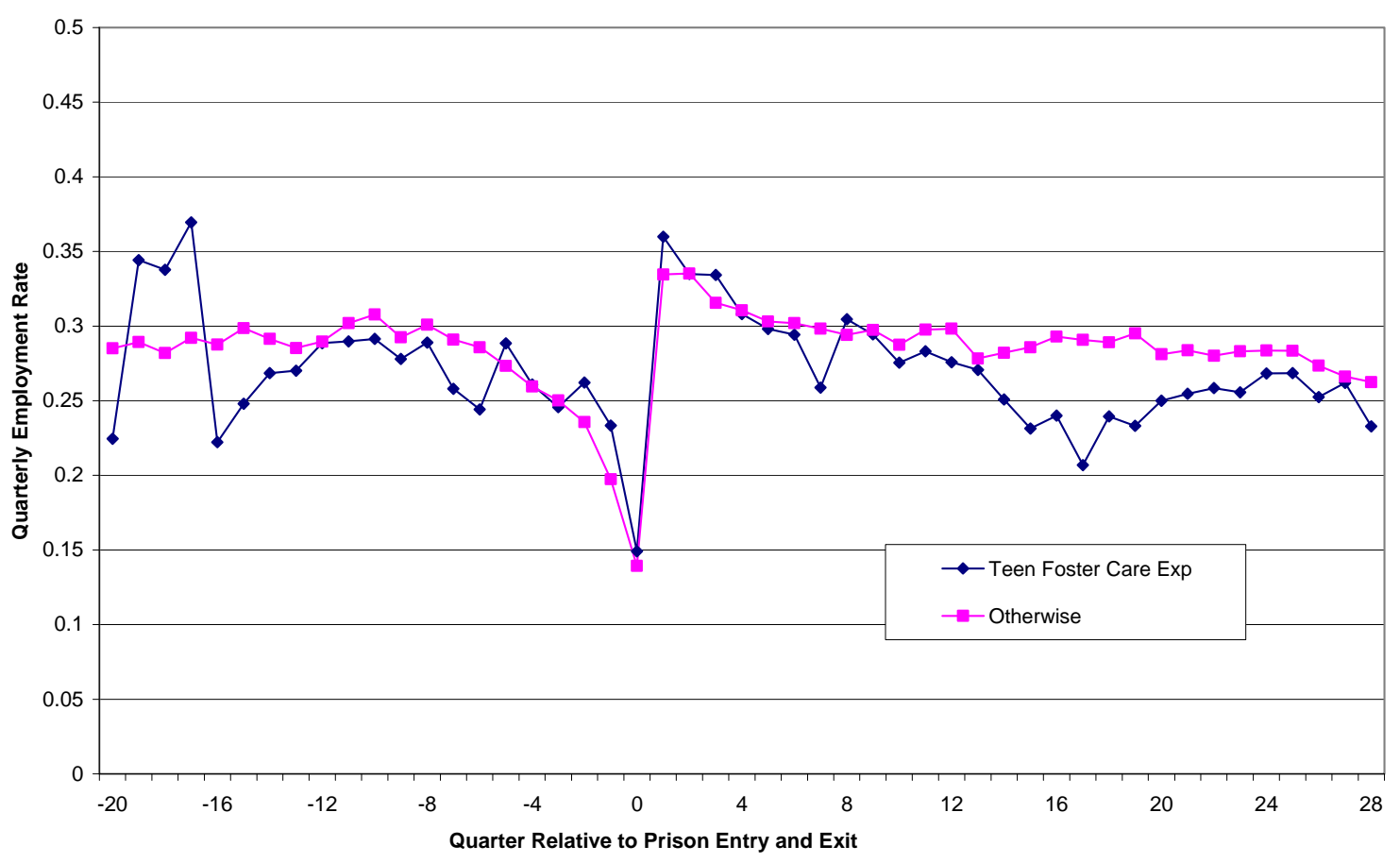

Figure 6: Quarterly Earnings When Working of Female Ex-Prisoners Born Between 1966 and 1983

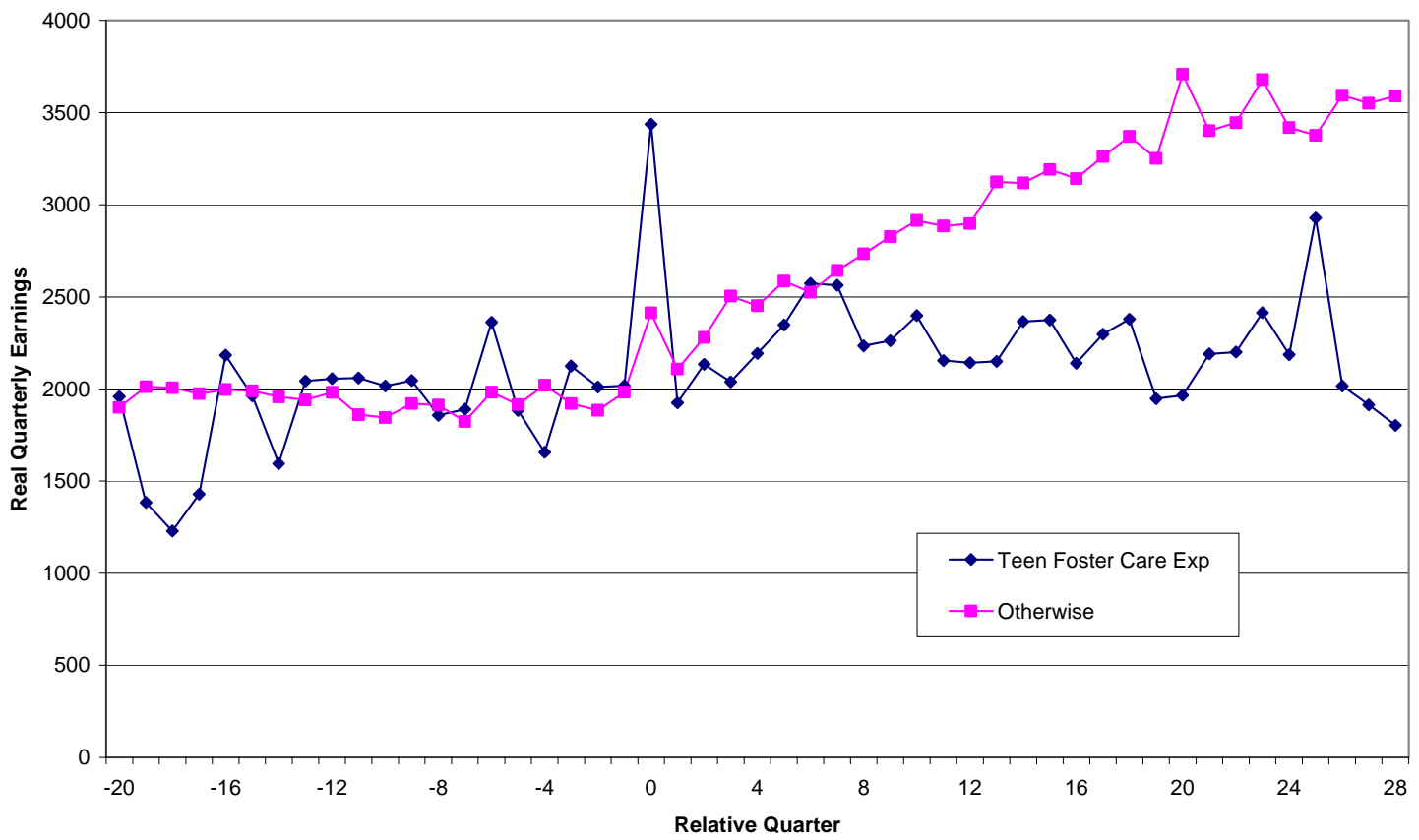


This document is a research report submitted to the U.S. Department of Justice. This report has not been published by the Department. Opinions or points of view expressed are those of the author(s) and do not necessarily reflect the official position or policies of the U.S. Department of Justice.

Figure 9: Quarterly Earnings When Working of Female Ex-Prisoners Born Between 1976 and 1983

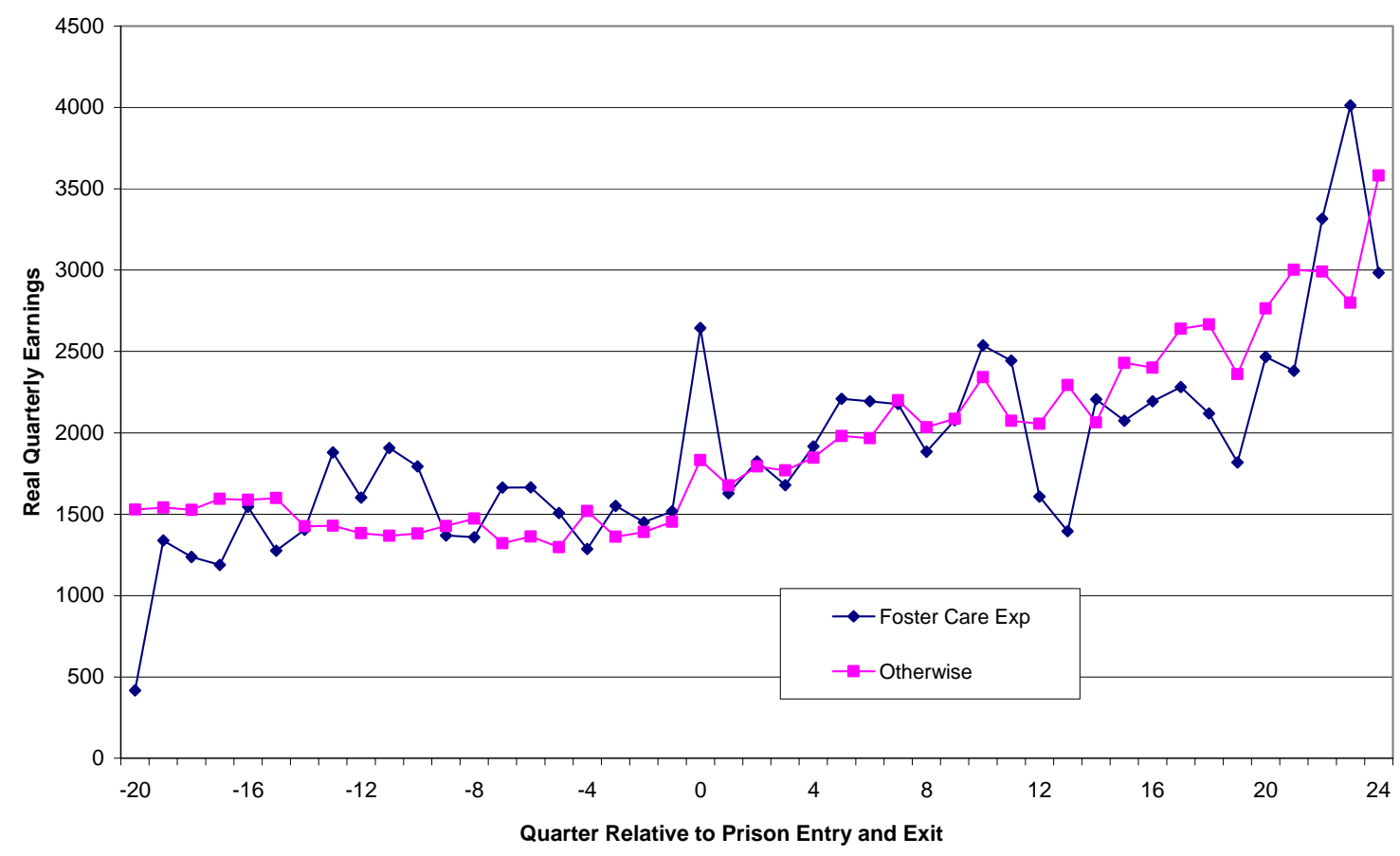

Figure 10: Fraction in Prison after Exiting First Prison Spell, for Female Ex-Prisoners Born Between 1961 and 1983

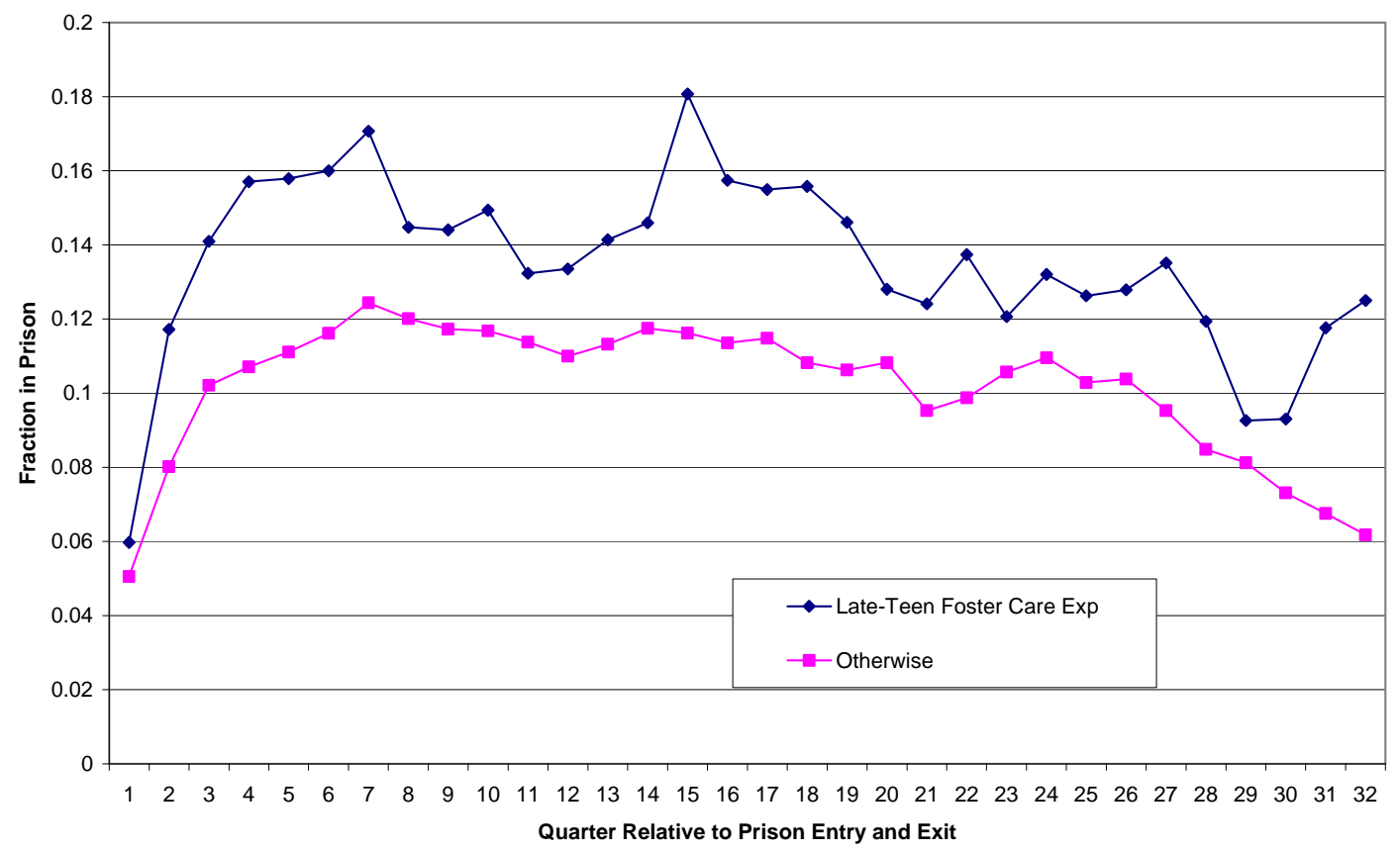


This document is a research report submitted to the U.S. Department of Justice. This report has not been published by the Department. Opinions or points of view expressed are those of the author(s) and do not necessarily reflect the official position or policies of the U.S. Department of Justice.

Figure 11: Fraction in Prison after Exiting First Prison Spell, for Female Ex-Prisoners Born Between 1966 and 1983

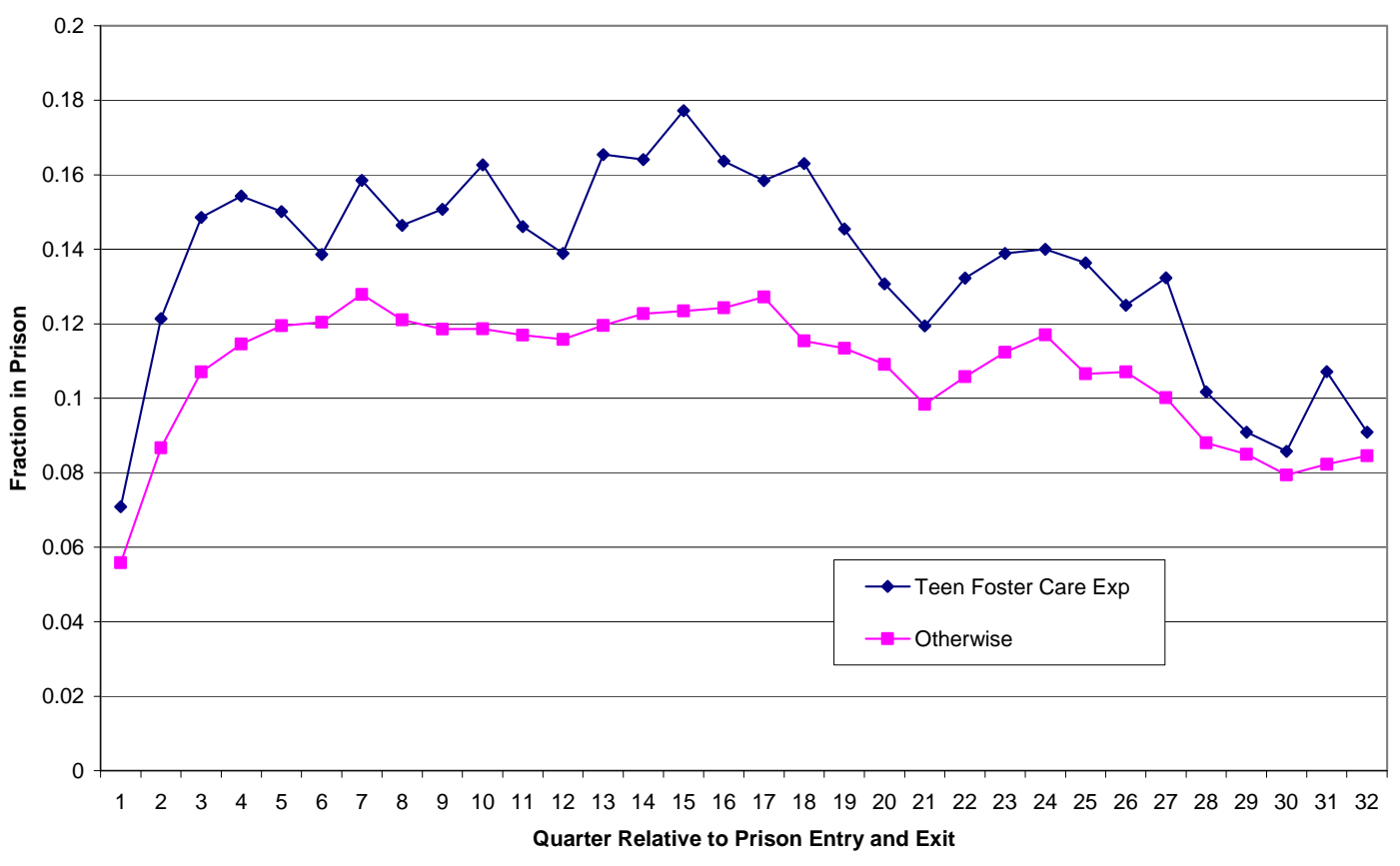

Figure 12: Fraction in Prison after Exiting First Prison Spell, for Female Ex-Prisoners Born Between 1976 and 1983

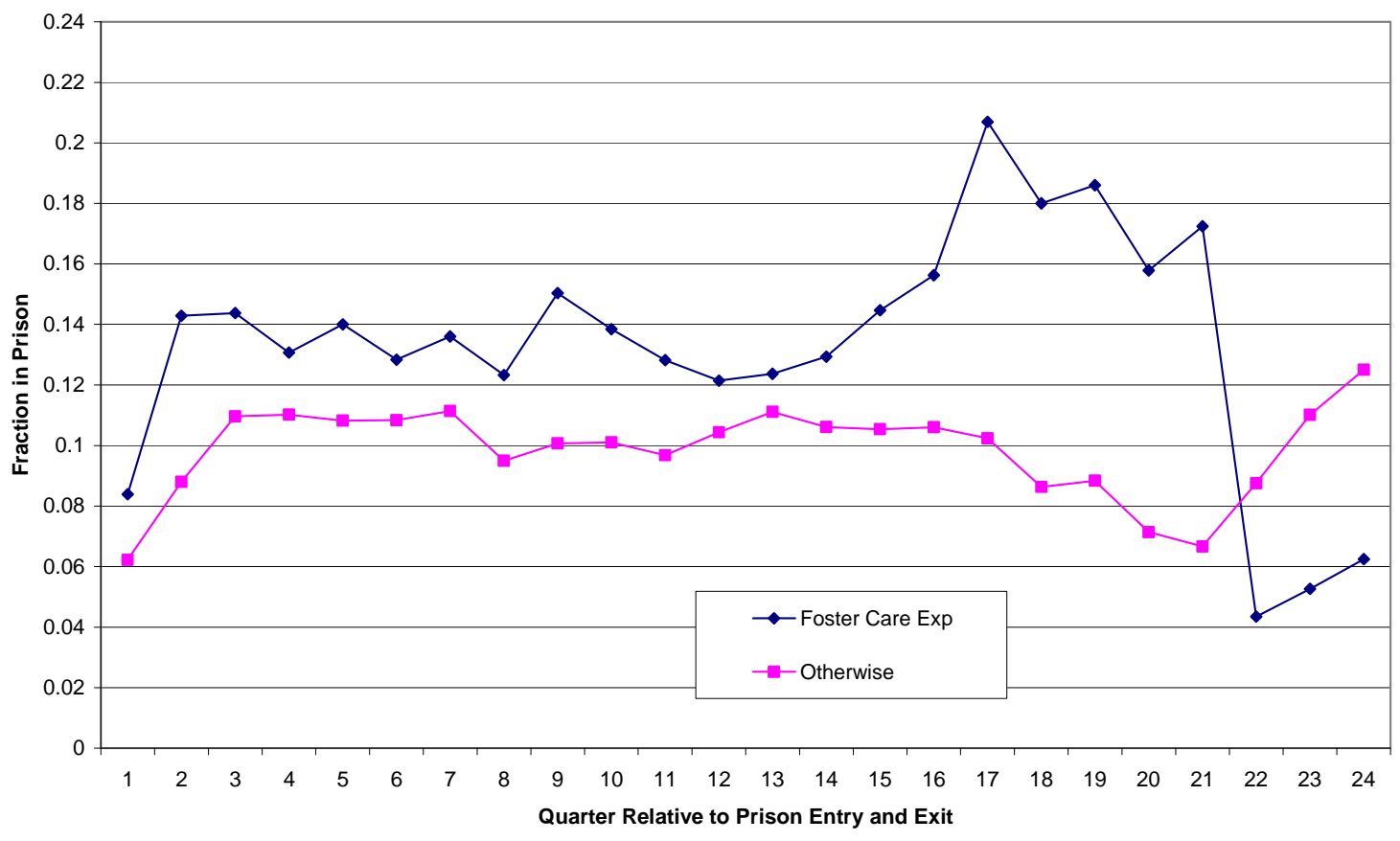


This document is a research report submitted to the U.S. Department of Justice. This report has not been published by the Department. Opinions or points of view expressed are those of the author(s) and do not necessarily reflect the official position or policies of the U.S. Department of Justice.

Figure 13: Fraction in Prison after Exiting First Prison Spell, for Female Ex-Prisoners Born Between 1961 and 1983 Who Were in

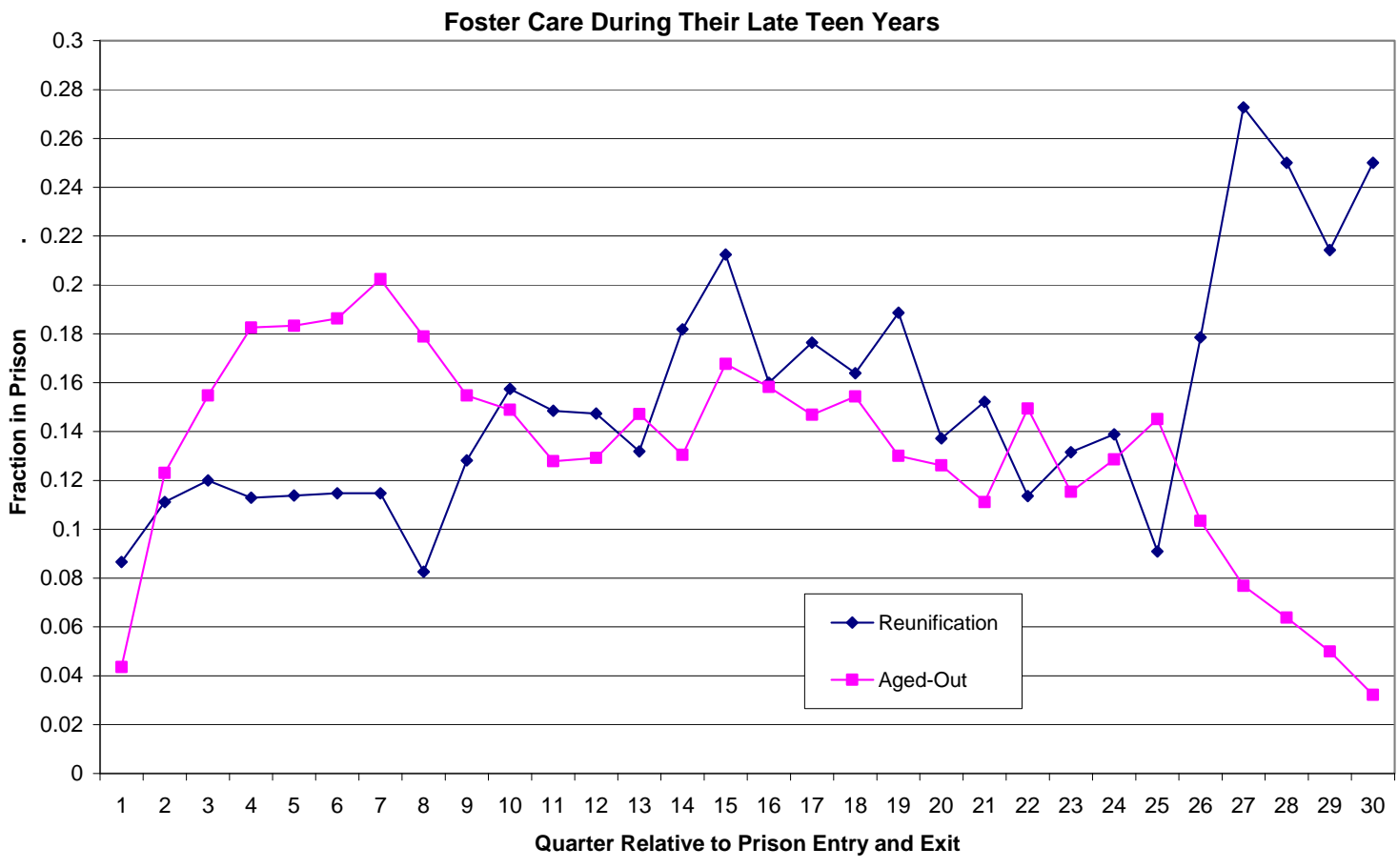

Figure 14: Fraction in Prison after Exiting First Prison Spell, for Female Ex-Prisoners Born Between 1961 and 1983 Who Were in Foster Care During Their Late Teen Years

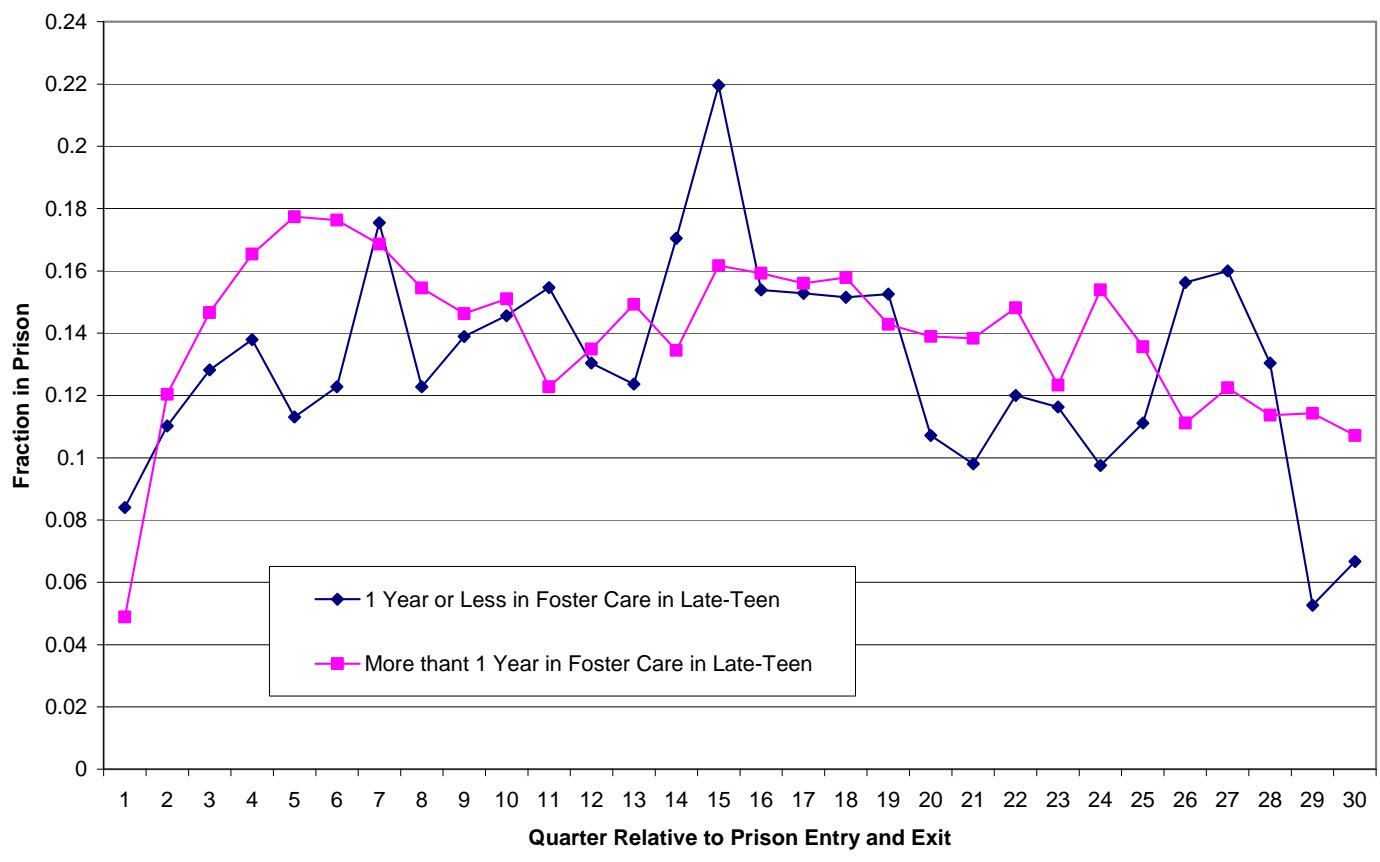


This document is a research report submitted to the U.S. Department of Justice. This report has not been published by the Department. Opinions or points of view expressed are those of the author(s) and do not necessarily reflect the official position or policies of the U.S. Department of Justice.

Figure 15: Female Ex-Prisoners Who Were in Foster Care During Their Late Teens Have Slighter Lower Employment Rates and Much Lower Earnings When They Work Compared to Observationally Similar Ex-Prisoners Who Were Not In Foster Care

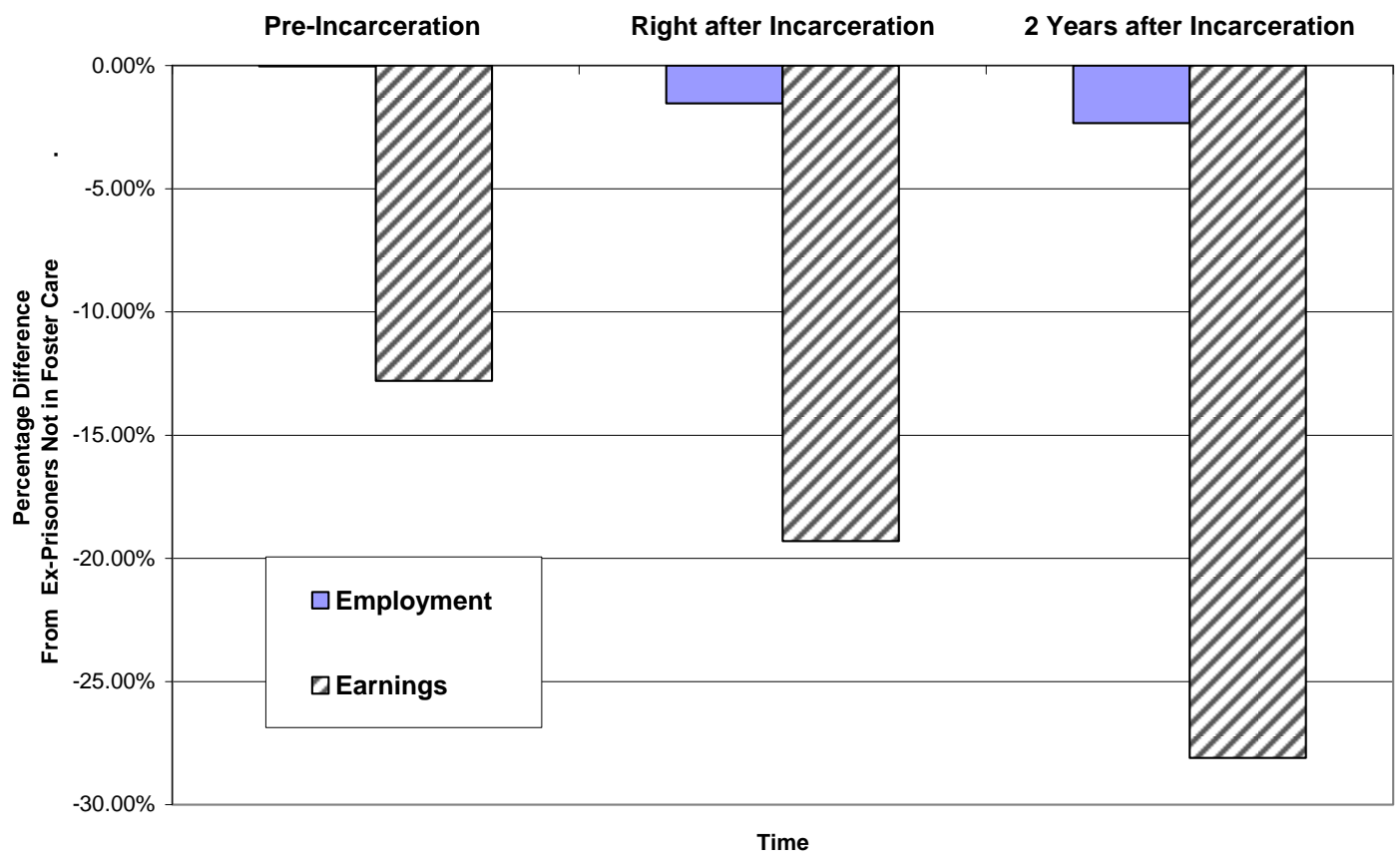




\section{Table 1}

Estimates of Numbers of Children in Institutions, Foster Family Care, and Adoptive Homes, 1910-1960

\begin{tabular}{cccc} 
& Institutions & $\begin{array}{c}\text { Foster Family } \\
\text { Care }\end{array}$ & Adoptive Homes \\
\hline 1910 & 101,403 & 61,000 & \\
1923 & 132,258 & 61,475 & $3,354 ?$ \\
1933 & 140,352 & 102,577 & $5,833 ?$ \\
1950 & 95,073 & 98,082 & $80,000^{*}$ \\
1960 & 70,892 & $163,000^{* *}$ & 107,000 \\
\hline
\end{tabular}

Notes: *-estimate for 1951;** -estimate for 1961. Source: Bernadine Barr, "Estimates of Numbers of Children in Institutions, Foster Family Care, and Adoptive Homes, 1910$1960 "$

Table 2

Percentage of Incarcerated Women in Foster Care As Children, by Year of Birth and Age When In FC

\begin{tabular}{llcc} 
& \multicolumn{3}{c}{ Age When in Foster care } \\
Year of Birth & $\mathbf{0 - 1 8}$ & $\mathbf{1 0 - 1 8}$ & $\mathbf{1 5 - 1 8}$ \\
\hline $1976-1983$ & $16.9 \%$ & $13.0 \%$ & $5.8 \%$ \\
$1966-1983$ & $(9.5)$ & $7.3 \%$ & $3.7 \%$ \\
$1961-1983$ & $(9.2)$ & $(7.1)$ & $3.2 \%$ \\
\hline
\end{tabular}

Notes: Percentages indicate percentage of female state prisoners with childhood foster care experience during the indicated age category; includes spells that started during or overlapped with the indicated age category. Numbers in parentheses are estimated. Source: Figures computed by the authors from matched IDOC and DCFS administrative data bases. 


\section{Table 3A}

\section{Incidence of Late Teenage Foster Care among Female State Prisoners}

(Birth Cohort 1961 to 1983)

Age Admitted Percentage of entrants in foster care as children by birth year

\begin{tabular}{llllll} 
To Prison & All cohorts & $1961-65$ & $1966-70$ & $1971-75$ & $1976-83$ \\
\hline $17-40$ & 3.2 & 2.2 & 2.9 & 3.8 & 5.8 \\
\hline$<18$ & 8.9 & $---(1)$ & --- & 4.8 & 9.9 \\
$18-24$ & 4.5 & $--{ }^{(1)}$ & 4.2 & 4.3 & 5.4 \\
$25-29$ & 2.8 & 3.3 & 2.5 & 2.8 & $-{ }^{(1)}$ \\
$30-40$ & 2.0 & 1.8 & 2.6 & - (1) $^{(1)}$ & $-{ }^{(1)}$
\end{tabular}

Table 3B

Incidence of Tween/Teen Foster Care among Female Prisoners

(Birth Cohort 1966 to 1983)

Age Admitted Percentage of entrants in foster care as teens by birth year

\begin{tabular}{lllll} 
To Prison & All cohorts & $1966-70$ & $1971-75$ & $1976-80$ \\
\hline $17-35$ & 7.3 & 5.3 & 7.7 & 12.5 \\
\hline$<18$ & 17.9 & $--{ }^{-1)}$ & 9.5 & 20.0 \\
$18-24$ & 9.7 & 8.2 & 8.8 & 12.0 \\
$25-29$ & 4.7 & 4.4 & 5.5 & $-{ }^{(1)}$ \\
$30-35$ & 4.4 & 4.4 & $--{ }^{(1)}$ & $--{ }^{(1)}$
\end{tabular}

Notes: The percentages shown in the table are the percentage of Illinois State prisoners admitted between 1989 and 2001 and who were born between 1961 and 1983 (Table 3A) 1966 and 1983 (Table 3B) and who experienced at least one late teen (Table 3A) or tween/teen (Table 3B) foster care spell. (1): It is not possible for a state prisoner to be in the given cell. For example a woman born between 1966 and 1970 would have turned 18 prior to 1989, the first year of our administrative data on prison admissions. A woman born between 1971 and 1975 would turn 30 in 2001, the last year of our administration data on prison admissions. Source: Authors' calculations from matched IDOC and DCFS administrative data. 
Table 4

Incidence of Childhood Foster Care among Female Prisoners (for Illinois State Prisoners From the 1976 to 1983 Birth Cohort)

\begin{tabular}{|c|c|c|c|c|c|c|}
\hline Age at first & Percentag & Care a & s Child & Iren by & Birth & Year \\
\hline Prison Spell & All years & 1976 & 1977 & 1978 & 1979 & 1980 \\
\hline $17-24$ & $16.9 \%$ & $16.3 \%$ & $17.2 \%$ & $15.6 \%$ & $18.5 \%$ & $13.9 \%$ \\
\hline$<18$ & 27.5 & 12.5 & 14.9 & 26.7 & 37.5 & 41.7 \\
\hline 18 & 16.5 & 0 & 28.8 & 21.1 & 12.2 & 11.8 \\
\hline 19 & 16.1 & 19.2 & 14.3 & 20.7 & 17.1 & 11.6 \\
\hline 20 & 15.4 & 17.5 & 15.2 & 14.9 & 18.8 & 7.7 \\
\hline 21 & 13.5 & 12.8 & 16.2 & 11.1 & 15.9 & --- \\
\hline 22 & 18.2 & 23.4 & 17.4 & 5.9 & --- & --- \\
\hline 23 & 14.0 & 12.5 & 17.6 & 0 & --- & --- \\
\hline 24 & 22.2 & 25.0 & 0 & --- & --- & -- \\
\hline
\end{tabular}

Source: Authors' calculations from matched IDOC and DCFS administrative data.

Table 5

Days in Foster Care for Female State Prisoners with Childhood Foster Care Spells

\begin{tabular}{llll} 
Total Time In FC & Age 0-18 & $\mathbf{1 0}-\mathbf{1 8}$ & $\mathbf{1 5 - 1 8 +}$ \\
\cline { 2 - 4 } Birth Cohort & $\mathbf{1 9 7 6 - 1 9 8 3}$ & $\mathbf{1 9 6 6 - 1 9 8 3}$ & $\mathbf{1 9 6 1 - 1 9 8 3}$ \\
Maximum Days Possible & $\mathbf{6 , 5 7 4}$ & $\mathbf{2 , 8 5 0}$ & $\mathbf{1 , 0 9 6}$ \\
& & & \\
$25^{\text {th }}$ Percentile & 241.5 & 105.0 & 104.0 \\
Median & 971.5 & 746.5 & 699.0 \\
$75^{\text {th }}$ Percentile & $2,158.5$ & $1,828.0$ & $1,762.0$ \\
& & & \\
Mean & $1,355.0$ & $1,195.6$ & $1,157.6$ \\
(Standard Deviation) & $1,316.7$ & $1,371.0$ & $1,363.1$ \\
Number of Women & & & \\
With FC experience & 168 & 458 & 603 \\
\hline Notes: Source: Authors' calculations from merged IDOC and DCFS administrative data.
\end{tabular}


Table 6

Resolution of Childhood Foster Care Spells for Female State Prisoners Age When in Foster Care

Total Time In FC Birth Cohort

Reunified with parent

Adopted

Subsidized guardianship

Other outcome/aged-out $\frac{\text { Age 0-18 }}{1976-1983}$

$44.1 \%$

0.6

1.2

54.2 168 $10-18$ 1976-1983

$41.1 \%$

0.0

0.8

58.2
$45.4 \%$

0.2

0.2

54.1 458
15-18+ 1961-1983

$45.8 \%$

0.2

0.2

$53.7 \%$

Number of Women

With FC experience 129

603

Table 7

First Placements for Childhood Foster Care Spells of Female State Prisoners Age When in Foster Care

Total Time In FC

Birth Cohort

Home of a Relative

Foster Care Boarder

Hospital/Health Facility

Private Agency

DCFS Institution

Private Institution
Age 0-18 1976-1983

$19.6 \%$

22.0

9.5

3.0

8.9

7.7 168 $10-18$ 1976-1983

20.9\%

15.5

7.0

2.3

11.6

10.1 129 458 603

15-18+ 1961-1983

4.8

2.5

6.8

12.8

Number of Women

With FC experience

Source: Authors' calculations from matched IDOC and DCFS administrative data. 


\section{Table 8}

Demographic Profile and Distribution of Criminal Offenses of Incarcerated Women from the 1976-1983 Birth Cohort, by Childhood Foster Care History

\begin{tabular}{|c|c|c|c|c|c|c|}
\hline & \multicolumn{4}{|c|}{ Age When in Foster Care } & \multirow{2}{*}{\multicolumn{2}{|c|}{ Never in FC }} \\
\hline & \multicolumn{2}{|c|}{$10-18$} & \multicolumn{2}{|c|}{$0-18$} & & \\
\hline & No. & $\%$ & No. & $\%$ & No. & $\%$ \\
\hline \multicolumn{7}{|c|}{ Demographic Characteristics: } \\
\hline African-American & 76 & $58.9^{*}$ & 100 & $59.5^{* *}$ & 410 & 49.6 \\
\hline White & 46 & 35.6 & 59 & 35.1 & 314 & 38.0 \\
\hline Hispanic & 5 & $3.9^{* *}$ & 6 & $3.2^{* * *}$ & 92 & 11.1 \\
\hline High School Graduate & 20 & 15.5 & 24 & 14.3 & 130 & 15.7 \\
\hline Cook County Resident & 51 & $39.5^{*}$ & 70 & 41.7 & 391 & 47.3 \\
\hline Married & 7 & 5.4 & 12 & 7.1 & 45 & 5.5 \\
\hline Mother & 75 & 58.1 & 94 & 56.0 & 432 & 52.3 \\
\hline Av. No. of kids & \multicolumn{2}{|c|}{$1.09^{*}$} & \multicolumn{2}{|c|}{1.07} & \multicolumn{2}{|c|}{0.91} \\
\hline Av. Age at imprisonment & \multicolumn{2}{|c|}{20.1} & \multicolumn{2}{|c|}{20.1} & \multicolumn{2}{|c|}{20.3} \\
\hline \multicolumn{7}{|l|}{ Criminal Offenses: } \\
\hline$\overline{\text { Substance Abuse }<1>}$ & 61 & 47.3 & 78 & 46.4 & 341 & 41.3 \\
\hline Person Crimes & 39 & 30.2 & 54 & 32.1 & 248 & 30.0 \\
\hline Property Crimes & 54 & $41.9^{* *}$ & 65 & 38.7 & 271 & 32.8 \\
\hline Drug Crimes & 29 & $22.5^{* *}$ & 39 & $23.2^{* *}$ & 262 & 31.7 \\
\hline Sex Crimes & 4 & 3.1 & 4 & 2.4 & 11 & 1.3 \\
\hline Other Crimes & 3 & 2.3 & 6 & 3.6 & 34 & 4.1 \\
\hline Number of observations & 129 & 100.0 & 168 & 100.0 & 826 & 100.0 \\
\hline
\end{tabular}




\section{Demographic Profile and Distribution of Criminal Offenses of Incarcerated Women from the 1966-1983 Birth Cohort, by Tween/teen Foster Care History}

\begin{tabular}{|c|c|c|c|c|c|}
\hline \multirow{3}{*}{ Birth Cohort: } & \multicolumn{4}{|c|}{ In Foster Care Between 10 and 18} & \multirow{3}{*}{$\begin{array}{l}\text { Never in FC } \\
1966-1983 \\
(5)\end{array}$} \\
\hline & \multicolumn{2}{|c|}{$1966-1983$} & \multirow[b]{2}{*}{ (3) } & \multirow{2}{*}{$\begin{array}{l}1976-1983 \\
(4)\end{array}$} & \\
\hline & (1) & (2) & & & \\
\hline \multicolumn{6}{|c|}{ Demographic Characteristics: } \\
\hline African-American & $59.4 \%$ & $51.0 \%$ & $66.3 \%$ & $58.9 \%$ & $65.4 \%$ \\
\hline White & 34.1 & 42.3 & 27.2 & 35.6 & 27.2 \\
\hline Hispanic & 5.0 & 5.8 & 4.5 & 3.9 & 6.6 \\
\hline High School Graduate & 19.4 & 20.2 & 18.7 & 15.5 & 26.7 \\
\hline Cook County Resident & 45.0 & 35.6 & 52.4 & 39.5 & 57.8 \\
\hline Married & 8.1 & 9.1 & 6.9 & 5.4 & 10.3 \\
\hline Mother & 74.5 & 76.5 & 73.6 & 58.1 & 76.4 \\
\hline Av. No. of kids & 1.96 & 2.01 & 2.05 & 1.09 & 2.07 \\
\hline Av. Age at Imprisonment & 23.51 & 23.69 & 23.92 & 20.14 & 25.12 \\
\hline \multicolumn{6}{|l|}{ Criminal Offenses: } \\
\hline$\overline{\text { Substance Abuse }<1>}$ & 56.3 & 55.9 & 58.7 & 47.3 & 56.0 \\
\hline Person Crimes & 23.1 & 19.3 & 26.1 & 30.2 & 18.5 \\
\hline Property Crimes & 36.9 & 43.1 & 32.0 & 41.9 & 32.5 \\
\hline Drug Crimes & 31.5 & 28.2 & 33.8 & 22.5 & 42.9 \\
\hline Sex Crimes & 4.7 & 6.1 & 3.6 & 3.1 & 1.7 \\
\hline Other Crimes & 3.9 & 3.3 & 4.5 & 2.3 & 4.4 \\
\hline Number of Observations & 458 & 208 & 246 & 129 & 5788 \\
\hline
\end{tabular}

Notes: $<1>$ This measure is self-reported when women are admitted into prison. The columns are defined as follows (1) all female prisoners in the 1966 to 1983 birth cohort who has at least one tween/teen foster care spell as a child; (2) female offenders whose foster spell ended with reunification; (3) female offenders whose foster care spell ended when they aged out of the system; (4) all female prisoners in the 1976 to 1983 birth cohort with a tween/teen foster care spell. This column is same as column 1 of Table 8. (5) Female offenders who had no tween/teen foster care spell. Source: Authors' calculations from the matched IDOC and DCFS administrative data. 


\section{Table 10 \\ Employment and Earnings Differences Among Female Prisons Who Were in Foster Care During their Late Teens}

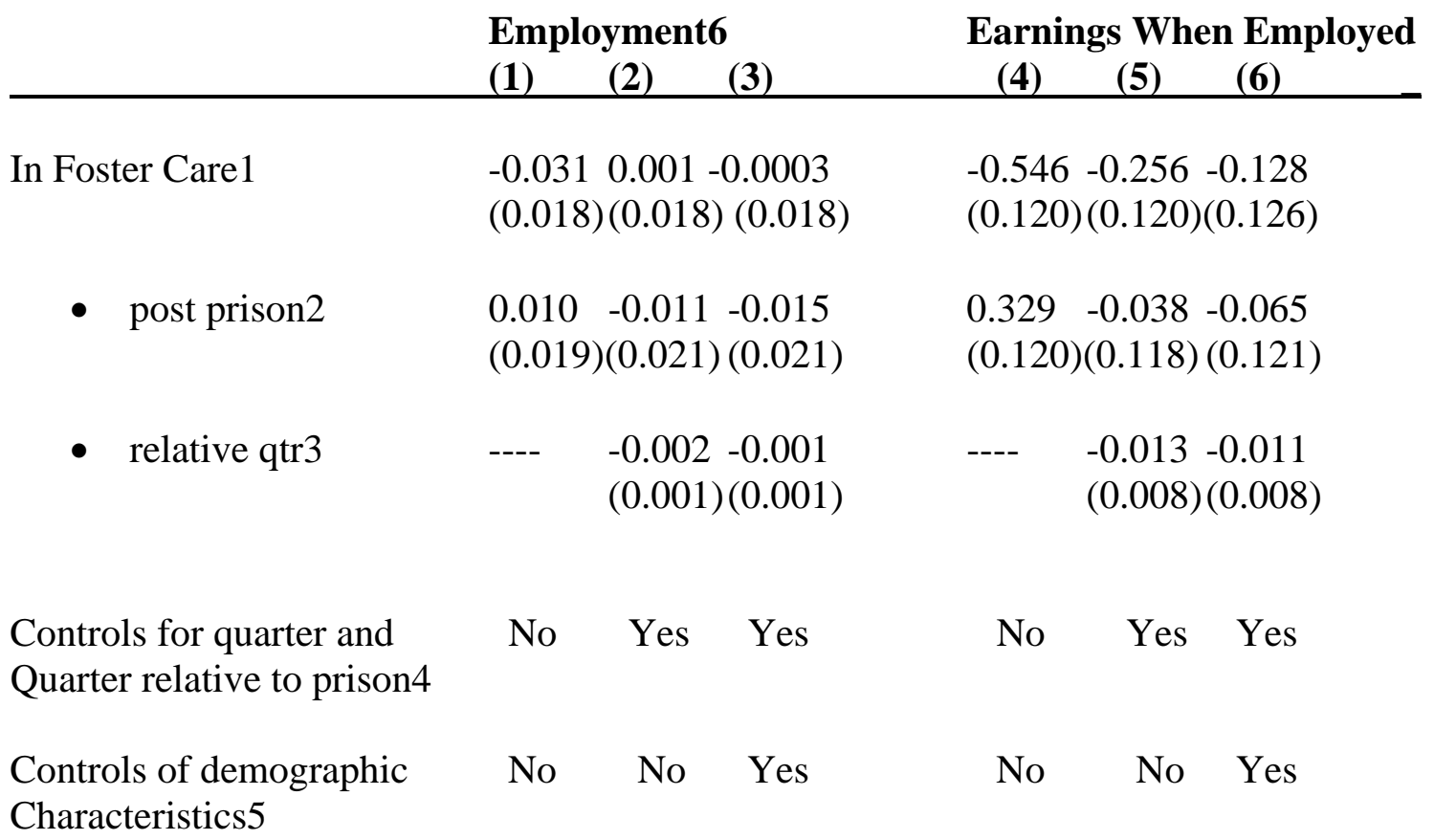

Notes: 1 - Indicator variable for whether in foster care during late teens years (15 to 19) as a child. 2 -Interaction between whether in foster care and whether the current period is is after a women's first prison spell. 3 - “Triple” inaction between foster care, post-prison and relative quarter. A negative coefficient indicates that the disparity between employment and earnings gets large (and more negative) with time since exiting prison. 4 - Includes 34 quarterly dummy variables indicating quarters 1995:I through 2003:II and 41 relative quarter indicator variables indicating whether the current quarter is up to 8 quarter prior to or up 33 quarters after the quarter of parole from prison. 5 - Includes controls for criminal offense category associated with first prison spell, years of schooling, race, and marital status. 6 - Dependent variable is quarterly employment rates. 7 - Dependent variable is the natural log of quarterly earnings given that a woman worked and earned at least \$1 during the quarter. Source: Authors' calculation from matched IDOC, DCFS, IDES administrative records. 


\title{
Incarcerated Mothers, Their Children's Placements into Foster Care, and its Consequences for Reentry and for Labor Market Outcomes
}

\author{
Haeil Jung \\ Robert LaLonde \\ Rekha Varghese
}

The University of Chicago

November 2007

This research was supported by the Chicago Community Trust and the National Institute of Justice. We have benefited from comments by Henry Brady, Robert George, Susan George, Marilyn Moses, and Anne Powell, and participants in the Center for Human Potential and Public Policy and the Incarcerated Women and Their Children workshops at the University of Chicago, and participants at the National Institute of Justice Conference, July 17 to 19, 2006 in Washington D.C. The views expressed in this paper are those of the authors and do not reflect the views of the National Institute of Justice or any agency of the state of Illinois. The authors are responsible for all errors. Send correspondence to Robert LaLonde, r-lalonde@uchicago.edu or The Harris School, 1155 East $60^{\text {th }}$ Street, Chicago, IL 60637. 


\section{Introduction}

A recent study of a nationally representative sample of child welfare abuse and neglect cases found that 1 in 8 cases overall and 1 in 5 cases involving African-American families where a parent had been arrested during the previous six months. In cases associated with an arrested parent, 90 percent of the time the arrested parent was the child's mother. In addition, in about two-thirds of these cases, the family had been subject to a previous abuse and neglect investigation (Phillips, Burns, Wagner, and Barth, 2004). As a result of these findings, these authors concluded that “...there also were secondary costs associated with a parental incarceration that are borne by child welfare system....” (p. 182) They recommended that a study of arrested parents rather than of children of the child welfare population "would provide greater insight into the complex of factors affecting the likelihood of child welfare involvement in families following a parent’s arrest.” (p. 183)

This study examines an important part of the population of arrested mothers: those who were incarcerated in state prison. These are women who almost always have had multiple contacts with the criminal justice system, and often were their children’s only custodial parent prior to their arrests. Among this population of state prisoners, we examine the connection between incidence and timing of out-of-home (foster care) placements of the children of mothers entering prison for the first time and whether such child welfare contacts are associated with less successful "reentry" after prison. ${ }^{1}$ We address the following four questions:

\footnotetext{
${ }^{1}$ The Pew Commission on Children in Foster Care defines foster care as "a living arrangement for children who a child protective services worker or a court has decided cannot live safely at home. Foster care
} 
This document is a research report submitted to the U.S. Department of Justice. This report has not been published by the Department. Opinions or points of view expressed are those of the author(s) and do not necessarily reflect the official position or policies of the U.S. Department of Justice.

(i) What is the incidence and characteristics of out-of-home placements among women in prison;

(ii) What is the timing of these placements relative to the timing of these women's incarcerations;

(iii) Is the incidence and characteristics of out-of-home placements for incarcerated women associated with their transitions into the labor market after paroling from prison;

(iv) What impact do criminal justice polices that increase the likelihood and duration of women's incarcerations in prisons have on the child welfare system in general and on the frequency of out-of-home placements in particular?

Instead of relying on survey data, our study is based on matched administrative records from the Illinois Department of Corrections (IDOC), the Illinois Department of Children and Family Services (DCFS), and the Illinois Department of Employment Security (IDES). We begin with a sample of more than 19,000 women who exited from Illinois state prisons starting in the third quarter of 1989 through the second quarter of 2003. These records were then matched to the DCFS's foster care records that extended from 1975 through the second quarter of 2002. We identify about 4,100 of these female prisoners had at least one of their children ever in foster care. But we also find that many of their children's foster care spells did not overlap their prison spells.

Finally, to explore the association, if any, of these women's child welfare contacts with their reentry prospects after prison, our administrative records were then matched to the state's quarterly wages records. These records report total quarterly earnings in formal jobs with Illinois employers starting in first quarter of 1995 and extending through the second quarter of 2003.

arrangements include non-relative foster homes, relative foster homes (also known as "kinship care"), group homes, institutions, and pre-adoptive homes (Pew 2004). 
This document is a research report submitted to the U.S. Department of Justice. This report has not been published by the Department. Opinions or points of view expressed are those of the author(s) and do not necessarily reflect the official position or policies of the U.S. Department of Justice.

In the remainder of this paper we first summarize with what has been found in previous empirical studies of this population. Next, in section III, we describe our data. In section IV, we analyze the incidence and timing of out-of-home placements relative to the timing of women's prison spells. In section V, we show how out-of-home placements or “substitute care” for these women’s children are associated with their labor market outcomes after prison. Finally, in section VI we discuss the implications of policies that increase the number of women in prison on the child welfare system.

\section{Incidence of Out-of-Home Placements among the Female Prison Population}

\section{A. Incidence of Foster Care from a Survey of Prisoners}

To date there is relatively little empirical evidence on the incidence of foster care among the children of women in prison and its consequences for families and for these women’s reentry after parole. ${ }^{2}$ According to the 1997 Survey of Inmates in State and Federal Correctional Facilities (SISFCF), about 10 percent of mothers in state prisons reported that their children were in the care of a foster home parent, an agency, or institution. ${ }^{3}$ This survey also finds that incarcerated mothers were much more likely to report that their children were in foster care than were incarcerated fathers (2 percent) (Mumola, 2000).

\footnotetext{
${ }^{2}$ See Simmons (2000) for summary on lack of information on the children of incarcerated mothers and on incarcerated mothers' contacts with the child welfare system; See Bloom and Steinhart (1993) for a reference to a Massachusetts study.

${ }^{3}$ Results of an earlier survey of prison inmates in 1991 reported a similar percentage for incarcerated women. Note neither the 1991 nor the 1997 surveys asked for information about the timing of these foster care placements. See Snell (1994).
} 
This document is a research report submitted to the U.S. Department of Justice. This report has not been published by the Department. Opinions or points of view expressed are those of the author(s) and do not necessarily reflect the official position or policies of the U.S. Department of Justice.

The possibility that prison may have contributed to the incidence of children's foster care spells is suggested by the SISFCF survey responses where that incarcerated mothers were substantially more likely than fathers to report living with their children prior to arrest. These mothers were also more likely than the fathers to have been the only parent living with their children in the month before their arrests. The survey estimates that 41 percent of the mothers in prison had been living alone with their children compared to $4 \%$ of the fathers. These results suggest that incarcerating a woman potentially has a greater impact on children than incarcerating a man, and their role as custodial parents could influence women after prison - especially her efforts to be reunified with her children.

\section{B. Incidence and Outcome of Foster Care in the United States}

To better understand the significance of child welfare contacts for female prisoners in Illinois, we summarize what is known about the incidence of foster care among women and children nationwide. At the end of each of the last 10 fiscal years, approximately 500,000 to 600,000 U.S. children were in foster care (HHS, 2006). About one-half of these children start new foster care spells, some for the first time, and the rest were in spells that continued over from the previous year. Therefore, these figures indicate that at any given time, approximately $0.7 \%$ of U.S. children 19 years and under are in foster care. ${ }^{4}$

\footnotetext{
${ }^{4}$ See http://nccanch.acf.hhs.gov/pubs/factsheets/fosterdlinks.cfm.cfm. These figures are based on statistics from the Adoption and Foster Care Analysis and Reporting System (AFCARS) for fiscal years 2000 or 2001. AFCARS data include all children in foster care, regardless of their eligibility for Title IV-E reimbursement. The number of people in the U.S. who were 19 years or less was $80,769,000$. See the Economic Report of the President, 2004, Table B-34 p. 325. At end of fiscal year 2000 there were 547,415 children in foster care or approximately 0.7 percent of all children.
} 
Among U.S. children in foster care in recent years, approximately one-fourth were 5 years or under, another one-half were between the ages of 6 and 15 and the remaining children were between 16 and 20 years. ${ }^{5}$ African American children are overrepresented in the foster care population nationwide. They constitute $15 \%$ of the U.S. child population, but $41 \%$ of the foster care population. ${ }^{6}$ White children constitute about $40 \%$ of the foster care population and Hispanic children about $15 \%$ of the foster care population.

When U.S. children are placed in "substitute care” about one-half of them live in the homes of non-relatives. Another 30 percent reside with relatives. Finally, the remaining 20 to 25 percent of foster children reside in variety of living arrangements, including group homes or institutions or pre-adoptive homes. When their spells end, approximately 55 to 60 percent of them are reunified with their parents. Another 15 to 20 percent leave to live with their adoptive parents. The ratio of children's foster care spells that are resolved by reunification as opposed to adoption is roughly 2 or 3 to 1 . The remaining children leave foster care in other ways including aging out-by reaching age 18-or by running away.

\section{Incidence and Outcome of Foster Care in Illinois}

The same foster care records that we study for incarcerated women in this paper have been analyzed extensively by Wulczyn et. al. (2000). Their study provides information about the incidence, duration, and the outcomes of foster care spells in

\footnotetext{
${ }^{5}$ See http://pewfostercare.org/research/docs/Demographics0903.pdf, Figure 1.

${ }^{6}$ Nationwide, Native American children also are over represented in the foster care population. These children constitute about 1 percent of the U.S. population, but comprise 2 percent of the foster care population.
} 
Illinois between 1983 and 1998. This period nearly coincides with period covered by our matched administrative data base. They report that during this 16 year period 144,885 Illinois children spent time in "substitute care;” for the period from 1990 through 1998, the figure was 109,226 children. These figures both constitute unduplicated counts of the number of children that spent time in foster care. Approximately, 60 percent of these foster children were African-Americans. Such children have been heavily overrepresented in the state's foster care population; statewide 20 percent of children are African-American. (See Wulczyn et. al., 2000, Figure 3.6.)

In Illinois, the foster care caseload grew sharply starting in 1988 (17,761 children at year end) through 1994 (46,105 children at year end) it remained relatively steady during the mid-1990s, and declined in both 1997 and $1998 .^{7}$ This sharp rise in case loads resulted largely from a sharp rise in entry rates of 0 to 4 year old children. Between 1988 and 1994 the entry rate of pre-school children into foster doubled from 4 to 8 per 1,000, before falling sharply after 1994. By contrast, the entry rate of school-aged children rose to about 2 per 1,000 before falling back modestly after 1994 .

Wulczyn et. al. (2000) also report that the duration of foster care spells are substantially longer in Illinois than in other U.S. states, including California and New York. During the period covering the years 1988 to 1998, 25 percent first foster care spells lasted 10 months or less; 50 percent lasted 39 months or less; 75 percent lasted 74 months or less. (See Wulczyn et. al., 2000, Figure 4.1.) The median duration of a

\footnotetext{
${ }^{7}$ Recent statistics indicate that Illinois' foster care caseload has fallen back to 1988 levels. In 2005, there were 2005 about 18,000 who spend time in foster care; one-half of these children were from Cook County (DCFS, 2007).
} 
completed foster care spell was 1,162 days. The duration of foster care spells approximately doubled between 1988 and the mid-1990s.

Among foster care spells that began between 1988 and 1995 and ended prior to December 31, 1998, 47 percent resulted in the child being reunified with her mother; 20.2 percent in the child being adopted; and 2.4 percent in the child being placed with a relative in a subsidized guardianship. ${ }^{8}$ As was the case for foster care spells nationwide. When they are resolved, the ratio of those ending with reunification as opposed to adoption also is more than 2 to 1 .

\section{Incidence of Arrest and Incarceration among Mothers of Foster Children}

The previous study that is most similar to ours was conducted by the Vera Institute. That study examined matched foster care, arrest and incarceration records for women in New York City in 1991 and 1996. Those researchers constructed the sample used in their analysis differently than the way we constructed the sample used in our analysis. Like the study cited above by Phillips et. al. (2004), the Vera Institute study starts with sample of women who have had contacts with the child welfare system. But instead of a sample of women involved with abuse and neglect allegations, the Vera Institute researchers started with samples of all mothers whose children had entered foster care in either 1991 or 1996. Then they matched these administrative foster care records to records on arrests, jail and prison incarcerations. Accordingly, they could calculate that about 10 to 12 percent of foster care children during those years had mothers who were incarcerated (in either jail or prison) during at least part of their foster care spell.

\footnotetext{
${ }^{8}$ Nearly all adoptions were of children 10 years or old or younger. See Wulczyn et. al. 2000, Figure 5.3.
} 
By contrast in our study, we start with a sample of women who were incarcerated in state prison over a 12 year period and then match these records to the state of Illinois foster care records that extend back for over 25 years. Accordingly, as we show below, we can calculate that about 17 percent of women prisoners had their children in foster care while they were in prison; a larger percentage of these prisoners had children in foster care at some point prior to the end of our sample period in 2002. Therefore, the Vera Institute study is based on a population of mothers with children in foster care, whereas our study is based on a population of mothers incarcerated in prison.

Despite these differences in design, the Vera Institute study reaches two conclusions that constitute points of reference for our study. First, women whose children are in the foster care system are likely also to have had some contacts with the criminal justice system. The study finds more than one-third of all foster care mothers were arrested at some point during their "lifetimes.” About one-fifth of these foster care mothers were ever incarcerated. The majority of all arrests-many women were arrested more than once--were for misdemeanors and did not lead to any incarceration. Second, only for a small percentage of children in foster care does their mothers arrest appear to be associated with their placements into foster care. Instead, foster care placements were more likely to precede their mother’s arrests or incarcerations.

\section{Matched Prison and Child Welfare Administrative Data}

As discussed above the starting point for our study is a sample of incarcerated mothers. The Illinois Department of Corrections provided us with women’s admission and exit records for each fiscal year starting in July 1, 1989 (the start of the fiscal year in 
Illinois) and continuing until June 30, 2003. These files contain information on each woman's criminal offense, whether she reported a substance abuse problem at the time of her admission to prison, and the entry and exit dates of each prison spell. These files also include demographic information on inmates' race, birth date, schooling attainment, county of from which they were sentenced to prison, marital status, reported number of children ever born and social security numbers.

In the appendix we describe how these prison data were matched to administrative data from DCFS and IDES. The DCFS's child welfare data include information on the timing of all children's entry and exit dates into foster care, their placements, and whether and how their foster care spells were resolved by the end of the sample period. These foster records cover the years from 1975 through 2002. As a result we can easily identify whether incarcerated mothers had children in foster care long before entering prison.

The IDES’s quarterly wage records contain, for each calendar quarter, the total wage and salary earnings that these women received from Illinois employers in jobs covered by the state unemployment insurance system. These are formal jobs in which the employer also makes contributes to the employees’ social security. The quarterly wage records cover the period from January 1, 1995 (1995:I) through June 30, 2003 (2003:II).

In this study, we analyze two groups of women prisoners. When characterizing the incidence of foster care spells among prisoners' children we begin with the sample of all women prisoners and eliminate those women who do not report having any children when they enter prison. We then calculate the number of women who have at least one 
child on in the DCFS records and characterize the timing and resolution of their foster care spells.

When we examine how the incidence and resolution of these children's foster care spells are associated with their mothers’ demographic characteristics, holding offense, and labor market outcomes, we limit our attention to women who exited IDOC facilities for the first time between 1995:I and 2001:II. This limitation is necessary because the state’s quarterly wage records are unavailable prior to January 1, 1995. However, an advantage of this limitation is that we are fairly certain that our sample follows women after their first prison spells.

In the analysis in this paper, we can follow all parolees for at least one year and some for up to eight years after exiting prison. We measure women’s quarterly employment rates and earnings relative to the entry and exit quarters of their first prison spells. So if we report in our figures below an employment rate of 0.30 during quarter -4 this means that during the $4^{\text {th }}$ quarter prior to the quarter that women enters prison for the first time, on average 30 percent were employed and earned at least $\$ 1$ in a wage or salaried job. By using state administrative IDES records, we can follow these women's employment histories in legal jobs for many years both before and after they enter and exit prison for the first time.

\section{Incidence and Timing of Foster Care Placements}

\section{A. Overview of Incidence and Resolution of Foster Care Spells}


This document is a research report submitted to the U.S. Department of Justice. This report has not been published by the Department. Opinions or points of view expressed are those of the author(s) and do not necessarily reflect the official position or policies of the U.S. Department of Justice.

The merged administrative records indicate that about 26 percent of women incarcerated in Illinois state prisons between 1989:I and 2002:II had at least one of their children in the foster care at some point between 1975 and 2002:II. But 15 percent of incarcerated women reported at the time they were admitted to prison that they had no children. Therefore, about 30 percent of incarcerated mothers in Illinois had at least one of their children ever in foster care. This percentage implies that compared to the female population, female prisoners are much more likely to have had contacts with the child welfare system.

These contacts child welfare system often occur when these women are not in prison. We find that about 65 percent of these women had at least one of their children's foster care spells end prior to having been admitted to prison for the first time. In only about 37 percent of foster care spells that were resolved prior to prison was the affected child reunified with his mother. Other spells were resolved when the child was either adopted or placed into a subsidized guardian ship. ${ }^{9}$ In other cases the foster care ended because the child "aged out” of the system or was a classified as a "runaway."10

Although the vast majority of women in prison are mothers, most do not have any children in foster care while they are in prison. Indeed, the merged Illinois administrative records indicate that most mothers in prison have never had any contact with the child welfare system. For about 70 percent of the mothers incarcerated during the 14 year

\footnotetext{
${ }^{9}$ One way a foster care case could be resolved in Illinois is with a subsidized guardianship. In these instances a foster child 12 years or older is placed most likely with relative of the child. The guardian continues to receive subsidies until the child is 18 years old. At that point the legal relationship ends. Unlike an adoption, when a child is placed into a subsidized guardianship, the biological mother's parental rights are not necessarily terminated.

${ }^{10}$ DCFS also has programs that assist a foster care child's transition to independence starting at age 15. In addition, children in Illinois can receive support and services from DCFS through age 21 and beyond if they are enrolled in college, vocational training, or an employment program.
} 
period covered by our sample we find no evidence that their children had ever been in the child welfare system. As shown by Table 1, we reach the same conclusion when we limit our sample to the 8 years covered both by the DCFS and IDES data. In addition, as we observed in the previous paragraph, among those mothers whose children had been in foster care, in a significant percentage of these spells (about 55 percent in the 8 year sample) had resolved prior to prison.

The Illinois evidence indicates that the incidence of child welfare contacts is relatively high among the population of female prison population. We find that at any point in time about 17 percent of incarcerated mothers had at least one child in foster care. This percentage is about 20 times higher than it is for the female population of child bearing age. Further, we find an additional 3 percent of mothers had already lost their parental rights to one or more children prior to entering prison for the first time.

One striking difference between children's foster care spells that overlap with their mother's prison spells and foster care spells that are resolved prior to a mother's prison term is that the overlapping foster care spells are very unlikely to be resolved with the mother being reunited with her child. As shown by Table 2, approximately 13 percent of these overlapping foster care spells, the child was reunited with his mother. In nearly 60 percent of these foster care spells, the child is adopted or placed into a subsidized guardianship. In another paper, we address the question of whether prison "causes” this apparent strong statistical association between loss of parental rights and simultaneous contacts between the corrections and child welfare systems. Instead, we examine below 
whether incentives to be formally reunified with their children appear to influence these women's outcomes in the labor market after they are paroled from prison.

\section{B. The Timing of the Start of Foster Care Spells.}

Above we observed that many of the foster care spells of the children of incarcerated mothers were resolved prior to prison. But what about mothers whose prison stays overlapped with their children’s foster care spells? Is prison associated with the start of such spells?

We find that prison is not associated with the start of these overlapping foster care spells. As shown by Table 4, only about 6 percent of the overlapping spells started within 90 days of the mothers' entry into prison. About 25 percent of the overlapping spells (c.f. the first four rows of Table 4) started within one year of the start of mothers’ prison stay. By contrast, about one-third of these overlapping foster care spells began more than 3 years prior to the mothers' entry into prison for the first time. Therefore, the Illinois data indicates that when the children of incarcerated mothers are in foster care, these spells usually began well before prison and were unlikely precipitated by the state's decision to incarcerate their mothers.

Another way to understand the timing of children's foster care spells that overlap their mothers’ prison spells is to ask how many days these foster care spells had been in progress when their mothers went to prison. As shown by the last row of Table 4, these spells had been in progress for an average of 1,033 days when these children's mothers went to prison; the median length of the “ongoing” foster care spells was 816 days. As 
shown by Table 5, these durations are roughly similar among women of different schooling levels, county of residence, holding offenses, and whether the child also had a sibling in foster care. The only exception was for the children of white mothers and children of mothers who had worked during the year prior to prison. Their foster care spells were more likely to have begun during the year prior to their mother's first prison stay.

One reason that we observe these overlapping foster care spells are unlikely to be resolved by mothers being reunited with their children is that a majority of these children had already been in foster care for two or more years prior to their mothers’ incarcerations. The duration of these foster care spells (in Table 4) are consistent with the mean and median durations of all completed foster care spells in Illinois as reported by Wulczyn et. al. (2000). The difference between these overlapping foster care spells and all completed foster care spells in the state is that the former were still incomplete and in progress at the start of a mother's prison spell. Given that the chance of a child reunifying with his mother is known to decline with time in foster care, it is not surprising that these overlapping spells tend to be resolved with mothers' losing their parental rights to their child.

\section{Mothers' Demographic Characteristics}

The female prison population is an economically disadvantaged population of mothers. Approximately one-half of female prisoners were African-American high school dropouts, about one-third were high school graduates, 20 percent were non-Hispanic whites, roughly one-fourth were under 25 when incarcerated in prison for the first time. 
Prior to prison their quarterly employment rates were 25 to 30 percent. When they worked they earned on average about $\$ 2,500$ per quarter. These are the approximate earnings expected of a full-time minimum wage worker.

Among prisoners whose children were ever in foster care, these women are modestly more likely than other prisoners to be African-American, high school dropouts, and in their late 20s. However,

\section{The Children of Incarcerated Mothers}

The incidence of foster care is especially high among women with many children. The most important predictor of whether a prisoner reported that she had ever had child in foster care was the number of children she reported having when she was admitted to prison. Among women reporting that they had four or more children, 44 percent had children in foster care prior to 2002:II. By contrast, the figure for all other prisoners was about 20 percent.

In other work, we have observed that women with many children constituted the fastest growing segment of the female prison population (George and LaLonde, 2002). By fiscal year 2000, women with four or more children constituted 25 percent of women in Illinois prisons. Accordingly, below when we examine the association between child welfare contacts and labor market outcomes after parole, we account for the number of children, as well as other observed attributes of these mothers.

Our matched administrative data enable us to estimate the number of children who had mothers that spent time in Illinois prisons during the time period covered by our 
This document is a research report submitted to the U.S. Department of Justice. This report has not been published by the Department. Opinions or points of view expressed are those of the author(s) and do not necessarily reflect the official position or policies of the U.S. Department of Justice.

sample and the fraction of these children who spent time in foster care and in foster care while their mothers were in prison. Because mothers whose children spent time in foster care had more children on average than other incarcerated mothers, the incidence of child welfare contacts among the children of incarcerated mothers is larger than the incidence of child welfare contacts among the women themselves.

During period from 1989:III through 2001:II, we estimate that there were nearly 35,000 children in Illinois whose mothers spent time in prison. ${ }^{11}$ Our matched administrative data indicates that about 11,600 of these children spent time in foster care prior to 2002:III. Therefore, at least one-third of the children of incarcerated mothers also spent time in the foster care system during their childhoods. We estimate that about onehalf of these children were in foster care when their mothers were in prison. Because our sample period ends in 2002, the possibility remains that this fraction has grown in recent years as the younger children age toward adulthood. ${ }^{12}$

Recall that the Vera Institute study found that somewhat more that one-third of New York city children in foster care had mothers who had been arrested during the lifetimes and 20 percent of them had mothers that had been incarcerated in either in jail or prison. Taken together both our Illinois study and the Vera Institute’s New York City study document the considerable overlap between the female corrections and child welfare populations.

\footnotetext{
${ }^{11}$ We arrive at this figure by multiplying the number of women incarcerated at least once in Illinois prisons, between 1989:II and 2001:II, 14,321, times the average number of children reported by these women at the time they entered prison or 2.43 for a total of about 34,800 children.

${ }^{12}$ The number of children even born to those women also could grow if they later give birth to children after leaving prison. However, we expect the fertility rate among women after prison to be relatively low as their average age when they enter prison for the first time is 31.5 years.
} 


\section{The Association between Labor Market Outcomes After Prison and Children's Foster Care Status}

One goal of prison reentry initiatives is to integrate returning prisoners into the labor force. High levels of employment after prison would be viewed as an indicator that these initiatives were successful and that these women where in the process of making the transition from prison to self-sufficiency. Although little is known about labor force transitions after prison for women, even less is understood about how these transitions are affected when children are involved, especially if these children are in foster care when their mothers are paroled from prison.

In theory, linkages with the child welfare system could foster or impede reentry. There is no compelling rationale for believing women with child foster care spells would do better or worse in the labor market than their counterparts whose children never spent time in the child welfare system. Having a child in foster care and losing parental rights may indicate a level of life skills associated with very poor labor market outcomes. In this case, prison authorities and operators of reentry programs could use children's foster care spells as indicator of their mothers' likely labor market success. Alternatively, having a child in foster care while in prison may provide a woman with an incentive to work in a wage and salaried job after prison so as to facilitate being reunified with her child. Under these circumstances, employment outcomes for women whose children were in foster care while they were in prison may be better than those of other incarcerated mothers.

We use our longitudinal earnings data to distinguish among the foregoing hypotheses. To do so we examine the temporal patterns of quarterly employment rates, 
earnings, and the earnings when women are working for the following groups of mothers who paroled from Illinois prisons after starting in 1995:I.

(i) those who never had a child in foster care between 1975 and 2002:II;

(ii) those who had a child in foster care, but regained custody of the child prior to entering prison for the first time;

(iii) those who had a child in foster care and lost her parental rights prior to entering prison for the first time;

(iv) those who had a child in foster care, this foster care spell overlapped her first prison spell and who regained custody of the child during the sample period.

(v) and those who had a child in foster care, this foster care spell overlapped her first prison spell and who never regained custody of the child during the sample period.

In table 6, we summarize the distribution of women among these five groups of mothers. ${ }^{13}$ As indicated above, most women who go to prison have children but those children are not in the child welfare system while they are in prison. In keeping with this finding 74 percent of female parolees did not have children in foster care during the sample period. Some of these women did not have children when admitted to prison.

The next largest group of women prisoners consists of those whose children's first foster care spells over lap their prison spells and who never regained custody of these children during the sample period. These women constitute approximately 16 percent of our sample. Finally, the other two groups of interest here-those women whose children's foster care spells started and ended prior to their first prison spell—are approximately equally divided between women who regained custody and women who

\footnotetext{
${ }^{13}$ Because the sample for our analysis of the connection between labor market outcomes and child welfare contacts is limited to mothers who parole from their first prison spell after January 1, 1995, the percentages given in Table 6 differ from elsewhere in this paper.
} 
did not regain custody of their children during the sample period. Oldest children whose foster care spells overlapped their mothers prison spells, but later reunited with their mothers, comprise only about 6 percent of all foster care spells.

\section{A. Labor Market Outcomes of Incarcerated Women}

We begin our analysis by comparing the quarterly earnings histories of mothers whose children never had any contact with the child welfare system and those whose children were in foster care while they were in prison. The pattern of earnings and employment during the pre-prison period we have documented elsewhere for the population of female parolees in Illinois (LaLonde and Cho, 2005). As shown by Figure 1 , the quarterly earnings of these women are relatively low during both the pre- and postprison period. During the $8^{\text {th }}$ quarter prior to prison these women earned on average $\$ 600$ per quarter. This amount is the equivalent of working for about 10 hours per week at the federal minimum wage of $\$ 5.15$ per hour.

The Illinois data indicate that women who parole from prison had poor employment histories prior to prison and poor, but improving employment histories, after prison. The low earnings of incarcerated mothers reflect their status as economically disadvantaged persons. This status does not depend as much on their child welfare contacts, although women without them appear to be more employable. Significantly, both groups' earnings are on average greater after prison than they were before prison. As we have observed in earlier research, prison does not appear to adversely affect these women’s already poor employment prospects (Cho and LaLonde, 2005). That finding does not appear to depend on a mother's child welfare contacts. 
This document is a research report submitted to the U.S. Department of Justice. This report has not been published by the Department. Opinions or points of view expressed are those of the author(s) and do not necessarily reflect the official position or policies of the U.S. Department of Justice.

\section{B. Labor Market Outcomes and Child Welfare Contacts}

We now turn to examine how women's employment histories are associated with their linkages to the child welfare system while in prison. We find that the quarterly earnings of women who have no foster care records during the sample period consistently exceed those women whose children's foster care spells over lap with their prison spells. As shown by Figure 1, the gap between these two group's quarterly earnings both three year before and three years after prison is about $\$ 300$ per quarter. Further, this gap in earnings tends to widen somewhat in the post-prison compared to the pre-prison period. This evidence indicates that female prisoners who also have children in the child welfare system are less employable; they were less employable both prior to going to prison for the first time as well as afterwards; the difference is wider prior to going to prison.

We find that there are two reasons why female prisoners with children in foster care have lower earnings: First, they are less likely to be employed during any given quarter. Second, and more importantly, they earn less when they work. As shown by Figure 2, we observe that quarterly employment rates of prisoners with children in the child welfare system were consistently below those of their counter parts whose children never appear in the state’s foster care records. During the post-prison period, the gap between these two groups' quarterly employment rates is about 2 percentage points. This gap is lower after prison than before prison.

Whatever improvement in the relative employment prospects suggested by the quarterly employment data in Figure 2 is outweighed by the growing gap in quarterly earnings among these two groups of women when they were working. As shown by 
Figure 3, when those women without child foster care histories work, they earned about $\$ 3,000$ per quarter at the end of the first year after exiting prison. By contrast, the earnings of mothers whose children were in foster care while they were in prison earned about $\$ 500$ per quarter less when they were working.

Incarcerated women with children in foster care are generally less employable than other incarcerated women, but we also find that after prison the gap between them and their counterparts who had no child welfare contacts gets wider. Incarcerated mothers who never had children in foster care appear to be more successful reentrants. They have earnings that grow more rapidly after prison than the earnings of women whose children where in foster care while they were in prison.

This difference in post-prison earnings growth contrasts with the pre-prison period during which the earnings gap between these two groups of mothers became smaller. Nonetheless, the pre-prison earnings histories of these mothers reinforce our earlier contention that women who never have a child foster care spell were more employable to start with than their counterparts who had children in foster care while in prison. Further, those mothers without child welfare contacts also appear to adjust better after they parole from prison.

\section{Women Whose Children's Foster Care Spells Ended Prior to Prison}

In the next three figures, we compare incarcerated mothers with no foster care records for their children to women who have such records, but whose spells were resolved prior to going to prison. Among this later group of women we distinguish 
between women who were reunified with their children and those who lost parental rights to at least one of their children. As shown by Figure 4, the quarterly earnings of women who lost parental rights to one of their children prior to going to prison had the lowest quarter earnings after prison. The post-prison quarterly earnings of women who were reunified with their children prior to prison are greater than the earnings of their counterparts who lost parental rights to at least one child. But neither of these two groups of women earn as much as women whose children were never in foster care.

These groups’ earnings histories prior to prison suggest that women who were reunified with their children prior to prison were more employable to begin with than were their counterparts who lost parental rights to at least one child prior to going to prison. The earnings of mothers who were reunited with their children prior to entering prison are similar to women who never had any child welfare histories for their children during the sample period. The pre-prison earnings of mothers who lost parental rights prior to prison were about $\$ 300$ per quarter, or about one-half of those of their counterparts who were reunified with their children prior to entering prison.

The foregoing evidence indicates that losing parental rights to a child prior to prison is a good predictor of labor market outcomes both before and after prison. Indeed, the especially poor labor market performance of such women might be a factor that explains why they never were reunified with their children.

The next two figures indicate that the reason for these differences in average quarterly earnings is that mothers who are reunited with their children prior to entering prison are more likely than other mothers to be employed during any given quarter (c.f. 
Figure 5). We find that they are more likely to be employed than even mothers whose children never appear in the state's foster care records. By contrast, as shown by Figure 6, when these mothers who were reunified with their children are employed their earnings are relatively low. They earn about the same if not a little less than other women, especially mothers who lost parental rights to at least one child prior to entering prison. Indeed, although these mothers who regained their parental rights were more likely to be employed, they tended to earn less when they worked and experience essentially no earnings growth after prison.

\section{The Timing of Prison, Child Welfare Contacts and Labor Market Outcomes}

These findings indicate that having children in the child welfare system is an indicator of poor labor market outcomes, but prison does not likely cause these outcomes to be worse. Among mothers in the corrections system, those that the state has removed at least one of their children from their custody are less employable than other women. We explored further whether it made difference whether these foster care spells were resolved prior to a mother's first prison stay or during or after these mothers where incarcerated in prison. Although mother who lost parental rights prior to prison appear to have modestly improved labor market outcomes, the differences are small enough that we find it instructive to ignore the timing of the spell and instead to organize children's foster care spells by whether the mother was reunified with her child.

As shown by Figures 7 through 9, mothers who are reunified with their children have labor market outcomes that are similar to mothers who never had any contact with the child welfare system. By contrast, mother's who lose parental rights have lower earnings 
both before and after they go to prison. As suggested above, this group also does not experience any earnings growth after prison in contrast to other mothers.

Women who were reunified with their children are more likely to be employed than their counterparts who lost parental rights. This finding holds before and after prison. This finding is not surprising if child welfare authorities use employability as determinant to resolve these cases. But it is important to recognize that our data indicate that women who are reunified with their child have consistently higher employment rates and not simply higher employment rates around the time they are reunified with their children (c.f. Figures 5 and 8).

\section{E. Are The Mothers Labor Markert Outcomes Associated with Her Other Attributes?}

The evidence we present in Figures 1 through 9 indicates that an incarcerated mother's status of having her children in foster care is an indicator of low levels of general skills and employability. The evidence is less supportive of the idea that this status “causes” poor labor market outcomes and therefore impedes these women's reentry prospects. Here we explore these points further by asking: Does having a child in foster care indicate especially poor labor market performance or does it reflect other observed attributes such as being a high school dropout or having served time for a drug offense? Does knowing the foster care status of a prisoner's children provide any independent information about the likely labor market success of these women once they are paroled?

To address these questions, we regression-adjusted our three labor market outcomes (quarterly earnings, quarterly employment rates, and log quarterly earnings if 
employed) for other observed attributes of the women. (See the appendix for a discussion of how we regression-adjust these outcomes.) The attributes available on IDOC records are age, years of schooling, marital status, race/ethnicity, number of children, holding offense (e.g. person, property, drug or other violations), and time served. We test whether after holding constant these attributes are there differences among labor market outcomes of these women given the foster care status of their children. We compare these outcomes for the foster care groupings defined in Table 6 .

The regression adjusted employment and earnings outcomes still indicate that incarcerated mothers whose children spent time in foster care perform worse in the labor market than other incarcerated women. The difference between such women and mothers whose children have never been in foster care is that these women earn less when they are working. As shown by Figures 10 through 12, when mothers with child welfare contacts work they earn between 10 and 35 percent less prior to prison and 20 to 25 percent less two years after prison compared with observationally similar mothers whose children never were in foster care. ${ }^{14}$

In Figure 10 these percentages appear to be lower after prison compared to before prison although these changes could have arisen by chance. It is clearer that the incarcerated mothers whose children foster care spells overlap their prison spells consistently earn about 20 to 25 percent less than incarcerated women whose children are never in foster care. Evidence that these percentages reflect general skills or "life skills"

\footnotetext{
${ }^{14}$ The phrase "observationally similar" means that we compare women whose schooling, race/ethnicity/ age, marital status, county of residence, offense category, and time served are similar. Table A in the Appendix presents the adjusted and unadjusted estimated regression coefficients associated with Figures 7 through 9.
} 
is found when we observe (in Appendix Figure A) that these percentages are even larger when we do not adjust for these women's demographic characteristics and offenses. Mothers whose attributes are known to be associated with lower earnings also are more likely than other incarcerated mothers to have their children in foster care while in prison.

By contrast, as shown by Figure 11, these earnings gaps when mothers are working widen between the pre- and post-prison periods for mothers who were reunified with their children prior to prison. This widening occurs even though such mothers were more likely to be employed during any given quarter than other mothers in our sample. We doubt, however, that this widening results because of the challenges associated with reforming their families after prison. Women whose children were never in foster care face similar challenges.

Finally, in Figure 12, we observe that two years after paroling from prison, mothers whose children where either adopted or placed into a subsidized guardianship prior to the start of their prison spells earn about 20 to 25 percent less than observationally similar mothers whose children never were in foster care. This gap is about the same as it was for mothers whose children were in foster care while they were in prison. As we observed above in Table 2, those women also usually lose their rights to their children. This evidence suggests losing parental rights, although more common among women involved with the criminal justice system, probably does not result from these contacts. Rather having had a child in foster care and losing rights to that child is an indicator of poor life skills and predicts poor reentry outcomes no matter what the timing of such foster care spells. 
Taken together, our results indicate that the following: First, having a child ever in foster care is an indication of poorer labor market outcomes both prior to entering and after exiting prison. Second, knowing whether the mother is ever reunified with her child is associated with improved labor market outcomes, but such women do not do a well as women who never had children in the child welfare system. Third, these differences among incarcerated women hold both during the pre- and post-prison periods.

\section{Discussion}

In this paper we have documented that merging different state administrative databases yields valuable information about the female prison population and their children. In Illinois, we find incarcerated mothers whose children have been in foster care are even more economically disadvantaged that other incarcerated women. This finding holds especially among mothers who are not ultimately reunited with their children. Whether their children's foster cares spells are resolved prior to their first prison spell or coincide with their time in prison, their economics outcomes and chances for self sufficiency appear especially poor.

However are these findings the result of their contacts with the child welfare system or do they arise because these women have attributes and behaviors that make them likely to cross paths with both child welfare and the criminal justice systems? Our analysis indicates that the latter explanation is the most likely for the following reasons:

(i) Children of incarcerated mothers are rarely placed in foster care because of their mothers' entry into prison. 
(ii) About one-third of the children of incarcerated mothers have spent time in foster care, but these spells usually start long before their mothers’ first prison spell and many of these foster care spells end prior to their mothers' first prison stay.

(iii) The labor market outcomes of incarcerated mothers whose children spend time foster care are worse than other incarcerated women both before and after prison.

(iv) Among mothers whose children spent time in foster care, the ones who appear to be the most employable are those who were reunited with their children; their outcomes are the most similar to mothers whose children appear to have never had contacts with the child welfare system.

(v) Mothers whose children are in foster care while they are incarcerated would appear to have a significant incentive to perform well after their paroles in order to facilitate being reunited with their children; but in fact they perform more poorly in a the job market than other observationally similar exprisoners.

We conclude that the child welfare contacts of incarcerated mothers are valuable indicators that policy makers and program operators can use to predict poor reentry outcomes among these women. We find that these mothers are especially economically disadvantaged compared to other incarcerated women. As a result, we expect that such women will require more services upon reentry to successfully integrate them. 
Notice the post-prison difficultly that they likely face are probably not associated with trying to reestablish their families after prison. Women who do the worst in the job market after prison are those who have lost parental rights to one or more of their children. Their counterparts who were reunified with their children prior to prison to better and even observationally similar mothers whose children never spent time in foster care do better still. Accordingly, one way to understand these results is that child welfare authorities appear to recognize and act on attributes of these women that apparently are associated with both being poor parents and with being poor workers. 


\section{References}

AFCARS (2007). Adoption and Foster Care Analysis and Reporting System, see http://nccanch.acf.hhs.gov/pubs/factsheets/fosterdlinks.cfm.cfm.

Bloom , Barbara and David Steinhart (1993). Why Punish the Children? National Council on Crime and Delinquency, December 1993.

Butcher, Kristin and Robert LaLonde (2007). "Female Offenders Use of Social Welfare Programs Before and After Jail and Prison: Does Prison Cause Welfare Dependency?” Federal Reserve Bank of Chicago, working paper, November 2006.

The Annie E. Casey Foundation (2002, March). "Partnerships Between Corrections and Child Welfare: Collaboration for Change, part two," http://www.aecf.org/initiatives/familytofamily/tools/16937.pdf.

Cho, Rosa, and Robert LaLonde (2005). “The Impact of Incarceration in State Prison on the Employment Prospects of Women,” IZA Working Paper, No. 217.

DCFS (2007), see web site of the Illinois Department of Children and Family Services: www.state.il.us/dcfs/docs/chapter7.pdf

Ehrensaft, Miriam, Ajay Khashu, Timothy Ross, Mark Wamsley (2003). Patterns of Criminal Conviction and Incarceration Among Mothers of Children in Foster care in New York City, New York: Vera Institute of Justice and Administration for Children's Services December 2003.

George, Susan and Robert LaLonde, (2002). “Incarcerated Women in Illinois State Prisons: An Analysis of Administrative Data," working paper, The University of Chicago, June 2002.

Goerge, Robert; Van Voorhis, John and Lee, Bong Joo (1994). Illinois Longitudinal and Relational Child and Family Research Database. Social Science Computer Review, 12:3, 351-365.

Moses, M.C. (1995). Keeping Incarcerated Mothers and their Daughters Together: Girl Scouts Beyond Bars. Retrieved April 26, 2005 from the National Institute of Justice Web site: http://www.ncjrs.org/pdffiles/girlsct.pdf.

Mumola, Christopher J. (2000). "Incarcerated Parents and Their Children,” The U.S. Department of Justice, Office of Justice Programs, Bureau of Justice Statistics, NCJ 182335, August 2000. 
Murray, Joseph, Carl-Gunnar Janson, David P. Farrington (2007). “Crime In Adult Offspring Of Prisoners: A Cross-National Comparison Of Two Longitudinal Samples,” Criminal Justice and Behavior, 34 (1, January): 133-149

Pew (2004). "Fostering the Future: Safety, Permanence, and Well-Being for Children In Foster Care.” Pew Commission on Children in Foster Care. See http://pewfostercare.org.

Phillips, Susan, Barbara Burns, Ryan Wagner, and Richard Barth (2004). "Parental Arrest and Children Involved With Child Welfare Services Agencies,” American Journal of Orthopsychiatry, 74(2): $174-186$.

Simmons, C.W. (2000). "Children of Incarcerated Parents: A Report Prepared at the Request of Assemblymember Kerry Mazzoni,” March 2000, Retrieved from California Research Bureau Web site:http://www.library.ca.gov/crb/00/notes/v7n2.pdf.

Snell , Tracy (1994) Women in Prison, Washington D.C.: U.S. Department of Justice, Bureau of Justice Statistics.

Wulczyn, Fred (1996). “A Statistical and Methodological Framework for Analyzing the Foster Care Experiences of Children,” Social Service Review, 70(2, June): 318-329

Wulczyn, Fred H, Kristen Brunner Hislop, and Robert M. Goerge (2000). Foster Care Dynamics 1983 - 1998: Alabama, California, Illinois, Iowa, Maryland, Michigan, Missouri, New Jersey, New York, North Carolina, Ohio, Wisconsin: A Report from the Multistate Foster Care Data Archive, Chicago: The Chapin Hall Center For Children At The University Of Chicago. 


\section{Appendix}

\section{Matching the IDOC and Chapin Hall Integrated Administrative Databases.}

To match individual records from the Illinois Department of Corrections (IDOC) and the Chapin Hall Integrated Database (IDB), the Chapin Hall Center for Children used probabilistic record matching. This method assumes that researchers can not match individuals' records for a single shared variable (or field) in two data sets with complete confidence. So for example, even it was possible to match former inmates' social security numbers in different data sets some matches would inevitably be in error. Instead, Chapin Hall based its matches on a statistical model that estimates the probability that two records in two different databases are for the same person using matches between as many variables as possible. For this study, these variables included all known last names, first names, birthdates, race/ethnicity indicators, and last known residence. See Goerge Van Voorhis, John and Lee (1994).

The Illinois Department of Corrections (IDOC) admission and exit records contain information on the category of each female inmate's criminal offense, whether an inmate reports a substance abuse problem at the time of admission to prison, and the entry and exit dates of each prison spell. These files also include demographic information on inmates' race, birth date, years of schooling, the country from which they were sentenced to prison, marital status, and number of children.

The individual records in the IDB file come from essentially two sources: the Illinois Department of Human Services (DHS) and Illinois Department of Children and Family (DCFS) services. The DHS records provide information on Food Stamp, AFDC/TANF, and Medicaid spells covering the period from 1990 through 2001. The DCFS records contain information on child welfare contacts, including foster care spells of either the women themselves or their children dating back to 1975 .

The foster care administrative data from the IDB are from the Illinois Department of Children and Family Services' Child and Youth Centered Information System (CYCIS). The system tracts information on the timing and placement in non-relative foster boarding homes, placement in kinship foster homes, and placement in "congregate care” facilities. CYCIS also includes information the timing and exit destination from substitute care (e.g., reunification, adoption, guardianship, death, independence, runaway, detention). The first foster care spells in the data base started in 1975. In this study we have records through the end of 2002.

The match rate between the IDOC file and the IDB was approximately 82 percent. Match rates outside of Cook County were higher; match rates in Cook County were 78 percent. The sample we use in this study consists of 6,991 women who do not have an IDOC prison spell between 1990 and 1995, and who do have such a spell between January 1, 1995 and December 31, 2000. Consequently, we consider our sample to consist of first-inmates with social and/or child welfare histories.

\section{Matching the Merged IDOC and IBD data base with IDES Administrative Data}

The earnings data that we use in this study starts with IDOC file of women formerly incarcerated in state prison in Illinois between 1989:II and 2003:II. This file was matched by the Chapin Hall Center for Children to the quarterly wage records maintained by the IDES. The common identifier in this match was the women's social security 
number. On the IDOC file this number is reported by women when they were admitted to prison. On the IDES file this number is reported by Illinois employers each quarter. Because machine readable quarterly wage records were available from IDES only since the first quarter of 1995, our analysis of the earnings of women with and without child welfare contacts is limited to those women who report being mother and who paroled from state prison after this date.

The earnings information that we use in our study are earnings in jobs in Illinois that are covered by the state Unemployment Insurance (UI) system. Employers of such workers pay a tax on each worker's wages to the state in order to cover the cost of providing their former employees with unemployment insurance benefits in the event of a qualifying layoff. In such jobs the employer also would pay premiums for Workers Compensation insurance and contribute to the employees' Social Security. We do not have information on earnings from informal sources or from jobs not covered by the UI system, such as from self-employment, or in formal jobs in out-of-state establishments.

\section{The Statistical Model For Section $V$}

Our statistical model that we use to (regression) adjust for differences among incarcerated mother's characteristics and the timing of their spells of incarceration is adopted from Cho and LaLonde (2005). We estimate models of the following form:

$$
\mathrm{Y}_{\mathrm{it}}=\mathbf{X}_{\mathrm{it}} \mathbf{B}+\delta\left(\tau ; \mathbf{Z}_{\mathrm{i}}\right) \mathrm{f}_{\mathrm{i}}\left(\mathrm{t} ; \mathbf{Z}_{\mathrm{i}}\right)+\gamma_{\mathrm{t}}+\varepsilon_{\mathrm{it}}
$$

In (1), we define $\mathrm{Y}_{\mathrm{it}}$ as employment outcomes during calendar quarter $\mathrm{t}$. We consider three employment outcomes: (i) total quarterly earnings reported by all employers in Illinois; (ii) a dummy variable indicating whether a woman had any UI-covered earnings during the (calendar) quarter t; and (iii) total quarterly earnings during quarters when women were employed. The difference between outcomes (i) and (iii) is that in the latter case we exclude women during quarters when their earnings in UI-covered jobs equal 0.

The variable $\mathbf{X}_{\text {it }}$ denotes a vector of observed characteristics described above in the text. The only time-varying variable in $\mathbf{X}_{\text {it }}$ are a woman's age. But we also include indicator variables for whether the women has ever had a child in foster care and the timing and resolution of these foster care spells.

The term $\gamma_{t}$ denotes time-effects that account for the effect of changing statewide economic conditions and policies on the employment prospects of female inmates.' In our empirical work we control for these effects by including a vector of 34 dummy variables indicating the time period of the current calendar quarter. The first quarter is 1995:I and the last quarter is 2003:II These dummy variables also control for seasonal effects in the data. Incarcerated women were least likely to be employed during the first (winter) quarter.

The term $\varepsilon_{\text {it }}$ denotes unobserved characteristics. When we allow for an individual "fixed effect," we define the term $\varepsilon_{i t}$ as follows: $\varepsilon_{i t}=b_{i}+v_{i t}$. Otherwise, we assume that the time-varying component of the error is independently distributed. Our standard error estimates are "robust standard errors" that take account that the unobservable characteristics in our model are not identically distributed across individuals and time periods. 
This document is a research report submitted to the U.S. Department of Justice. This report has not been published by the Department. Opinions or points of view expressed are those of the author(s) and do not necessarily reflect the official position or policies of the U.S. Department of Justice.

In (1), the term $\delta\left(\tau ; \mathbf{Z}_{\mathrm{i}}\right)$ denotes the effect of prison on employment and the term $\mathrm{f}_{\mathrm{i}}\left(\mathrm{t}, \tau ; \mathbf{Z}_{\mathrm{i}}\right)$ denotes the relative quarter prior to, during, or since prison at time t. We define the term $\tau$ as the relative quarter or number of quarters between the current quarter and the quarter that a woman enters or exits prison. We allow the effect of prison, $\delta\left(\tau ; S_{i}, Z_{i}\right)$, to vary according to the number of quarters between the current quarter and the entry and exit quarters from prison. We assume, however, that these prison effects are time invariant. This restriction means that we assume that the effect of prison on earnings among early cohorts of parolees is the same as the effect of prison for later cohorts of parolees.

In our empirical work above, we explicitly examine the relationship between prison and employment rates during the period prior to entering prison. After some analysis of the data, we found that our post-prison results are sensitive to whether we control for prison-effects up to 8 quarters prior to the quarter that a woman enters prison. Knowing whether the current quarter was 8 or more quarters prior to the start of a prison spell does not predict post-prison employment rates. In terms of the notation above, we set $\delta\left(-9 ; \mathbf{Z}_{\mathrm{i}}\right)=\delta\left(-10 ; \mathbf{Z}_{\mathrm{i}}\right)=\ldots=0$. This restriction is sufficient to identify the prison effects that we report in the paper.

We specified the effect of prison on employment rates by allowing separate effects of prison in each of 8 pre-prison quarters and the quarters women are in prison, and each of the post-prison quarters. We also allow prison to have separate employment effects during the quarters that women enter and exit prison; and to have the same effect during each post-prison quarter.

The terms $\mathbf{Z}_{\mathrm{i}}$ in $\delta\left(\tau ; \mathbf{Z}_{\mathrm{i}}\right)$ denote a vector of characteristics to allow for heterogeneity in the effects of prison across individuals. In this analysis the vector $\mathbf{Z}_{\mathrm{i}}$ denotes the foster care status of the incarcerated mother's children. In our empirical work, we add to our specification of the prison effects an interaction term, which is the product of an indicator variable indicating whether the current period is after the quarter that a woman exits from prison and her children's foster care status. The coefficient associated with this interaction term is an estimate of the "effect" of prison on women with a given foster care status relative to women whose children were never in foster care. (See Table A). 
This document is a research report submitted to the U.S. Department of Justice. This report has not been published by the Department. Opinions or points of view expressed are those of the author(s) and do not necessarily reflect the official position or policies of the U.S. Department of Justice.

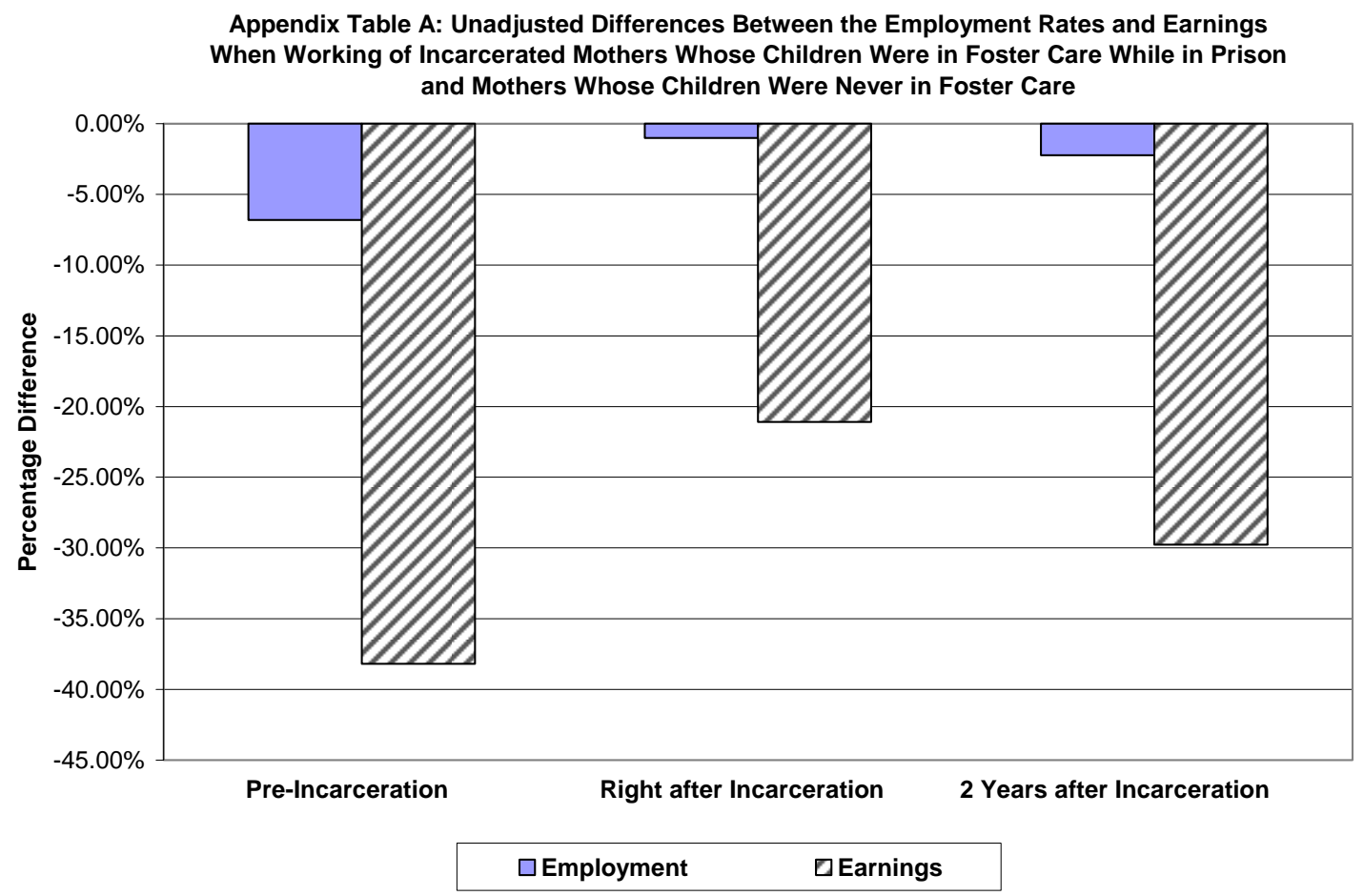

Appendix Table B: Unadjusted Differences Between the Employment Rates and Earnings When Working of Incarcerated Mothers Who Were Reunited with Their Children Prior to Prison and Mothers Whose Children Never Were in Foster Care

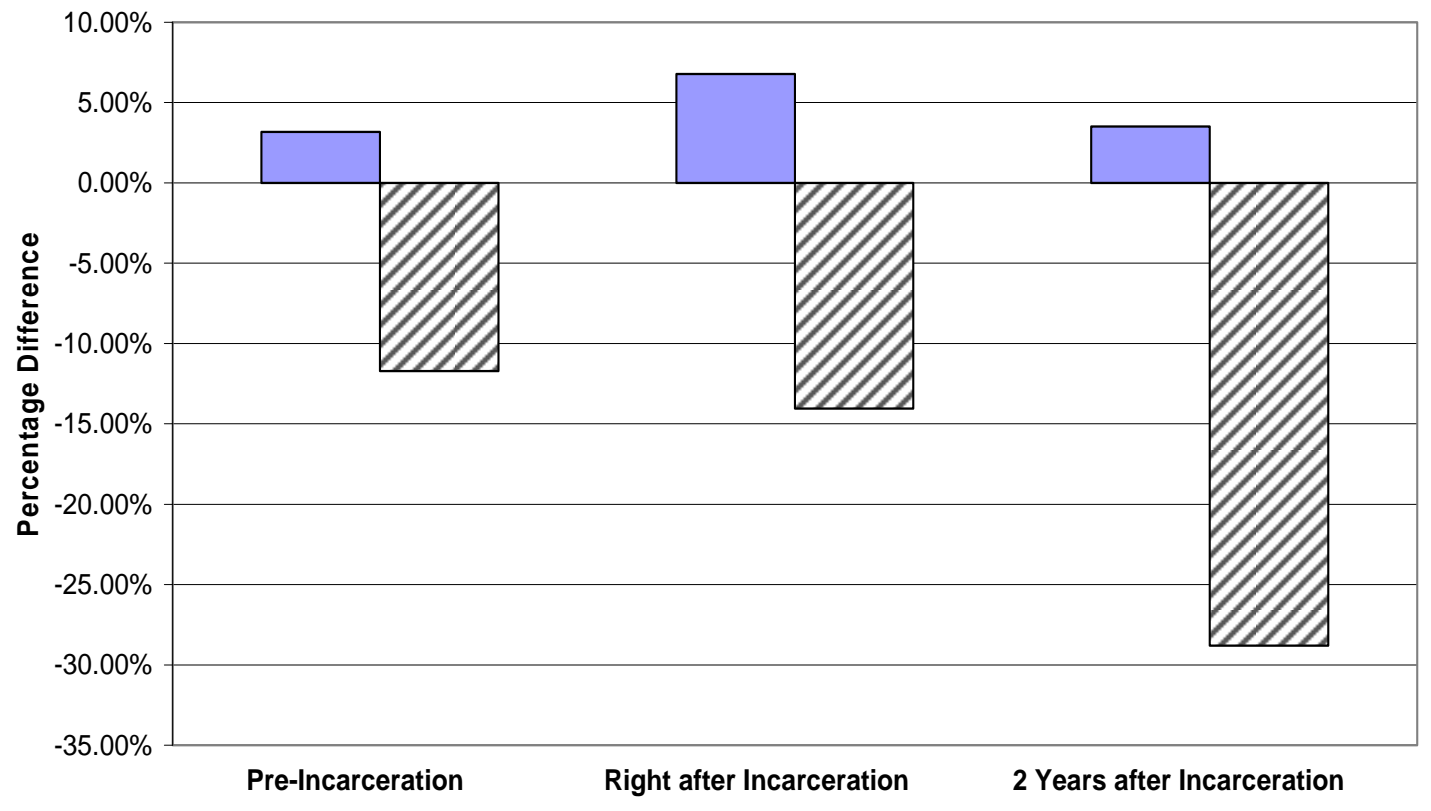

DEmployment $\quad$ Earnings 


\section{Appendix Table A \\ Number of Female Prisoners with Children in Foster Care and the Timing of These Foster Care Spells}

Total Female Prisoners

Exiting 1996:I to 2000:II

Report No Children

Total Female Prisoners with Children

With At Least 1 child Ever in Foster Care

With Foster Care Spells that End

Prior to First Prison Spell:

\author{
Ends with Reunification \\ Only FC Spell Ever \\ Ends with No Reunification
}

Only FC Spell Ever

With Foster Care Spells that

Overlay with First Prison Spell:

Ends with Reunification

Only FC Spell Ever

Ends with No Reunification

Only FC Spell Ever

Ends Because of Sample Frame

With Foster Care Spells that Begin

After First Prison Spell Ends:

Only FC Spell Ever
Number of Women

12,898

2,135

$16.6 \%$

10,763

2,905

$27.0 \%$

1,003

$9.3 \%$

307

$2.9 \%$

1,067

$9.9 \%$

370

$3.4 \%$

202

$1.9 \%$

53

$0.5 \%$

1,154

$10.7 \%$

353

$3.2 \%$

601

$5.6 \%$

892

$8.2 \%$

196

$1.8 \%$ 


\section{Appendix Table B \\ Resolution and Placement of Foster Care Spells of the Children of Incarcerated \\ Mothers, By Demographic Characteristic and Criminal Offense Category}

(Percentage of Foster Care Spells in Column Category)

\begin{tabular}{|c|c|c|c|c|c|}
\hline & \multicolumn{3}{|c|}{ Resolution } & \multicolumn{2}{|c|}{ Placement } \\
\hline & Reunification & Adoption & Aged Out & Boarding & $\begin{array}{l}\text { Home of } \\
\text { Relative }\end{array}$ \\
\hline Black & $28.5 \%$ & $34.8 \%$ & $14.9 \%$ & $16.5 \%$ & $41.5 \%$ \\
\hline White & 46.2 & 27.8 & 13.5 & 40.7 & 24.4 \\
\hline Hispanic & 28.1 & 37.7 & 14.3 & 16.9 & 38.5 \\
\hline Married & 40.2 & 26.3 & 14.7 & 28.0 & 35.3 \\
\hline High School Grad. & 34.6 & 30.7 & 14.0 & 21.4 & 39.2 \\
\hline Cook County Res. & 22.2 & 38.2 & 15.3 & 8.7 & 44.2 \\
\hline Substance Abuse & 31.0 & 34.9 & 14.6 & 19.6 & 39.5 \\
\hline Person Crimes & 30.5 & 33.1 & 13.8 & 20.7 & 36.3 \\
\hline Property Crimes & 34.9 & 31.5 & 13.9 & 24.1 & 37.3 \\
\hline Drug Crimes & 24.9 & 40.1 & 12.8 & 14.0 & 43.2 \\
\hline Sex Crimes & 32.3 & 32.6 & 17.7 & 25.6 & 23.1 \\
\hline Siblings in FC & 31.0 & 34.5 & 14.2 & 20.5 & 39.2 \\
\hline Total & 31.8 & 33.6 & 14.6 & 21.0 & 38.2 \\
\hline
\end{tabular}




\section{Appendix Table C \\ Regression Adjusted Differences in Labor Market Outcomes, by Foster Care Status of Incarcerated Women's Children.}

Foster Care Spell

Labor Market Outcomes:

Status Relative to Prison Employment Rate Earnings if Working

(1)

(3) (4)

Begins and Ends Prior to Prison-

Reunification:

$\begin{array}{lllll}\text { Difference } & 0.036^{*} & 0.018 & -0.090 & -0.049 \\ \text { Post-Prison Effect } & (0.017) & (0.016) & (0.100) & (0.107) \\ & 0.041^{*} & 0.043^{*} & -0.119 & -0.100 \\ \text { Post-Prison Tend } & (0.020) & (0.020) & (0.106) & (0.107) \\ & -0.004^{*} & -0.004^{*} & -0.012^{*} & -0.008 \\ & (0.001) & (0.001) & (0.006) & (0.006)\end{array}$

Begins and Ends Prior to Prison-:

Another Resolution:

$\begin{array}{lllll}\text { Difference } & -0.074 * & -0.036 * & -0.399 * & -0.376^{*} \\ \text { Post-Prison Effect } & (0.010) & (0.010) & (0.085) & (0.083) \\ & -0.006 & -0.006 & 0.163 & 0.212^{*} \\ \text { Post-Prison Tend } & (0.013) & (0.013) & (0.094) & (0.091) \\ & 0.001 & 0.001 & -0.008 & -0.007 \\ & (0.001) & (0.001) & (0.006) & (0.006)\end{array}$

Overlaps with Prison:

\begin{tabular}{lllll} 
Difference & $-0.057^{*}$ & -0.016 & $-0.353^{*}$ & $-0.240^{*}$ \\
\multirow{3}{*}{ Post-Prison Effect } & $(0.010)$ & $(0.009)$ & $(0.076)$ & $(0.075)$ \\
& $0.03)^{*}$ & $0.036^{*}$ & 0.117 & 0.130 \\
Post-Prison Tend & $(0.012)$ & $(0.012)$ & $(0.077)$ & $(0.083)$ \\
& -0.000 & -0.001 & $-0.009 *$ & $-0.009^{*}$ \\
& $(0.001)$ & $(0.001)$ & $(0.004)$ & $(0.004)$
\end{tabular}

$\begin{array}{llll}\text { Include Controls Variables: } & \text { No } & \text { Yes } & \text { No }\end{array}$

Notes: Estimates measured relative to women whose children never appear in the state's child welfare records during the sample period. Regressions without controls include adjustments for calendar quarter and time relative to the entry and exit quarters from prison. Controls are for age and time prior to or since prison, years of schooling, marital status, number of children, holding offense category, and time served. Quarterly earnings include individuals who have no reported earnings during the quarter. Earnings if working is measured in natural logs and include only women with at least \$1 in reported earnings during the quarter. The robust standard errors are in parentheses. An “*” indicates that the estimate is statistically significantly different from 0 at the 0.05 level of statistical significance. 
This document is a research report submitted to the U.S. Department of Justice. This report has not been published by the Department. Opinions or points of view expressed are those of the author(s) and do not necessarily reflect the official position or policies of the U.S. Department of Justice.

Figure 1: The Real Quarterly Earnings of Incarcerated Mothers,

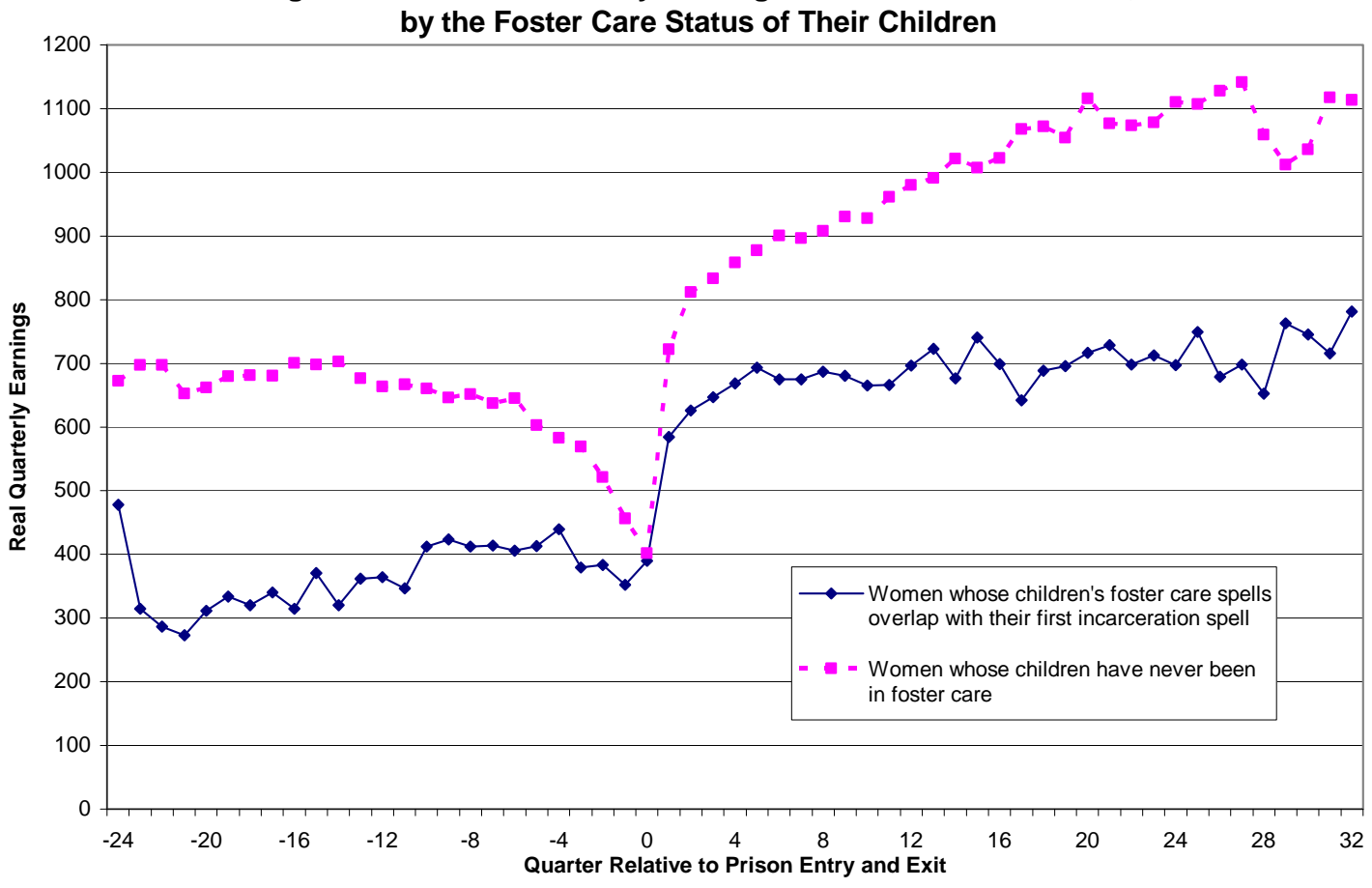

Figure 2: The Quarterly Employment of Incarcerated Mothers, by the Foster Care Status of Their Children

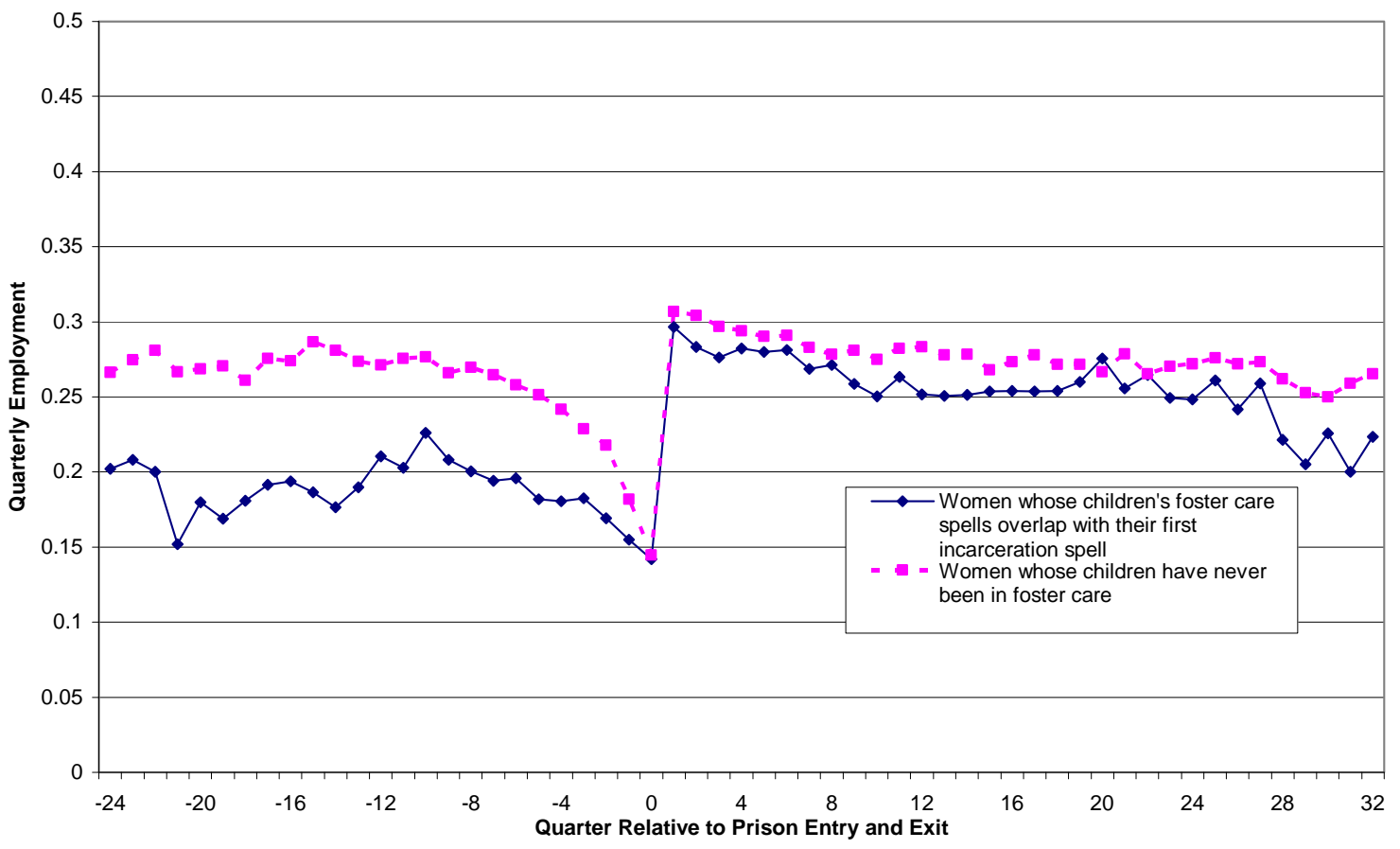


This document is a research report submitted to the U.S. Department of Justice. This report has not been published by the Department. Opinions or points of view expressed are those of the author(s) and do not necessarily reflect the official position or policies of the U.S. Department of Justice.

Figure 3: The Real Quarterly Earnings When Working of Incarcerated Mothers, by the Foster Care Status of Their Children

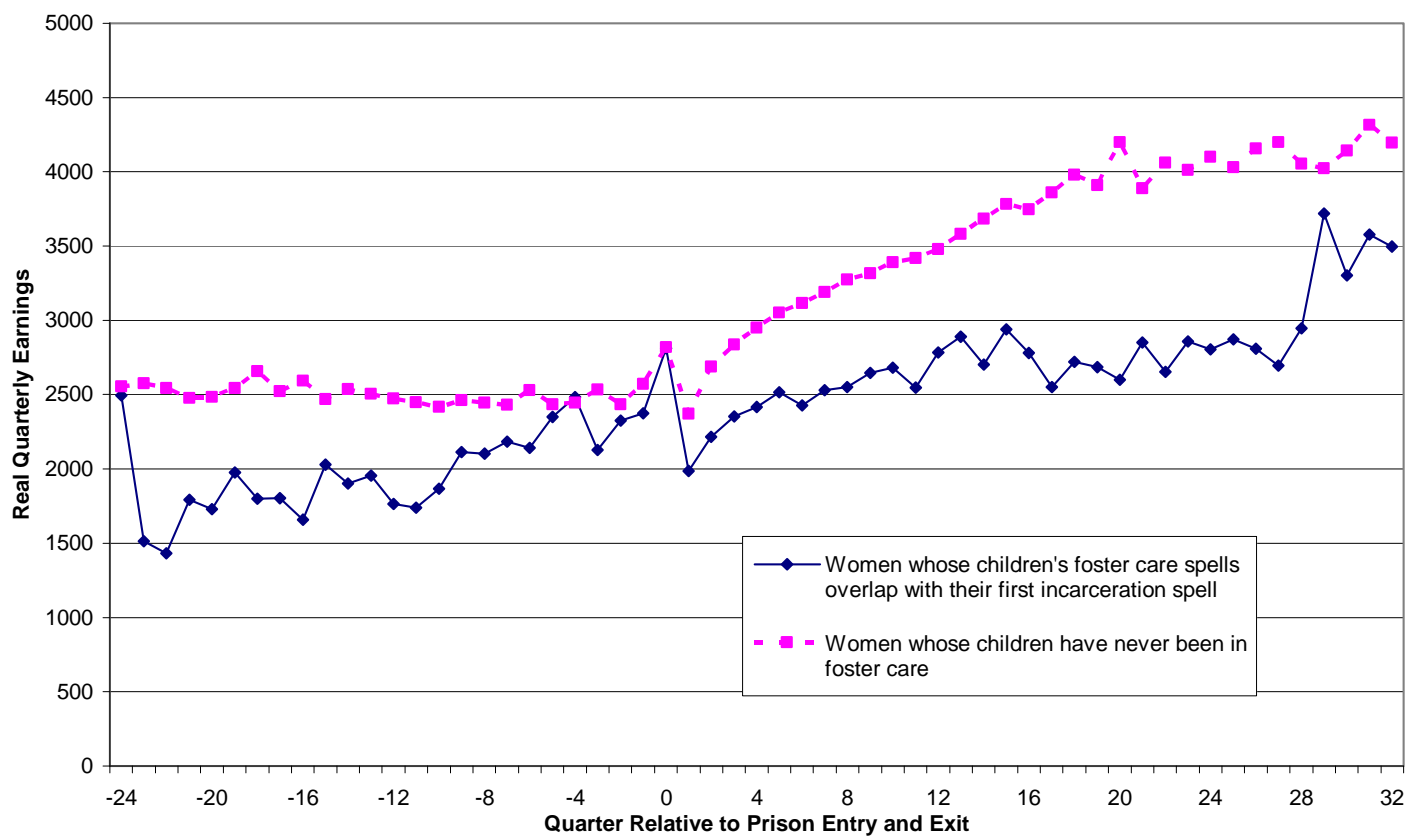

Figure 4: The Real Quarterly Earnings of Incarcerated Mothers, by the Pre-Prison Foster Care Status of Their Children

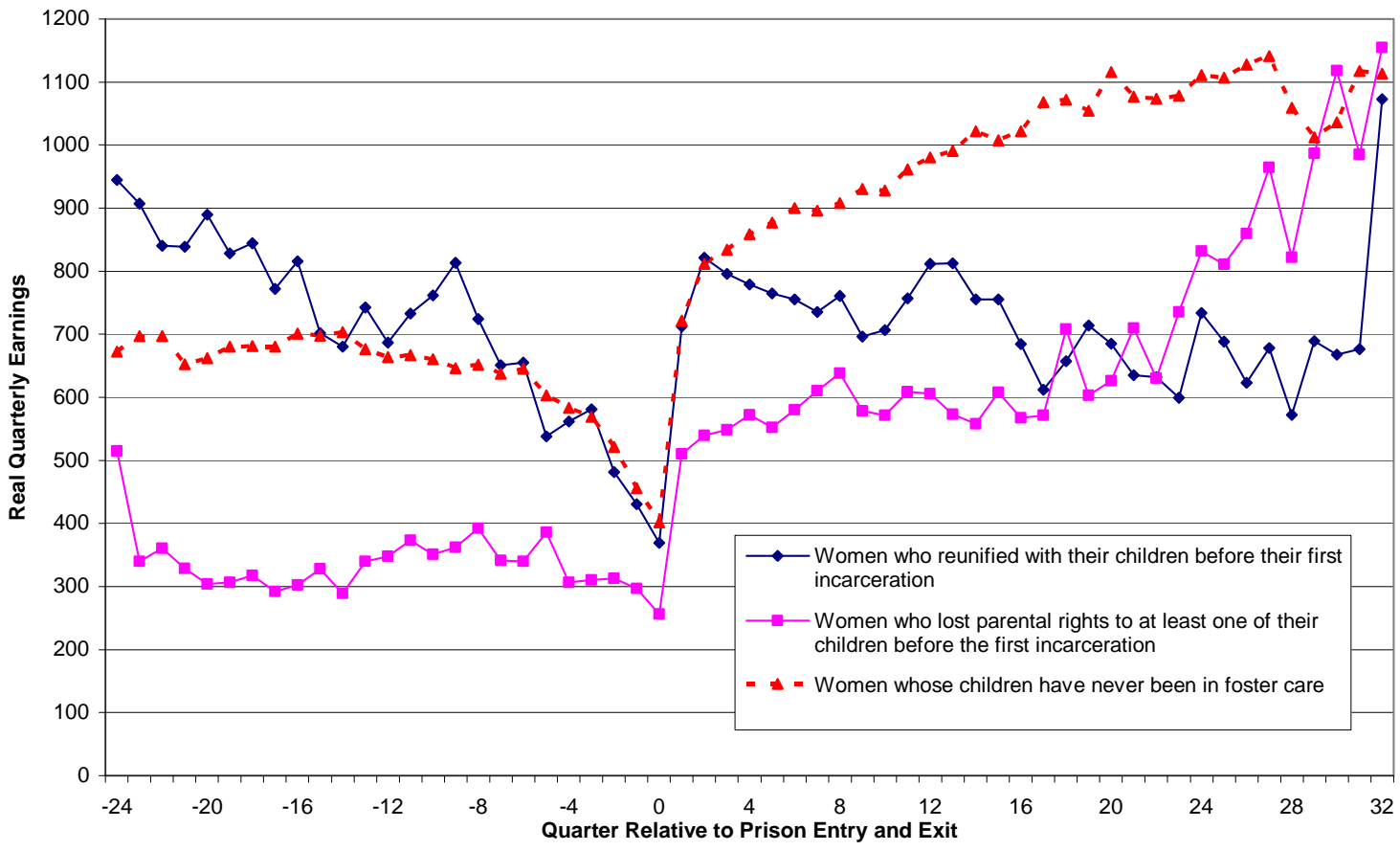


This document is a research report submitted to the U.S. Department of Justice. This report has not been published by the Department. Opinions or points of view expressed are those of the author(s) and do not necessarily reflect the official position or policies of the U.S. Department of Justice.

Figure 5: The Quarterly Employment of Incarcerated Mothers, by the Pre-Prison Foster Care Status of Their Children

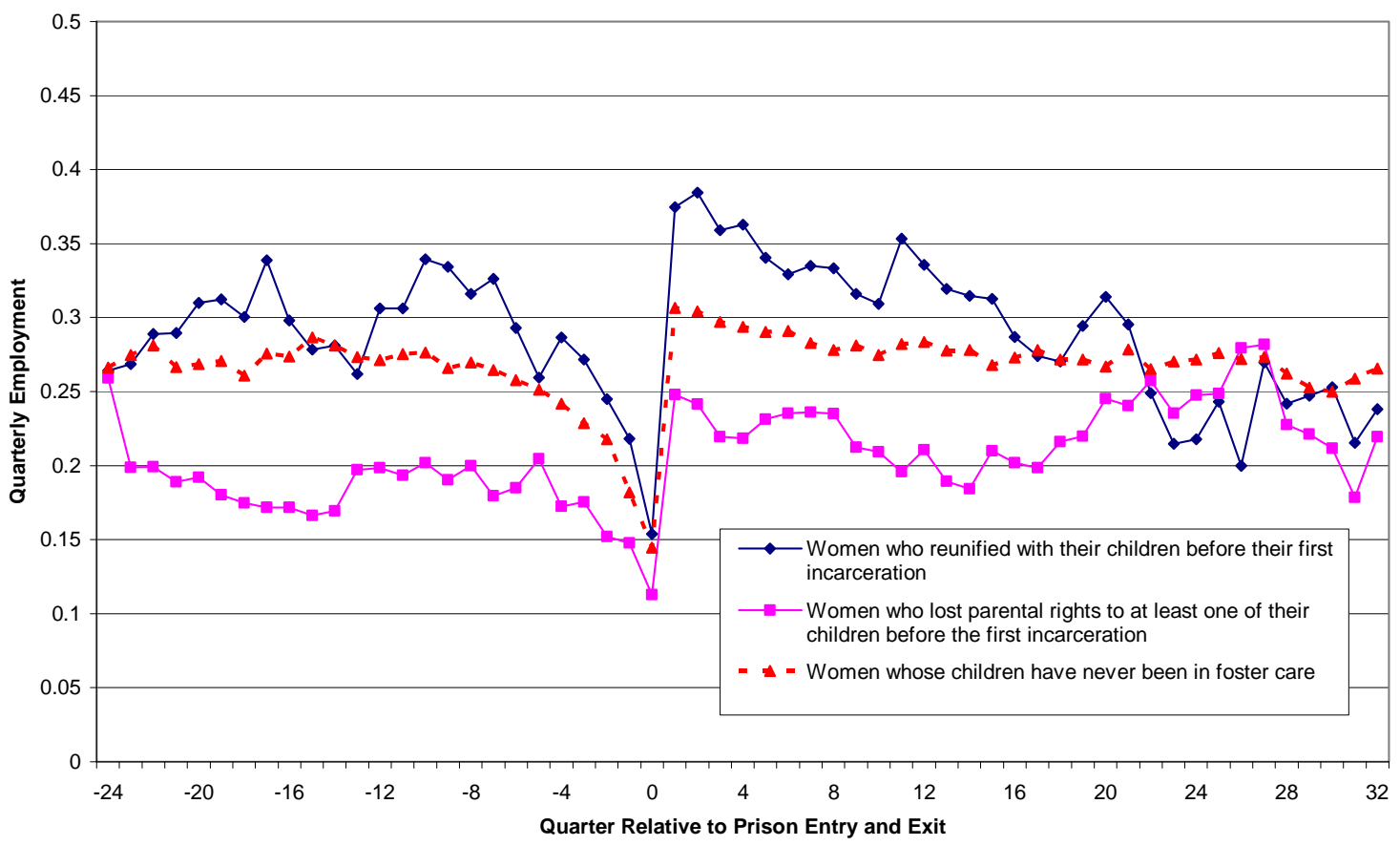

Figure 6: The Real Quarterly Earnings When Working of Incarcerated Mothers, by the Pre-Prison Foster Care Status of Their Children

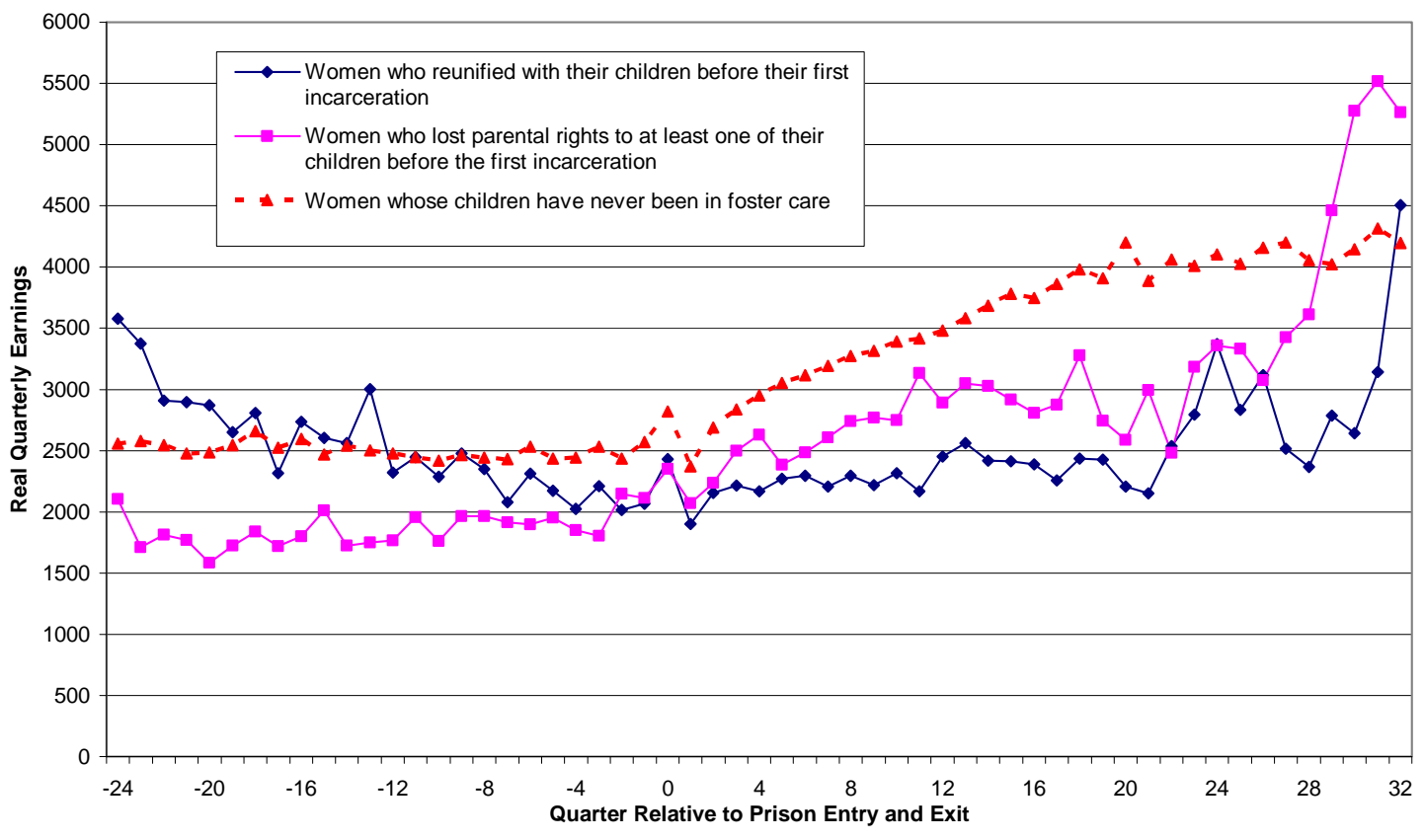


This document is a research report submitted to the U.S. Department of Justice. This report has not been published by the Department. Opinions or points of view expressed are those of the author(s) and do not necessarily reflect the official position or policies of the U.S. Department of Justice.

Figure 7: The Real Quarterly Earnings of Incarcerated Mothers, by the Different Foster Care Experience of Their Children

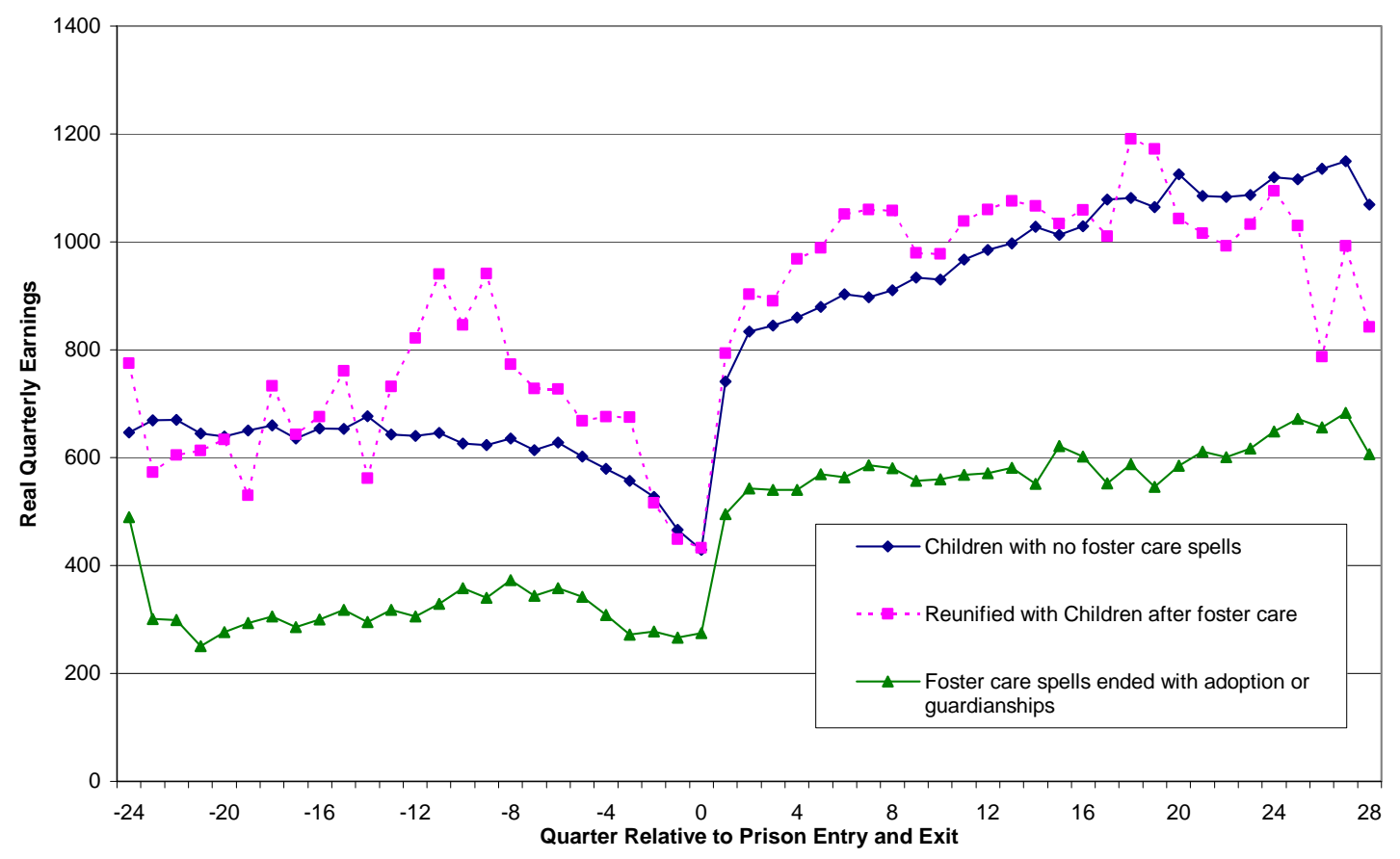

Figure 8: The Quarterly Employment of Incarcerated Mothers, by the Different Foster Care Experience of Their Children

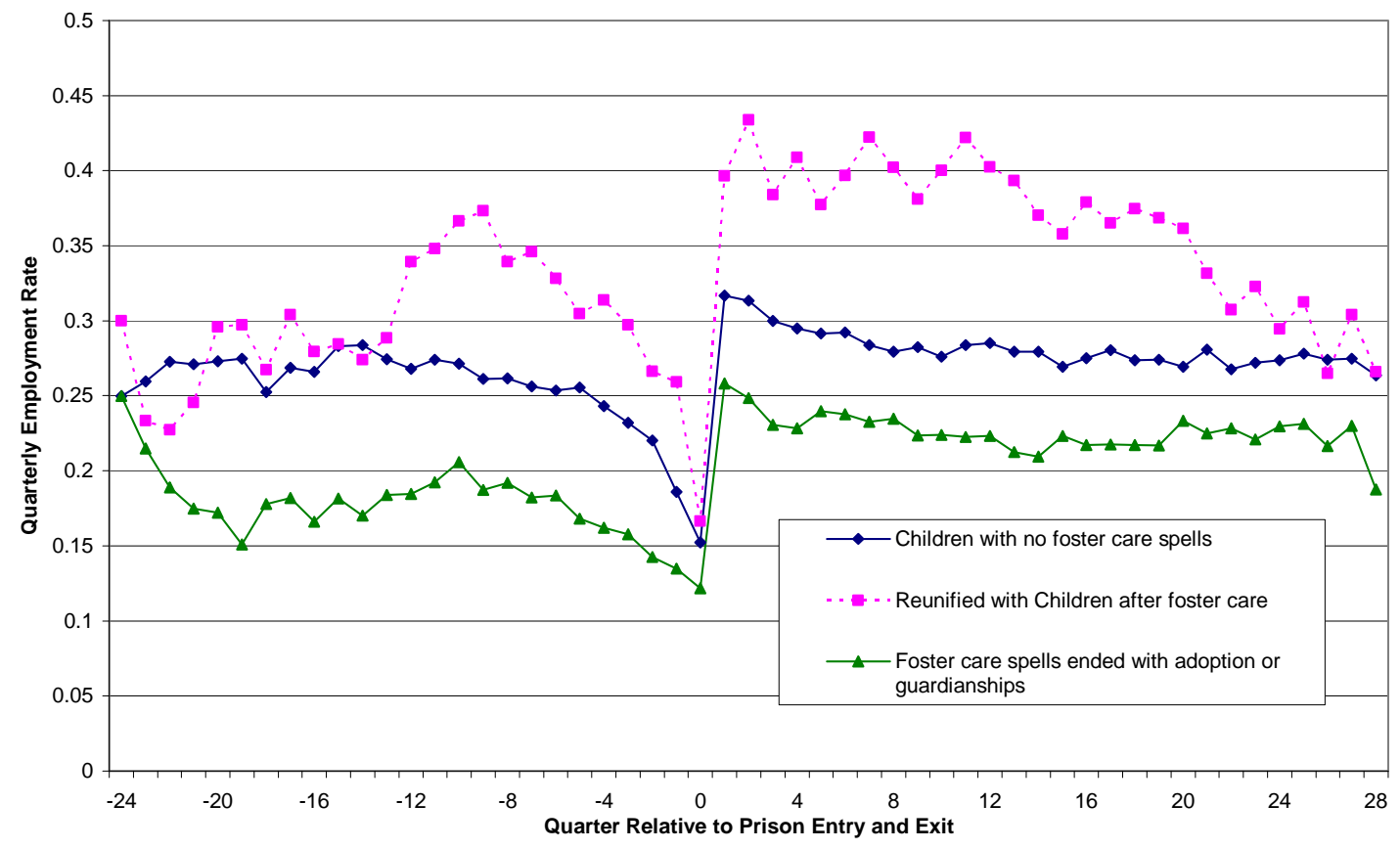


This document is a research report submitted to the U.S. Department of Justice. This report has not been published by the Department. Opinions or points of view expressed are those of the author(s) and do not necessarily reflect the official position or policies of the U.S. Department of Justice.

Figure 9: The Real Quarterly Earnings Conditional on Working of Incarcerated Mothers, by the Different Foster Care Experience of Their Children

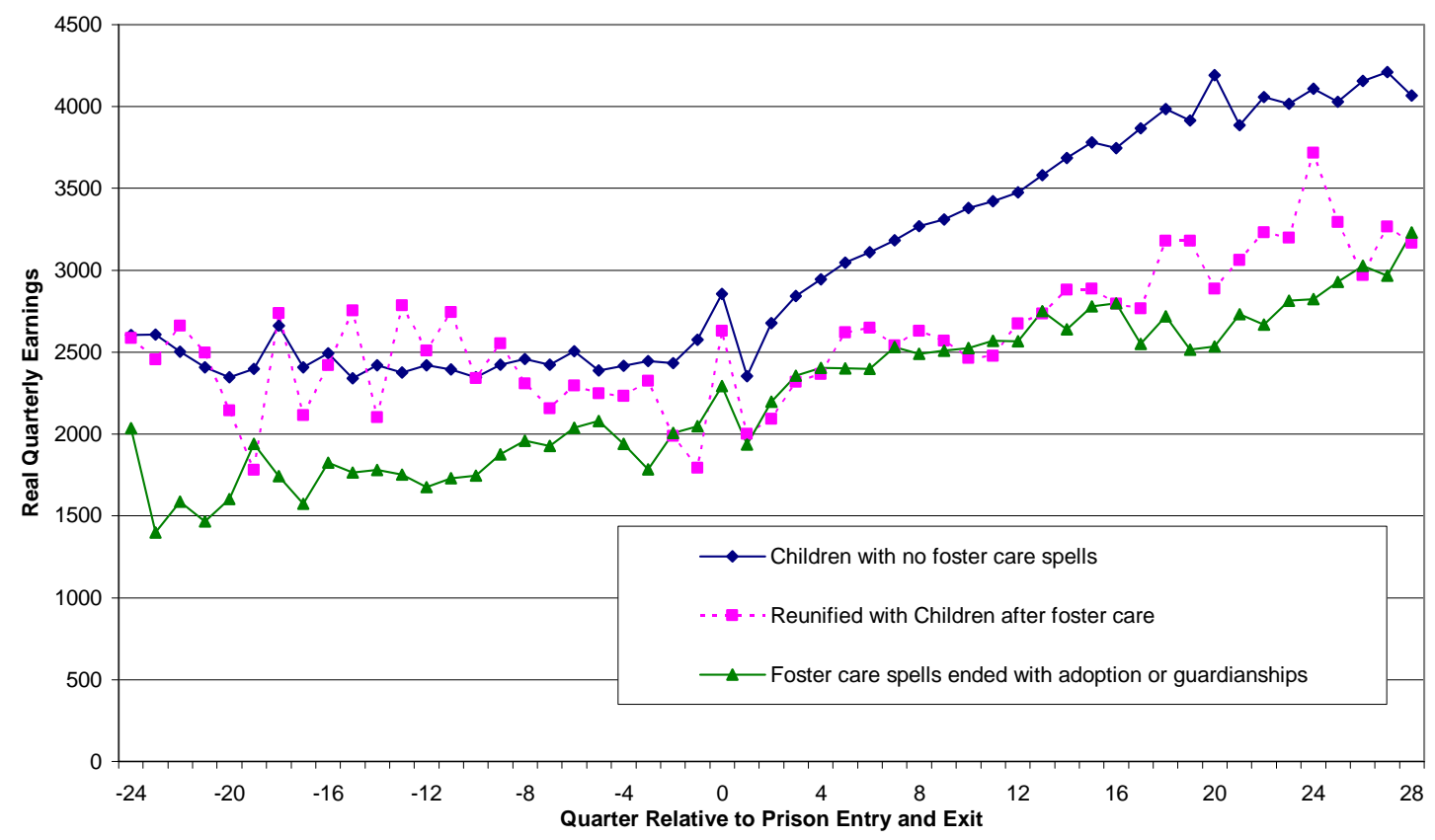


This document is a research report submitted to the U.S. Department of Justice. This report has not been published by the Department. Opinions or points of view expressed are those of the author(s) and do not necessarily reflect the official position or policies of the U.S. Department of Justice.

Figure 10: Employment and Earnings Differences between

Females Whose Kids in Foster Care While in Prison and Females Whose Kids never were in Foster Care(Regression Adjusted)

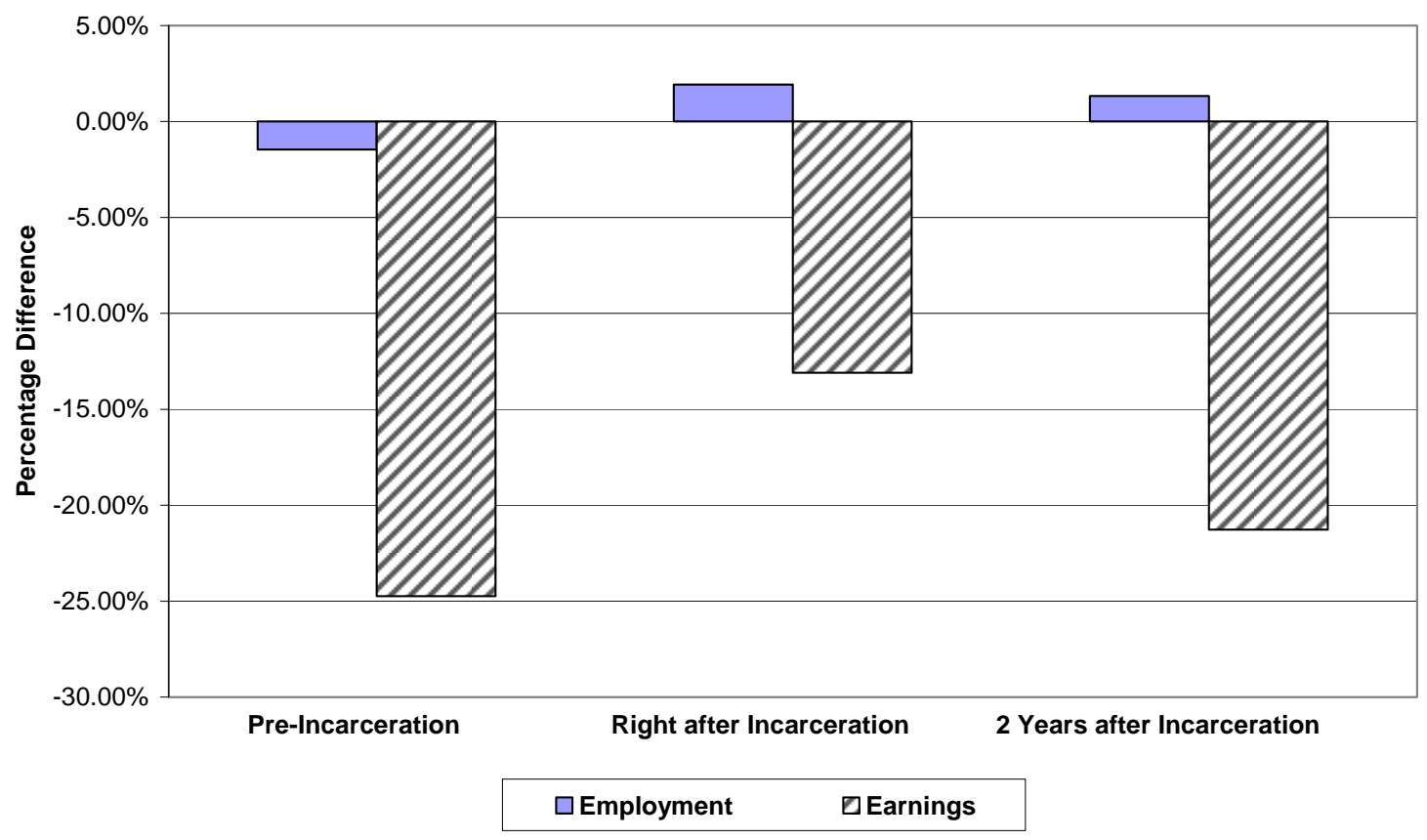

Figure 11: Employment and Earnings Differences between Mothers Who were Reunited with Their Kids in Foster Care Prior to Prison and Mothers Whose Kids never were in Foster Care (Regression Adjusted)

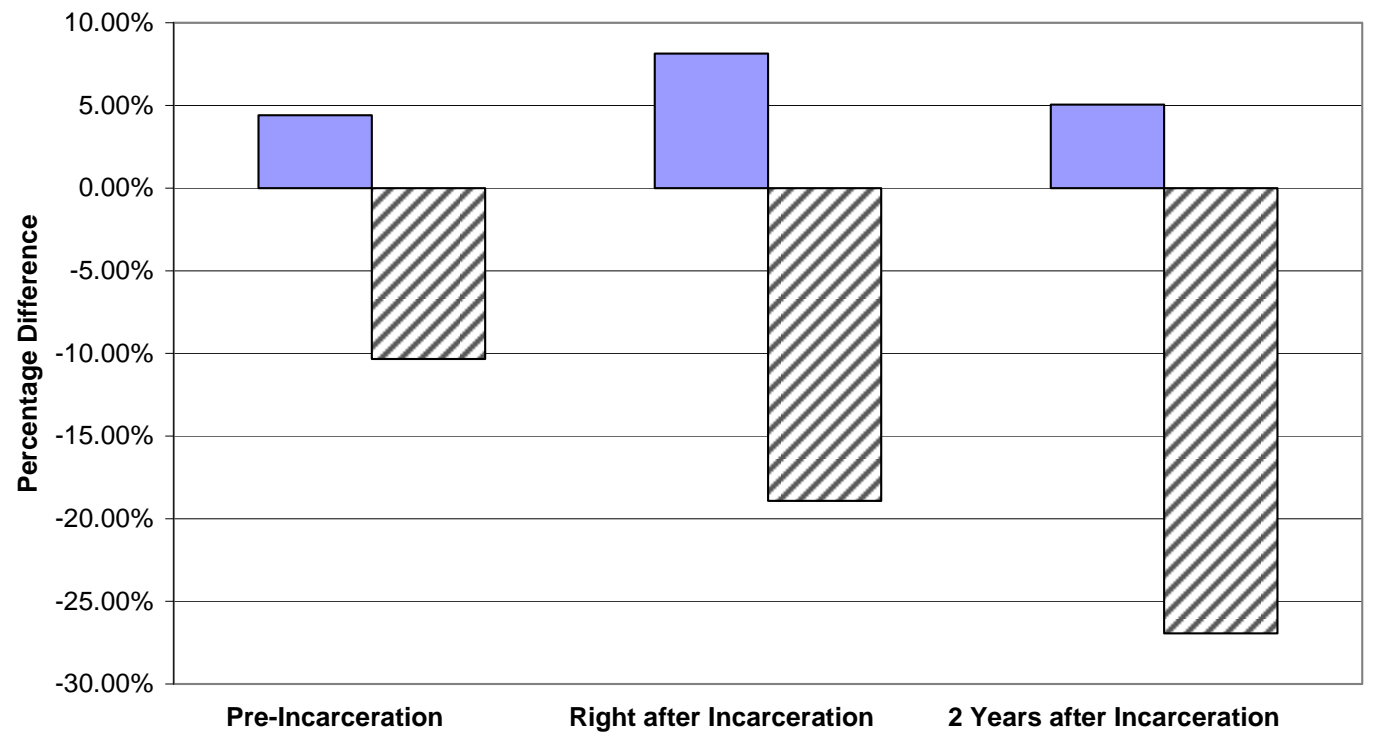

口Employment $\quad \square$ Earnings


This document is a research report submitted to the U.S. Department of Justice. This report has not been published by the Department. Opinions or points of view expressed are those of the author(s) and do not necessarily reflect the official position or policies of the U.S. Department of Justice.

Figure 12: Employment and Earnings Differences between Mothers Who Lost Parental Rights to at Least One of Their Children Prior to Prison and Mothers Whose Kids Never were in Foster Care (Regression Adjusted)

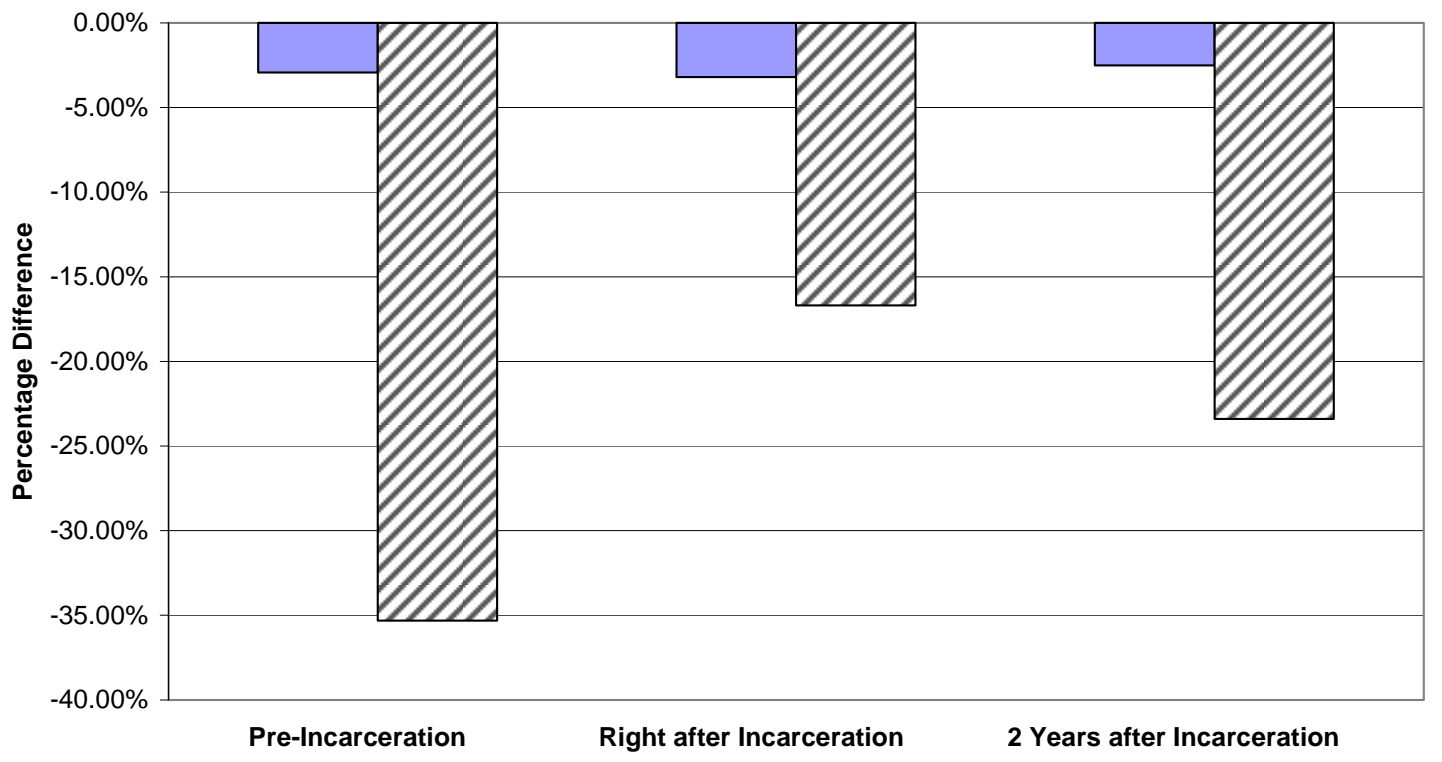

口Employment $\quad \square$ Earnings 
This document is a research report submitted to the U.S. Department of Justice. This report has not been published by the Department. Opinions or points of view expressed are those of the author(s) and do not necessarily reflect the official position or policies of the U.S. Department of Justice.

\section{Table 1}

Intersections between Foster Care Spells and Mother's Incarcerations

(Women incarcerated between 1/1/1995 and 6/30/2002)

Number Percentage
of Women of Women

Total women incarcerated

$11,050 \quad 100.0 \%$

Women who report being mothers when admitted

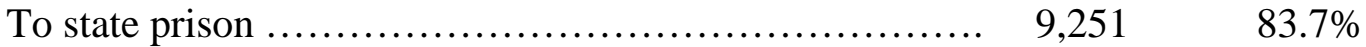

Women with children in foster care between 1975

And 2001:IV

Incarcerated Mothers with Children in Foster Care

While they are in prison ........................... 1,521 13.8\%

\section{Timing of Children's Foster Care Spells:}

Incarcerated Mothers with Children in Foster Care

$100 \%{ }^{*}$

One or more children in FC prior to $1^{\text {st }}$ prison spell:

Spell ends before prison.

Spell ends during or after prison

but before a $2^{\text {nd }}$ prison spell

Spell ends during or after prison

No $2^{\text {nd }}$ prison spell.

$30.9 \%$

Spell ends during or after a $2^{\text {nd }}$ prison spell

$19.4 \%$

One or more children in FC after $1^{\text {st }}$ prison spell

and prior to $2^{\text {nd }}$ prison spell ...............................89

$3.3 \%$

Notes: Sample limited to women incarcerated between 1995:I and 2000:II who were not incarcerated any time between 1989:III and 1994:IV and who were under 60 years of age on June 30, 2002. An -*- indicated that the percentages in the column may add up to more than $100 \%$ as a mother may have more than one prison spell after 1995:I or more than one child and the spells may occur at different times relative to the mother's incarceration(s). Source: Authors' calculations using on matched IDOC-DCFS-IDES administrative file. 
Table 2

Resolution of Foster Care Spells of the Children of Incarcerated Mothers

\section{A. Foster Care Spells That Occur while Child's Mother is Not Incarcerated:} Foster Care Spell Starts:

\begin{tabular}{|c|c|c|c|}
\hline & \multicolumn{3}{|c|}{ Before $1^{\text {st }}$ Prison Spell } \\
\hline & Ends Prior to & Ends prior to & No $2^{\text {nd }}$ \\
\hline & $1^{\mathrm{s}}$ Prison Spell & $2^{\text {nd }}$ Prison Spell & Prison Spell \\
\hline & (1) & (2) & (3) \\
\hline Reunited With Mother & $51.1 \%$ & $36.4 \%$ & $25.3 \%$ \\
\hline Adopted & $27.8 \%$ & $23.5 \%$ & $17.7 \%$ \\
\hline Subsidized Guardianship & $3.4 \%$ & $3.1 \%$ & $1.9 \%$ \\
\hline Still in Care & $0.0 \%$ & $24.1 \%$ & $47.4 \%$ \\
\hline Other Outcome/Over 18 & $17.7 \%$ & $13.0 \%$ & $7.6 \%$ \\
\hline
\end{tabular}

B. Foster Care Spells That Occur while Child's Mother is Incarcerated:

Foster Care Spell Starts

Before $1^{\text {st }}$ Prison Spell After $1^{\text {st }}$ Prison Spell

\begin{tabular}{|c|c|c|}
\hline $\begin{array}{l}\text { Ends During or } \\
\text { After the }\end{array}$ & $\begin{array}{l}\text { Ends During or } \\
\text { After the }\end{array}$ & $\begin{array}{l}\text { Ends During or } \\
\text { After a } 2^{\text {nd }}\end{array}$ \\
\hline $\begin{array}{l}1^{\text {st }} \text { Prison Spell } \\
\text { (1) }\end{array}$ & $\begin{array}{l}2^{\text {nd }} \text { Prison Spell } \\
(2)\end{array}$ & $\begin{array}{l}\text { Prison Spell } \\
\text { (3) }\end{array}$ \\
\hline $12.8 \%$ & $3.0 \%$ & $12.2 \%$ \\
\hline $49.5 \%$ & $46.4 \%$ & $27.8 \%$ \\
\hline $10.5 \%$ & $10.2 \%$ & $4.3 \%$ \\
\hline $17.6 \%$ & $33.2 \%$ & $51.7 \%$ \\
\hline $9.7 \%$ & $7.2 \%$ & $4.0 \%$ \\
\hline
\end{tabular}

Notes: See Table 1. 
Table 3

Foster Care Placements of Incarcerated Mother's Children

A. Foster Care Spells That Occur while Child's Mother is Not Incarcerated:

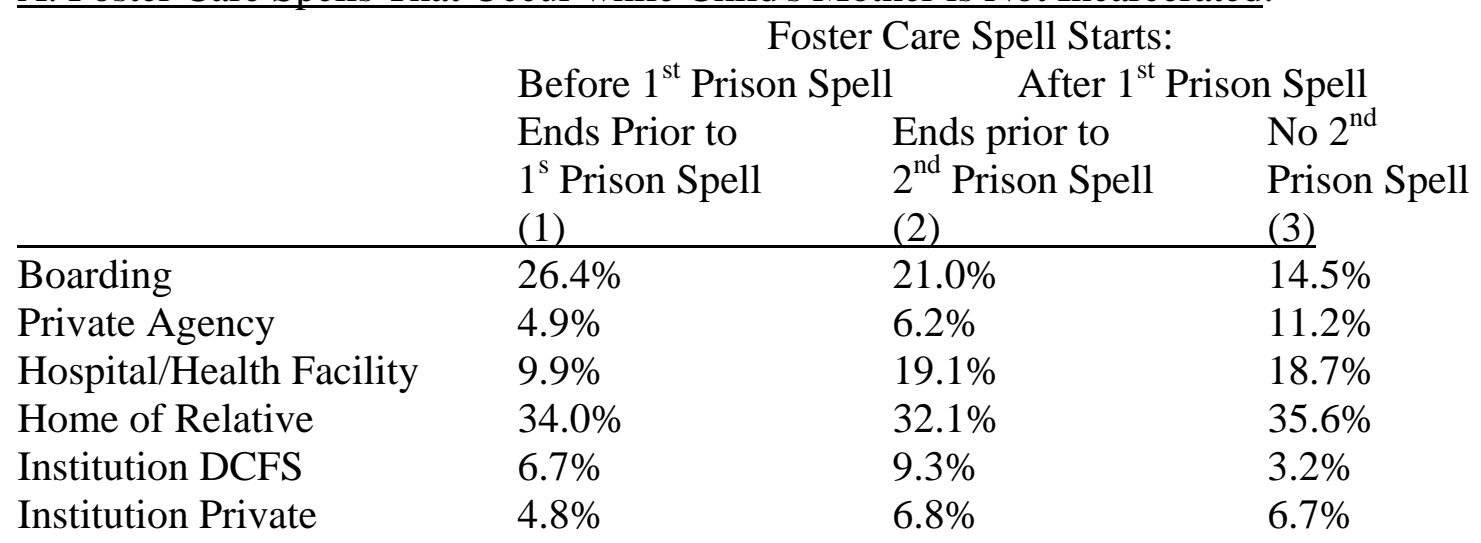

B. Foster Care Spells That Occur while Child's Mother is Incarcerated:

Foster Care Spell Starts

Before $1^{\text {st }}$ Prison Spell After $1^{\text {st }}$ Prison Spell Ends During or $\quad$ Ends During or Ends During or After the $1^{\text {st }}$ Prison Spell After the After a $2^{\text {nd }}$

\begin{tabular}{llll} 
& $\begin{array}{l}1^{\text {st }} \text { Prison Spell } \\
(1)\end{array}$ & $\begin{array}{l}2^{\text {nd }} \text { Prison Spell } \\
(2)\end{array}$ & $\begin{array}{c}\text { Prison Spell } \\
(3)\end{array}$ \\
\hline Boarding & $14.0 \%$ & $12.0 \%$ & $12.7 \%$ \\
Private Agency & $4.7 \%$ & $3.9 \%$ & $12.7 \%$ \\
Hospital/Health Facility & $11.1 \%$ & $11.4 \%$ & $23.6 \%$ \\
Home of Relative & $47.4 \%$ & $46.5 \%$ & $28.0 \%$ \\
Institution DCFS & $7.2 \%$ & $9.2 \%$ & $5.1 \%$ \\
Institution Private & $4.3 \%$ & $5.2 \%$ & $9.9 \%$ \\
\end{tabular}

Notes: See Table 1. 
Table 4

Timing of the Start of Children's Foster Care Spells that Overlap With Their Mothers' Incarcerations

\begin{tabular}{|c|c|c|c|c|}
\hline \multirow[b]{2}{*}{ Foster Care Spell Began: } & \multicolumn{2}{|c|}{ FC Spells } & \multicolumn{2}{|c|}{$\begin{array}{l}\text { Childs' FC Spell Length } \\
\text { Prior to Prison Entry }\end{array}$} \\
\hline & No. & Percent & Mean & Median \\
\hline 1 - 90 days before $1^{\text {st }}$ prison entry & 235 & 6.0 & 49.1 & 52 \\
\hline 91 - 180 days before $1^{\text {st }}$ prison entry & 232 & 6.0 & 135.3 & 134.5 \\
\hline 181 - 270 days before $1^{\text {st }}$ prison entry & 260 & 6.7 & 226.0 & 230 \\
\hline 271 - 365 days before $1^{\text {st }}$ prison entry & 239 & 6.1 & 313.7 & 312 \\
\hline 366 - 730 days before $1^{\text {st }}$ prison entry & 831 & 21.3 & 555.2 & 556 \\
\hline $731-1,095$ days before $1^{\text {st }}$ prison entry & 661 & 17.0 & 915.7 & 917 \\
\hline 1,096 or more days before $1^{\text {st }}$ prison entry & 1,437 & 36.9 & $1,936.3$ & 1,701 \\
\hline Total & 3,895 & 100.0 & $1,033.5$ & 816 \\
\hline
\end{tabular}

Notes: See Table 1. Length of foster care spells is in days. As shown in Table 1, there were 1,521incarcerated mothers whose children spent time in foster care while they were in prison. But there were 3,895 children with such foster care spells, because some children have the same mother. 


\section{Table 5 \\ Timing of the Start of Children's Foster Care Spells that Coincide With Their Mothers' Incarcerations, By the Demographic \\ Characteristic of the Mother}

(Percentage of Children in Indicated Category)

\begin{tabular}{|c|c|c|c|c|c|c|c|}
\hline Mother's & & & Foster & are Spel & Began B & fore (in Da & \\
\hline Characteristic & $1-90$ & $90-180$ & $180-270$ & $270-365$ & $365-730$ & 730-1,095 & $1,095+$ \\
\hline Black & 5.4 & 5.3 & 6.0 & 5.7 & 20.3 & 17.4 & 39.9 \\
\hline White & 10.0 & 10.4 & 12.0 & 7.8 & 23.9 & 14.6 & 21.3 \\
\hline Hispanic & 8.4 & 6.8 & 5.3 & 10.0 & 31.1 & 14.7 & 23.7 \\
\hline Married & 5.1 & 7.3 & 7.6 & 7.6 & 21.0 & 19.0 & 32.4 \\
\hline H.S. Graduate & 5.6 & 6.0 & 8.1 & 6.9 & 22.7 & 14.7 & 36.0 \\
\hline Cook County & 4.6 & 4.6 & 5.1 & 6.3 & 20.4 & 17.0 & 42.0 \\
\hline Substance Abuse & 5.4 & 6.0 & 6.5 & 5.4 & 21.2 & 16.8 & 38.8 \\
\hline Person Crimes & 6.6 & 9.1 & 9.5 & 8.8 & 26.4 & 9.1 & 30.5 \\
\hline Property Crimes & 6.7 & 5.6 & 7.0 & 6.3 & 22.5 & 19.5 & 32.5 \\
\hline Drug Crimes & 5.5 & 4.9 & 6.0 & 4.9 & 19.6 & 18.0 & 41.0 \\
\hline Sex Crimes & 7.7 & 8.8 & 1.1 & 14.3 & 18.7 & 11.0 & 38.5 \\
\hline Siblings in FC & 5.8 & 5.8 & 6.4 & 6.1 & 21.1 & 17.0 & 37.6 \\
\hline $\begin{array}{l}\text { Employed in Year } \\
\text { Before Prison with } \\
\text { Being Paid }>=\$ 1,000\end{array}$ & 9.3 & 8.6 & 10.2 & 8.0 & 18.1 & 17.8 & 28.2 \\
\hline
\end{tabular}

Notes: See Tables 1 and 4. 


\section{Table 6}

\section{Foster care and Prison Spells of Mothers and Their Children}

(Percentage of Incarcerated Mothers in Category)

1) No Children Ever In Foster Care: $74.2 \%$

2) At least One Child Foster Care Spell Begins and Ends Prior to First Prison Spell:

Ends With Reunification with Mother: 6.3\%

Ends With Another Outcome, Including Adoption: 11.2\%

3) Children’s Foster Care Spells Overlap with Prison Spell:

Ends With Reunification or another Outcome: $16.4 \%$

Notes: Sample limited to women who report having children when admitted to prison and either women who never have had children in foster care or their children's foster care spells begin prior to the day that they exited from their first prison spell. It is possible for a woman to be classified in both category 2 and 3 for both the same child or for different children. 


\title{
Does Time in Prison Affect a Mother's Chances of Being Reunified With Her Children in Foster Care? Evidence from Cook County, Illinois
}

\author{
Roland Holst \\ University of Chicago and State Street Consulting \\ Robert LaLonde \\ University of Chicago, NBER, and IZA
}

November 2007

This research was supported by grants from the Chicago Community Trust and the National Institute of Justice. We have benefited from comments by Henry Brady, Robert Goerge, Susan George, Marilyn Moses, and Anne Powell, and participants in the Center for Human Potential and Public Policy and the Incarcerated Women and Their Children workshops at the University of Chicago, and participants at the National Institute of Justice Conference, July 17 to 19, 2006 in Washington D.C. The views expressed in this paper are those of the authors and do reflect the views of the National Institute of Justice or any agency of the state of Illinois. The authors are responsible for all errors. Send correspondence to Robert LaLonde, r-lalonde@uchicago.edu or The Harris School, 1155 East $60^{\text {th }}$ Street, Chicago, IL 60637. 


\section{Introduction}

Under the federal Adoption and Safe Families Act (AFSA) of 1997, parental rights can be terminated if a child has been in foster care 15 of the last 22 months. To those who study or advocate for the children of incarcerated parents this policy change has raised concerns that it would become increasingly likely that incarcerated mothers would lose parental rights as a result of time spent in prison (c.f., Mauer, Potler, and Wolf, 1999). These concerns were heightened by the dramatic rise in the numbers of women incarcerated in prison during the 1990s and by policy changes designed to lengthen prison stays, such as truth in sentencing or three strikes legislation.

Statistics from national surveys of the prison population suggest that the ASFA can have only limited effects on the role that incarceration plays in the dissolution of families. About 10 percent of female prisoners report that their children are in foster care while they are in prison. The actual figure may be higher, and our research using administrative records from Illinois suggests that it is, because mothers whose children have been placed by the state with her relatives may not consider their child in foster care. The key the point is that the vast majority of mothers have made informal arrangements for their children while they are in prison.

However among incarcerated mothers whose children are in foster care, it is possible the ADFA has had the unintended effect of making it more likely that their imprisonment will cause them to lose their parental rights to some or all of their children. This paper uses a unique data base consisting of administrative records from Cook County, Illinois, 
and from the state of Illinois to track women incarcerated in jail or prison who have or have had children in the state foster care system. The questions that we examine here are the following:

(i) Are incarcerated mothers whose children are simultaneously in foster care less likely to be reunified with these children than other mothers whose children have had contacts with the child welfare system?

(ii) Does time spent in prison affect the likelihood that a mother is reunified with her child after she is paroled?

To address the foregoing questions this paper necessarily addresses several other related questions. These include what are the durations of foster care spells of children of incarcerated women? Are these spells longer if they occur while the mother is incarcerated than if they occur either before or after an incarceration? Among women who had children in foster care while they were incarcerated, what is the timing of the start of these spells relative to the date of a woman's prison spell? What is the average and median number of days that these foster care stays have been in progress when the mother enters prison?

The remainder of the paper is organized as follows: In section II we provide some additional background about the policy environment, especially in Illinois. In section III, we describe our merged administrative data. Section IV describes our empirical strategy. In Section V we present our empirical results. Finally, discussion and conclusions are found in Section VI.

\section{The Foster Care Policy Environment for Incarcerated Mothers}


[ To be supplied]

\section{Sample of Matched Administrative Records on Foster Care, Jail, and Prison}

\section{$\underline{\text { Spells }}$}

In this study, we examine the relationship between the outcomes of children's stay in foster care and the timing and duration of their mother's incarceration in state prison. We also include in our analysis as a comparison group a sample of mothers whose children also spent time in the state's child welfare system and who were incarcerated in Cook County, Illinois jail only once and for less than 1 week. These mothers also have had contacts with the criminal justice system, have been arrested at least once, but never have been incarcerated long enough for it to affect the duration of their children's foster care stays.

\section{A. Source of Matched Database}

The incarceration records used in this study come from two sources. First, the Illinois Department of Corrections (IDOC) admission and exit files for female offenders from provide a complete listing of all women admitted or discharged from the state prison system. The IDOC files made available for this study covered the period from 1989:III through 2003:II. Second, the Cook County Department of Corrections (CCDOC) file provides a complete listing of all women admitted or discharged from the Cook County Jail. The Cook County Jail files made available for this study covered a ten-year period from October 1992 to November 2002.

We limit our study of the relationship between the timing of mothers' incarceration and the resolution of their children's foster care spells to mother admitted to 
state prison from Cook County, Illinois. There are more than 100 counties in Illinois and each maintains its own jail records. Most have very small populations. Compiling a sample of women incarcerated in county jail is logistically difficult.

Most of the women entering state prison from Cook County passed through the cook county jail. When possible the jail record associated with a woman's transfer to prison was matched to these women's corresponding prison record. In these cases we measured time in prison as time in jail plus time in prison.

As shown by Figure 1, Cook County is home to 43 percent of the state's population and is the second most populous county in the United States. The county includes Chicago, the nation's third largest city. The majority of both the Cook County's female jail and prison populations are African-Americans most who have children and have been arrested for drug offenses. This population surged during the 1990’s. We estimate that in 2000, about 4,700 children from Cook County had a mother admitted to IDOC.

\section{B. Foster Care Spells of Incarcerated Mothers}

Our sample of incarcerated mothers is limited to women from Cook County, Illinois who (a) between January 1976 and December 2002 had at one child in the state foster care system and (b) after January 1, 1995 had either (1) one jail spell lasting a week less or (2) were incarcerated in state prison at least once. Our sample consists of 1,247 mothers with one short jail spell and 1,328 mothers with at least one prison spell.

By design the days of incarceration differ markedly between the prison and short jail samples of mothers. But, as shown by Table 1, the average days incarcerated in their first prison spell is 322 days, or about 10 months. Almost one-half of the women in our 
sample were incarcerated in prison for less than one year. These figures indicate that most women’s prison spells - at least in Illinois - are relatively short.

The offense categories shown in Table 1 indicate that mothers incarcerated in prison are likely to be held for drug law violations, especially drug possession. Mothers with short jail spells are less likely to have been arrested for drug sales, but more likely arrested for domestic battery and prostitution. Among both groups of mothers the percentages held for allegations of child endangerment or sex law violations is relatively high compared to the population of all women offenders (not shown in the table). These allegations relative prominence in our sample likely results because it is limited to incarcerated mothers who have had at least one child that spent time in the state's child welfare system.

The means of the other observed attributes of mothers in our sample indicate that the vast majority of them are African-American (80 percent); they are in their early to mid-thirties (33 years); have about 11 to 12 years of schooling; and have had contacts with the state's social welfare system. In addition only modest percentages of mothers in the prison or the short jail sub-samples ever worked for pay with an Illinois employer between 1995 and 2003.

Note that because the typical prison stay was less than one year, incarceration can not account for the relatively large numbers of mothers who never worked during the sample period. These observations underscore the point that these mothers who have had their children placed in the child welfare system constitute a highly economically disadvantaged population. Therefore, in addition to their contacts with the state's 
criminal justice system these mothers face other "barriers" that may prevent them from being reunified with their children.

The duration of these mothers' children's completed foster care spells indicate that they are widely distributed - ranging from a few days to more than one decade. As shown by the third row in Table 1, we observe that the mean days in completed foster care spells among the children of the prison mothers is 1,734 days; among children in the short jail sample the corresponding mean is 1,443 days. The difference between these two figures 291 days is close to the difference between the number of days mothers in the prison and short jail samples were incarcerated or 319 days (i.e., 322 - 2.6). The similarity between these two figures suggests a mechanical relationship between the duration of children's foster care spells and mothers days incarceration. We explore this point below where we observe that this relationship is coincidental because many of the prison mothers in our Cook County sample (about one-third) went to prison for the first time after their children’s foster care spells were completed.

As shown by Figure 3, the mean number of days for a child's completed foster care spell masks a lot of variation in the length of these spells. Roughly one-fourth of these spells lasted less than one year - with 10 percent of spells lasting less than one week. At the other extreme, roughly one-fourth of these spells lasted five or more years. In our analysis of these data this variable - the length of a completed foster care spell is negatively associated with a mother's likelihood of being reunified with her child.

\section{Incarceration Spells}


This document is a research report submitted to the U.S. Department of Justice. This report has not been published by the Department. Opinions or points of view expressed are those of the author(s) and do not necessarily reflect the official position or policies of the U.S. Department of Justice.

In our analysis of the relationship between prison and the outcome of child foster care spells, we consider four types of incarceration spells:

(i) Spells in which the mother had only one jail spell and that spell lasted seven or fewer days;

(ii) Spells in the mother's first prison spell followed a completed foster care spell for one or more of her children;

(iii) Spells in which the mother's first prison spell overlapped either a completed or a incomplete (i.e. right censored) foster care spell;

(iv) Spells in which the mother's first prison spell ended prior to the start of a completed or an incomplete (i.e. right censored) foster care spell.

We could have further divided category (i) into two groups: (a) jail spells that overlap with a child's foster care spell; and (b) jail spells that do not overlap with a child's foster care spell. Despite the short jail stays, the reunification rates between mothers and their children do differ between these types of spells.

We treat 1,247 mothers' with one short jail spell (i.e. spells lasting seven or fewer days) and who had at least one child in foster care prior to 2003, as the comparison group for our analysis. They share two important characteristics with the our sample of prison mothers: (a) they have been arrested at least once - so have had contract with the criminal justice system; and (b) they have had at least one of their children in foster care at some point either prior to, during, or after their incarcerations. 
Among those women with prison spells, we have 422 women whose foster care spells of their oldest child were resolved prior to their first prison spell (i.e., incarceration spell type (ii)). We have 724 overlapping incarceration spells (i.e., incarceration spell type (iii)). And we have 182 women whose foster care spells started after their first prison spell ended (i.e., incarceration spell type (iv)).

Our findings are consistent with policy makers’ contentions that children’s foster care stays tend to be longer when their mothers are in prison at the same time. As shown in Figure 4, the longer foster care stays are associated with the "overlapping” prison spells (spell types FC23 in the figure) whereas shorter foster care stays are associated with prison spells that start after the children's foster care spells have been resolved (spell types FC1 in the figure). However, as we indicate below this apparent association does not imply that prison extended children's stays in foster care, rather this association my reflect pre-existing differences among those mothers and their children who have tend to have “overlapping” incarceration spells.

\section{$\underline{\text { IV. Empirical Strategy }}$}

In our formal analysis below, we compare the reunification rates among mothers in the three prison groups to the mothers in the short jail group whose children's foster care spells were resolved prior to jail. If prison makes the loss of parental rights more likely, then we expect that those mothers whose prison spells overlap with their children's foster care spells are less likely than other mothers to be reunified with their children. Similarly, we expect longer prison stays to be associated with lower reunification rates than shorter prison stays. 
This document is a research report submitted to the U.S. Department of Justice. This report has not been published by the Department. Opinions or points of view expressed are those of the author(s) and do not necessarily reflect the official position or policies of the U.S. Department of Justice.

In our analysis we regression-adjust the differences in reunification rates to account for differences among mothers' observed characteristics and the criminal offenses that lead to their incarcerations. These independent variables are listed in Table 1, and include schooling and race. We also consider the importance of three other variables:

(i) Among the prison mothers the number of years that an ongoing foster care spells had been in progress prior to the day they were admitted to prison (or to jail if they first went to jail prior to being transferred to prison;

(ii) The total duration in years of the child's foster care spell;

(iii) Among the prison mothers, the years that they spent in prison.

The first of these variables - the child's time in an ongoing foster care spell when her mother enters prison - attempts to account for the idea that the vast majority of “overlapping” foster spells were in progress for some time prior to the mother entering prison. To the extent that longer spells tend to be resolved by the mother losing her parental rights, we expect that part of any association between foster care spells that overlap with time in prison and loss of parental rights results because such spells tend to be long spells anyway.

The second of these variables - the duration of the child's foster care spells attempts to account for the idea that mothers who go to prison may have unobserved characteristics that are associated with long foster care spells compared to mothers who while having contacts with the child welfare system have only one short jail spell. To be 
sure, a mother's prison spell may prolong her child's foster care spell. As a result, the duration of the child's foster care spell may be "endogenous" to the type of spell (i.e. does the foster care spell overlap with a prison spell). Indeed, in our Cook County sample, we find that the completed duration of foster care spells that overlap with their mothers' prison spells are about two years longer than foster care spells among children whose mothers had one short jail spell or children's foster care spells that were completed by the time the mother entered prison for the first time. Controlling for the duration of children’s foster care spells should reduce the apparent “effect” of an overlapping prison spell on the probability that a mother is reunified with her child.

The third of these variables - the time a mother spends in her first prison spell - is meant to address two issues. First, we considered the possibility that even after accounting for the category of the criminal offense that lead to a mother's incarceration that no matter what the timing of the foster care spell, time is prison is associated with unobserved attributes of the mother that that are associated with either increased or decreased chances of reunification. Second, we also interact the length of the mother's first prison stay with our indicator of whether the child's foster care spells overlap with her mothers prison spell. The objective here is to test whether among mothers with overlapping spells does the probability of reunification decline with time served in prison.

\section{Empirical Results}

\section{A. Differences in Reunification Rates among Incarceration Spells}

We being our analysis of reunification rates by examining the differences between the reunification rates of the four types of foster care spells defined above. We focus our 
analysis here on the mother's oldest child in foster care. As shown by Table 2,

reunification rates are much lower when the oldest child's foster care spell overlaps her mother's incarceration spell. In the sample of all foster care spells in Panel A, we observe that 5.3 percent of foster care spells that overlap with prison spells are resolved during the sample frame by the mother being reunified with her oldest child. Among foster care spells that overlap with their mother's one and only short jail spell the corresponding figure is 11.4 percent.

In panel B, we present percentages for the same categories but we exclude foster care spells that had not ended prior to the end of the sample frame (i.e., exclude right censored spells). Among completed foster care spells it is still the case that when these spells overlap the mothers' incarcerations that reunification is unlikely. When these spells overlap a mother's first prison spell, the reunification rate is only 8.3 percent.

Among foster care spells that ended prior to the mother's first incarceration, reunification rates while still low are much larger. As shown by Panel A of Table 2, when the oldest child's foster care spell ends prior to her mother's first prison spell she is reunited with her mother 28.8 percent of the time. (None of these spells are censored by design so that the percentages in Panel A and Panel B are the same.) The corresponding reunification rate among mothers with one short jail spell is 42.3 percent.

Not shown in the table is how the non-overlapping spells were resolved. Among mothers in the prison sample, their children were adopted or placed into a subsidized guardianship $49.1 \%$ of the time or they aged-out, ran away, or their spell was resolved in some other manner $22.2 \%$ of the time. Among women in the short jail sample, their children were adopted or placed into a subsidized guardianship 34.6\% of 
the time or they aged-out, ran away, or their spell was resolved in some other manner 23.3\% of the time. (In our earlier paper, we observed that among women in prison who also spent time themselves in foster care as children, it was very rare that their stays were resolved by an adoption. This resolution is much more common among the children of incarcerated women.)

Foster care spells that overlapped spells of incarceration are much more likely to be resolved by loss of parental rights and the adoption or placement of their child into a subsidized guardianship. Spells that overlapped with prison and were resolved prior to the end of sample frame were resolved by an adoption or subsidized guardianship 75.1 percent of the time and by some other manner 16.6 percent of the time. Similarly spells that overlapped short jail spells were resolved by an adoption or subsidized guardianship 57.3 percent of the time and by some other manner 21.9 percent of the time. These figures suggest that time incarcerated is not an important determining factor in how these foster care spells are resolved. We explore this contention further below.

\section{B. Differences in Reunification Rates Among Spell Types}

As shown by column 3, Table 3, when we limit our analysis to foster care spells resolved prior to the end of 1998, we observe the differences between the reunification rates of mothers whose children's foster care stays overlap with their first prison spell and mothers in the short jail sample is 55.8 percentage points. The gap with whose mother children’s foster stays are resolved prior to prison is 24 (i.e., -0.558 - -0.315) percentage points. These gaps are consistent with the view that by incarcerating women while their children are in foster care may be “causing” the break-up of families. As indicated by the table, this gap is associated with the mother's oldest child in foster care; in the appendix 
we observe that this gap rises to 30 percent when we consider reunification rates for the mother's youngest children in foster care. (This result is not surprising if for example loss of parental rights is associated with the age of child in foster care.)

After 1998, presumably under the ASFA policy environment, the foregoing gaps are much smaller. Now the gap in reunification rates with mothers in the short jail sample, is 16 percentage points and with mothers whose children's foster care spells were resolved prior to prison is 9 percentage points (i.e., -0.161 - -0.076). This change occurs because reunification rates for the other spell types fell sharply compared to the modest decline in reunification rates for the overlapping spells.

In Columns 1 and 3, we present the corresponding figures for the case in which we include the right censored spells. (See Panel A of Table 2.) This changes only the figures in the post 1999 columns, because the figures in the pre-1999 columns of the tables are for completed spells only. The gaps in reunification rates are smaller. But the treating the right censored spells this way understates the reunification rates when these spells are eventually resolved.

The foregoing results are reinforced when we observe the other estimated coefficients in column 1 of the table. They indicate that first the reunification rates for foster cares spells of mothers who later go to prison are only somewhat lower than the reunification rates of mothers who only had one short jail spell (i.e. the gap is about 7.6 percentage points and not statistically significant at conventional levels of statistical significance.) The results for spells that follow a mother's first prison spell are more ambiguous. But, they still suggest that these spells are more likely to be resolved by the mother being reunified with her child than are the "overlapping” spells. 


\section{Does Prison Affect the Resolution of Children's Foster Care Spells?}

[To be revised] We now turn to sort out the effects of a mother being in prison when her children are in foster care from the separate and possibly mechanical effects that prison may have on the duration of children’s foster care spells. (By mechanical effects we mean that when the spells are overlapping if a women spends nine months in prison this will “cause” her child’s foster care spell to be extended for at least an additional nine months.) Accordingly, we now compare reunification rates among the different types of incarceration spells holding constant the duration of the child's foster care spell. (I.e. Besides our vector of observed characteristics and category of criminal offenses, we add to the regression the completed duration of the child's foster care spell.)

As shown by column 2 of Table 3, when we compare children’s foster care spells with the same durations, reunification rates among the incarceration spells are approximately the same. Reunification rates among observationally similar mothers whose prison spells overlap their children's foster care spells are about the same as mothers who experienced only one short jail spell. As shown by the table the gap in reunification rates is only 1.1 percentage points. This result indicates that if prison is associated with an increased chance of a mother's loss of her parental rights, this effect works entirely through any effect that prison may have on the duration of her child's foster care spell. The mother having an overlapping prison spell per se is unlikely to affect the resolution of her child's foster care spell compared to how these spells are resolved for other mothers who have or who will have contacts with the criminal justice and corrections systems. 
Another result shown in the table that reinforces the foregoing point is that the reunification rates in overlap children's foster care spells are about 1.4 percentage points greater than the reunification rates for foster care spells that are completed before a mother's first prison spell. In other words, when we compare observationally similar mothers who spend time in prison and whose children's foster care spells lasted the same amount of time, we observe that the probability of reunification rates are similar no matter whether their children's foster care spells ended prior to prison or their children's foster spells overlapped with prison. Overlapping prison spells do not appear to affect the resolution of children's foster care spells other than to the extent that they may mechanically increase their foster care spells’ durations.

\section{Are Reunification Rates Affected by the Length of Ongoing Foster Care Spells}

[To be revised] The finding that children's foster care spells rarely start around the time their mothers enter prison suggests that one reason why overlapping incarceration spells are associated with much lower reunification rates than the rates for the other incarceration spells is because when children's foster care spells overlap mothers’ prison spells, these foster care spells have already been in progress for a long time. Long foster care spells are likely to end with the mother’s loss of her parental rights. As shown by column 3 of Table 3, we find that this explanation may account for about 25 percent of the difference between the reunification rates for overlapping spells and the other incarceration spell types (i.e. [0.18 - 0.13]/0.13).

One way to interpret the estimated coefficient of 0.13 in column 3 of the table, is to say we predict that when foster care spells overlap mothers’ prison spells and both spells start at the same time, reunification rates are about 13 percentage points lower than 
for these mothers compared with the rates for mothers who experience just one short jail spell.

The estimated coefficient of 0.025 suggests that for every year that a child has spent in foster care prior to the year her mother enters prison, the probability that this child is reunified with her mother declines by an additional 2.5 percent points. However, this finding is very fragile. Turning to columns 4 and 8 of the table, we observe that this relationship vanishes after we control for the mother's observed attributes and the duration of the child's foster care spell (i.e., -0.0025 in column 4). In column 8 we observe that one-half of this finding results from our controls for mothers' observed attributes (i.e., -0.0126 in column 8). Overall the results in column 4 suggest that the completed duration of the child's foster care is a much more important determinant of reunification rates than how much of that spell was already competed prior to the start of the mother's prison spell.

\section{E. Does Time in Prison Affect Reunification Rates?}

The possibility that time in prison is associated lower rates of parental reunification has been raised by many commentators who have criticed the Adoption and Safe Families Act. To investigate this concern we explicitly examine the relationship between time in prison and reunification rates among overlapping incarceration spells. To do this we control for time in prison or jail using a step function: less than 1 week, 1 week to 6 months, 6 months to two years, and two or more years. (We also experimented with other specifications and found no differences in the inferences we drew from this analysis.) As explained in the previous section of the paper, these controls account for the possibility that time in prison is associated with unobserved individual attributes that in 
turn are associated with either increased or lower reunification rates. For example, a mother who receives a longer prison sentence and therefore has a longer prison spells may have had more previous arrests that signal behaviors likely to be associated the loss of a child.

The variables of interest in this part of our analysis are those associated with the interactions between time in prison and whether a mother has an overlapping incarceration spell. As shown by columns 4 and 5 of Table 3, time in prison is not associated with lower rates of parental reunification, except possibly mothers whose first prison spell lasts two or more years. As shown by column 4, these woman reunification rates are about 9 percentage points lower (i.e. $-0.069-0.022$ ) than their counterparts who served less than 2 years in prison. However, the standard errors associated with these figures indicate that this estimated gap is not statistically significant at conventional levels of statistical significance. One reason for this finding is that in Illinois relatively few women serve more than two years in prison. (Recall above in Table 1, we observed that the first prison spell lasted an average of 9 months; the median spell was even shorter.) As a result, the standard errors associated with this estimate are relatively large. Among women who served between 6 months and 2 years in prison, reunification rates were about 2.2 percentage points greater than their counterparts who served less than 6 months in prison and whose incarceration spell overlapped with their child's foster care spell. Turning to column 5 of the table, we observe that this result holds even after we control for observed individual attributes and the completed duration of children's foster care spells. To be sure, these counterintuitive estimated “effects” are not 
statistically significant. But they underscore that time in prison for most of the sample of mothers does not appear to be associated with an increased risk of loss of parental rights.

\section{F. Adjusted Differences in Reunification Rates among Incarceration Spells}

As shown by column 6 of Table 3, once we control for a mother's observed attributes, the time spent incarcerated during her first jail or prison spell, and the completed duration of her child's foster care spell, overlapping spells and foster care spells associated with mothers with one short jail spell are about equally likely to be resolved with the mother being reunified with her child (i.e., the gap is -0.025). The same can be said for foster spells that were resolved prior to the mother's first prison spell (i.e., the gap is 0.019). Only foster care spells that begin after a mother has exited from prison for the first time appear to be associated with lower probabilities of reunification.

To the extent that the completed duration of foster care spells may be associated with longer prison stays we reestimate the foregoing relationships excluding this variable from the analysis. We find that after holding constant all other variables in the analysis overlapping spells are about 5 percentage points (i.e., -0.055) less likely to be resolved with the mother being reunified with her child than are the foster care spells of mothers who experienced only one short jail spell. If the foster care spell started prior to the date the mother entered prison this “effect” rises by about 1.5 percentage points for each year the child's foster care spell was in progress prior to the start of her mother's first prison spell.

In the appendix we also examine the relationship between incarceration spell types and reunification when the child in foster care is the mother's youngest child. As indicated above the unadjusted disparities between the resolution of the overlapping 
spells and the other spells are larger. However, controls for mother's observed attributes

and the completed durations of their children's foster care spells eliminates more than 80

percent of this gap. Still the figures in Appendix Table suggest that there is a stronger

case to be made that overlapping spells in the case of a youngest child in foster care is

less likely to be resolved with a mother being reunified with her youngest child than is

the case for the other incarceration spell types.

\section{Discussion}

Summarize findings:

(a) Few foster care spells start around the time a mother is incarcerated. About 75 percent are in progress for more than one year prior to a mother's first prison stay.

(b) Reunification unlikely if child's FC “overlaps” with mother's prison spell.

(c) This finding holds in both Pre- \& Post-ASFA, but the gaps are most pronounced prior to ASFA taking effect.

(d) Lower reunification rates for "overlapping” foster care/prison spells can partly explained by other variables.

(e) One factor is that FC spells have been ongoing for some time prior to entering prison for the first time and longer foster care spells are associated with lower reunification rates.

(f) Time served in prison not strongly associated with reunification rates.

(g) Time served in prison is very short for the median female prisoner.

(h) Post-ASFA era developments not consistent with time in prison "causing” lower reunification rates. 


\section{References}

Allen J. Beck and Paige M. Harrison, Prisoners in 2005, Bureau of Justice Statistics, U.S. Department of Justice (November 2006).

Allen J. Beck and Paige M. Harrison, Prison and Jail Inmates at Midyear 2005, Bureau of Justice Statistics, U.S. Department of Justice (May 2006),

CBR (California Blue Ribbon Commission on Children in Foster Care), "California Foster Children Continue to "Fall Through the Cracks," San Fransisco, Ca: Judicial Council of California Administrative Office Of The Courts, News Release No. 36 (June 19, 2007).

Miriam Ehrensaft, Ajay Khashu, Timothy Ross, and Mark Wamsley, Patterns of Criminal Conviction and Incarceration Among Mothers of Children in Foster Care in New York City, Vera Institute of Justice (December, 2003).

Natasha A. Frost, Judith Greene, and Kevin Pranis, HARD HIT: The Growth in the Imprisonment of Women, 1977 - 2004, Women’s Prison Association (May 2006),

Mauer, Marc, Cathy Potler, and Richard Wolf (1999). Gender And Justice: Women, Drugs, And Sentencing Policy, Washington D.C.: The Sentencing Project, (November 1999).

Smith, Gail ( ). "The Adoption and Safe Families Act of 1997: Its Impact on Prisoner Mothers and their Children,” www.womenandprison.org/motherhood/gail-smith.html 
Table 1

Mean Characteristics of Incarcerated Mothers with Children in Foster Care, by Prison and Short Jail Stays

\begin{tabular}{|l|l|l|}
\hline Characteristic/Outcome & $\begin{array}{l}\text { At Least One Prison } \\
\text { Spell }\end{array}$ & $\begin{array}{l}\text { Only One Short Jail } \\
\text { Spell }\end{array}$ \\
\hline Days in 1 $^{\text {st } \text { Incarceration Spell }}$ & 322.2 & 2.6 \\
\hline Incarcerated less than 6 months (\%) & $48.0 \%$ & ---- \\
\hline Days focal child in foster care & 1,734 & 1,443 \\
\hline $\begin{array}{l}\text { Child in FC while Mom incarcerated } \\
\text { (\%) }\end{array}$ & $55.3 \%$ & $44.0 \%$ \\
\hline FC child reunified with mother & $13.5 \%$ & $25.6 \mathrm{X} \%$ \\
\hline & & \\
\hline African American (\%) & $80.7 \%$ & $79.4 \%$ \\
\hline Highest grade attended & 11.31 & 11.52 \\
\hline High School Dropout (\%) & $48.1 \%$ & $41.7 \%$ \\
\hline Age of Mother & 33.1 & 33.8 \\
\hline Number of Children & 3.87 & 3.31 \\
\hline Only 1 Child (\%) & $23.3 \%$ & $33.5 \%$ \\
\hline Ever Received Food Stamps (\%) & $95.3 \%$ & $90.3 \%$ \\
\hline & & \\
\hline Employed in Illinois 1995:I - 2003:II & $57.6 \%$ & $65.6 \%$ \\
\hline Holding Offense: & & \\
\hline Drug Law Violation - Sale & $9.5 \%$ & $2.9 \%$ \\
\hline Drug Law Violation - Possession & $27.3 \%$ & $25.5 \%$ \\
\hline Theft & $12.0 \%$ & $13.1 \%$ \\
\hline Fraud & $2.8 \%$ & $3.1 \%$ \\
\hline Domestic Battery & $0.8 \%$ & $10.6 \%$ \\
\hline Other Battery & $2.7 \%$ & $6.2 \%$ \\
\hline Child Endangerment & $7.1 \%$ & $5.9 \%$ \\
\hline Sex Law Violation & $7.2 \%$ & $8.9 \%$ \\
\hline & & \\
\hline Number of Incarcerated Women & 1,328 & 1,241 \\
\hline No: See Secton & & \\
\hline
\end{tabular}

Notes: See Section III and Appendix for details on the construction of the prison and short jail samples of mothers. Source: Authors calculations from merged IDOC/CCDOC/Chapin Hall IDB data base. 
Table 2

Reunification Rates with Oldest Child in Foster Care, By Timing of Prison and Short Jail Stays

\section{Panel A - Includes Censored Foster Care Spells}

\section{Oldest Child's Foster Care Stay:}

Ended Prior to First Incarceration

Overlaps with First Incarceration

Starts During First Incarceration

Begins After First Incarceration Ends
Type of Incarceration:

Prison Short Jail

$28.8 \% \quad 42.3 \%$

$5.3 \% \quad 11.4 \%$

$16.0 \% \quad 42.9 \%$

$14.0 \% \quad 22.2 \%$

Panel B - Excludes Censored Foster Care Spells

\section{Oldest Child's Foster Care Stay:}

Ended Prior to First Incarceration

Overlaps with First Incarceration

Starts During First Incarceration

Begins After First Incarceration Ends
Type of Incarceration:

Prison Short Jail

$28.8 \% \quad 42.3 \%$

$8.3 \% \quad 20.3 \%$

$44.4 \% \quad 66.7 \%$

$31.0 \% \quad 54.5 \%$

Notes: Censored foster care spells are spells that were still in progress when the sample frame ended in 2002. These spells are were yet unresolved. Panel B is limited to foster care spells that have resolved either by reunification with the mother, and adoption of subsidized guardianship, or some other outcome, such as the child turning 18 and leaving child welfare. Source: Authors' calculations from merged IDOC/CCDOC/Chapin Hall IDB data base. 


\section{Table 3}

Estimates of the Effect of Time in Prison on the Probability of an Incarcerated Women Being Reunified With Here Child after Prison

(Percentage Point Differences with Women in Short Jail Spells; Right Censored Spells are Excluded)

Oldest Kid only

Timing of Foster Care and Short Jail Spells and The Probability of Reunification

\begin{tabular}{|c|c|c|c|c|c|c|c|}
\hline $\begin{array}{l}\text { Model } \\
\text { Dependent Variable }\end{array}$ & $\begin{array}{l}\text { year }>=1999 \\
\text { Reunification }\end{array}$ & $\begin{array}{l}\text { year>=1999 } \\
\text { Reunification }\end{array}$ & $\begin{array}{l}\text { year }<1999 \\
\text { Reunification }\end{array}$ & $\begin{array}{c}\text { year }<1999 \\
\text { Reunification }\end{array}$ & $\begin{array}{c}\text { all years } \\
\text { Reunification }\end{array}$ & $\begin{array}{c}\text { all years } \\
\text { Reunification }\end{array}$ & $\begin{array}{c}\text { all years } \\
\text { Reunification }\end{array}$ \\
\hline \multicolumn{8}{|l|}{ Independent Variables } \\
\hline FC 1 & -0.076 & 0.155 & -0.315 & -0.195 & -0.139 & 0.019 & -0.001 \\
\hline & $(0.126)$ & (0.097) & $(0.146)$ & $(0.170)$ & $(0.100)$ & (0.099) & (0.099) \\
\hline FC 23 & -0.161 & 0.165 & -0.558 & -0.273 & -0.320 & -0.025 & -0.070 \\
\hline & $(0.122)$ & $(0.094)$ & $(0.147)$ & $(0.172)$ & $(0.099)$ & (0.098) & (0.103) \\
\hline FC 6 & 0.120 & 0.213 & -0.033 & -0.188 & 0.019 & 0.054 & 0.062 \\
\hline & $(0.131)$ & $(0.104)$ & $(0.174)$ & $(0.202)$ & (0.108) & (0.105) & $(0.104)$ \\
\hline Log FC Length & & -0.115 & & -0.099 & & -0.104 & -0.103 \\
\hline & & $(0.010)$ & & $(0.006)$ & & $(0.005)$ & $(0.005)$ \\
\hline year >= 1999 & & & & & -0.094 & -0.029 & -0.069 \\
\hline & & & & & $(0.022)$ & $(0.019)$ & $(0.032)$ \\
\hline \multirow[t]{2}{*}{ Interaction FC23, year >= 1999} & & & & & & & 0.070 \\
\hline & & & & & & & $(0.039)$ \\
\hline \multirow{2}{*}{ Constant } & 0.286 & 0.880 & 0.700 & 0.786 & 0.513 & 0.753 & 0.772 \\
\hline & $(0.121)$ & $(0.144)$ & $(0.145)$ & $(0.197)$ & $(0.099)$ & $(0.120)$ & $(0.120)$ \\
\hline Controls & No & Yes & No & Yes & No & Yes & Yes \\
\hline \# of Observations & 776 & 772 & 1,076 & 1,076 & 1,852 & 1,848 & 1,848 \\
\hline R-Squared & 0.07 & 0.36 & 0.07 & 0.34 & 0.09 & 0.35 & 0.35 \\
\hline
\end{tabular}

Notes: See Table 1 for a list of control variables. 


\section{Table 4}

Estimates of the Effect of Time in Prison on the Probability of an Incarcerated Women Being Reunified With Here Child after Prison

(Percentage Point Differences with Women in Short Jail Spells; Right Censored Spells are Included)

Oldest Kid only

Timing of Foster Care and Short Jail Spells and The Probability of Reunification

\begin{tabular}{|c|c|c|c|c|c|c|c|}
\hline $\begin{array}{l}\text { Model } \\
\text { Dependent Variable }\end{array}$ & $\begin{array}{c}A \\
\text { year }>=1999 \\
\text { Reunification }\end{array}$ & $\begin{array}{c}\text { B } \\
\text { year }>=1999 \\
\text { Reunification }\end{array}$ & $\begin{array}{c}\text { C } \\
\text { year }<1999 \\
\text { Reunification }\end{array}$ & $\begin{array}{c}\text { D } \\
\text { year < } 1999 \\
\text { Reunification } \\
\end{array}$ & $\begin{array}{c}\mathrm{E} \\
\text { all years } \\
\text { Reunification } \\
\end{array}$ & $\begin{array}{c}\mathrm{F} \\
\text { all years } \\
\text { Reunification } \\
\end{array}$ & $\begin{array}{c}G \\
\text { all years } \\
\text { Reunification }\end{array}$ \\
\hline \multicolumn{8}{|l|}{ Independent Variables } \\
\hline FC 1 & $\begin{array}{l}-\mathbf{0 . 0 1 0} \\
(0.060)\end{array}$ & $\begin{array}{c}\mathbf{0 . 0 6 3} \\
(0.048)\end{array}$ & $\begin{array}{l}-0.315 \\
(0.146)\end{array}$ & $\begin{array}{l}-\mathbf{0 . 1 9 5} \\
(0.170)\end{array}$ & $\begin{array}{l}-0.008 \\
(0.057)\end{array}$ & $\begin{array}{c}\mathbf{0 . 0 4 4} \\
(0.054)\end{array}$ & $\begin{array}{l}-\mathbf{0 . 0 0 8} \\
(0.058)\end{array}$ \\
\hline FC 23 & $\begin{array}{l}-0.066 \\
(0.045)\end{array}$ & $\begin{array}{c}\mathbf{0 . 0 7 0} \\
(0.038)\end{array}$ & $\begin{array}{l}-0.558 \\
(0.147)\end{array}$ & $\begin{array}{l}-0.273 \\
(0.172)\end{array}$ & $\begin{array}{l}-0.165 \\
(0.052)\end{array}$ & $\begin{array}{c}\mathbf{0 . 0 0 7} \\
(0.050)\end{array}$ & $\begin{array}{l}-0.093 \\
(0.064)\end{array}$ \\
\hline FC 6 & $\begin{array}{c}\mathbf{0 . 0 4 6} \\
(0.048)\end{array}$ & $\begin{array}{c}\mathbf{0 . 0 3 1} \\
(0.043)\end{array}$ & $\begin{array}{l}-0.033 \\
(0.174)\end{array}$ & $\begin{array}{l}-0.188 \\
(0.202)\end{array}$ & $\begin{array}{l}-0.010 \\
(0.055)\end{array}$ & $\begin{array}{l}-0.032 \\
(0.053)\end{array}$ & $\begin{array}{l}-0.022 \\
(0.052)\end{array}$ \\
\hline Log FC Length & & $\begin{array}{l}-0.094 \\
(0.008)\end{array}$ & & $\begin{array}{l}-0.099 \\
(0.006)\end{array}$ & & $\begin{array}{l}-0.101 \\
(0.005)\end{array}$ & $\begin{array}{l}-0.100 \\
(0.005)\end{array}$ \\
\hline year >= 1999 & & & & & $\begin{array}{l}-0.086 \\
(0.022)\end{array}$ & $\begin{array}{l}-0.027 \\
(0.019)\end{array}$ & $\begin{array}{l}-0.098 \\
(0.032)\end{array}$ \\
\hline Interaction FC23, year >= 1999 & & & & & & & $\begin{array}{c}\mathbf{0 . 1 2 1} \\
(0.039)\end{array}$ \\
\hline Censored & $\begin{array}{l}-\mathbf{0 . 1 8 2} \\
(0.015)\end{array}$ & $\begin{array}{l}-0.176 \\
(0.015)\end{array}$ & & & $\begin{array}{l}-\mathbf{0 . 1 7 2} \\
(0.015)\end{array}$ & $\begin{array}{l}-\mathbf{0 . 1 6 6} \\
(0.014)\end{array}$ & $\begin{array}{l}-\mathbf{0 . 1 7 6} \\
(0.015)\end{array}$ \\
\hline Constant & $\begin{array}{c}\mathbf{0 . 2 1 9} \\
(0.047)\end{array}$ & $\begin{array}{c}\mathbf{0 . 6 7 7} \\
(0.078)\end{array}$ & $\begin{array}{c}\mathbf{0 . 7 0 0} \\
(0.145)\end{array}$ & $\begin{array}{c}\mathbf{0 . 7 8 6} \\
(0.197)\end{array}$ & $\begin{array}{c}\mathbf{0 . 3 8 1} \\
(0.056)\end{array}$ & $\begin{array}{c}\mathbf{0 . 6 7 8} \\
(0.076)\end{array}$ & $\begin{array}{c}\mathbf{0 . 7 3 0} \\
(0.080)\end{array}$ \\
\hline Controls & No & Yes & No & Yes & No & Yes & Yes \\
\hline \# of Observations & 1,493 & 1,489 & 1,076 & 1,076 & 2,569 & 2,565 & 2,565 \\
\hline R-Squared & 0.12 & 0.32 & 0.07 & 0.34 & 0.15 & 0.38 & 0.38 \\
\hline
\end{tabular}

Standard Errors in Parentheses 
Figure 1

\section{Cook County, Illinois}

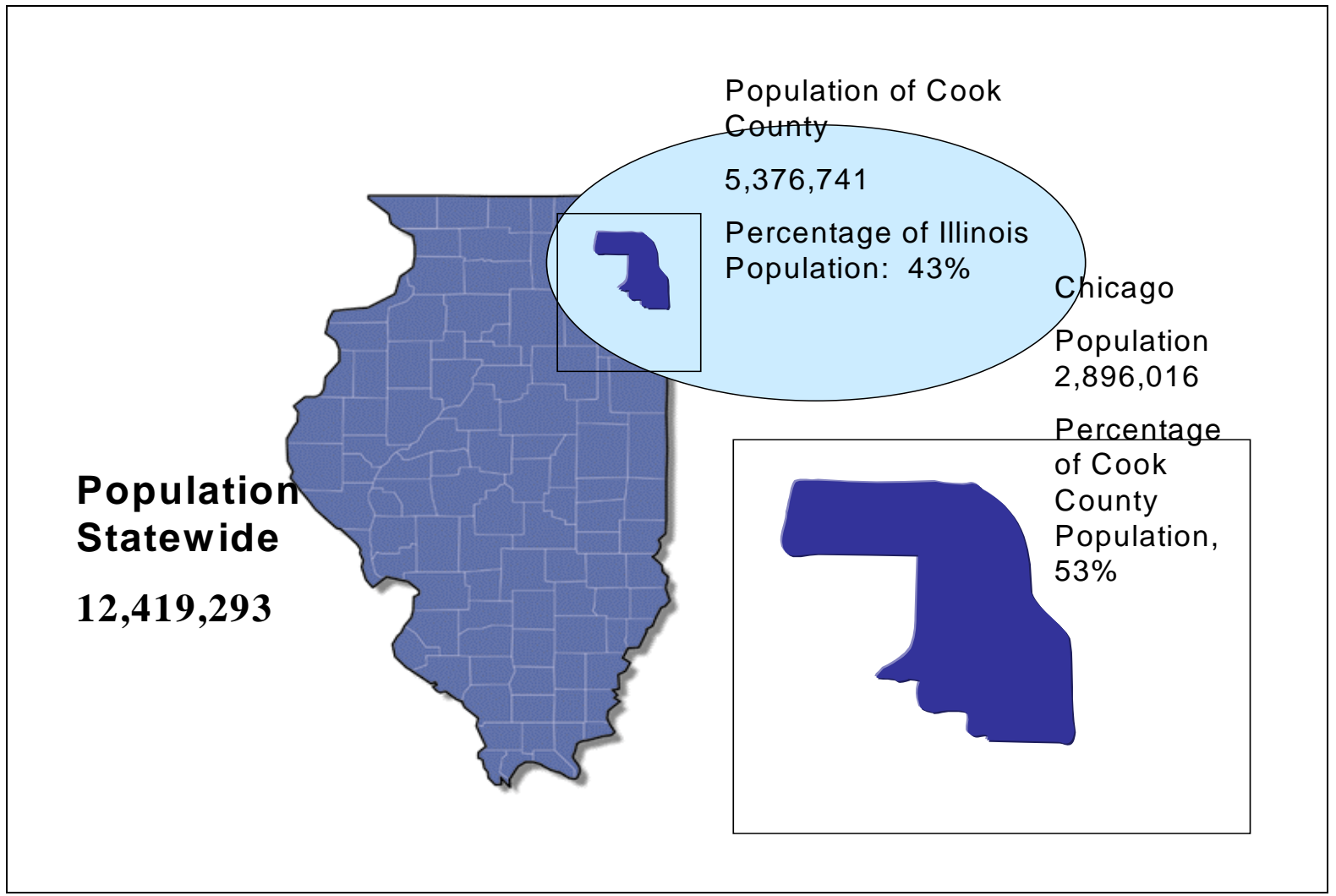

Source: George and LaLonde (2004). Stage Two: Women From Cook County Admitted To Jail Or State Prison And Their Children, p. 10. 


\section{Figure 2}

\section{Over lap Between Jail or Prison and Foster Care Spells}

There are Six Types of Foster Care Spells Relative to the Timing of a Jail or Prison Spell among women incarcerated from Cook County, Illinois. As shown by Figure A, in foster care spell type "FC1" the spell starts and stops prior to a women's first incarceration. Foster Care spell types "FC2" and "FC3" were in progress at the start of the incarceration spell. Foster care spell type "FC6" does not begin until after the woman has exited from her first incarceration spell. As shown by Figure B, only a very small percentage of spells start during the incarceration spell.

\section{Figure A:}

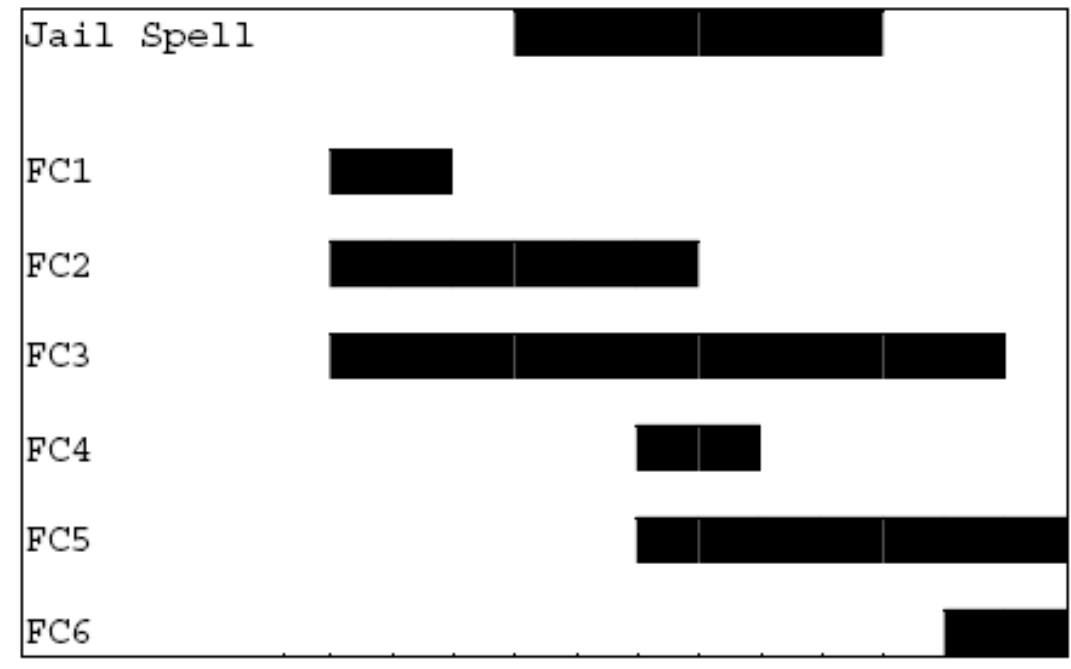

Figure B:

\begin{tabular}{|lcc|}
\hline & Total & $\begin{array}{c}\text { With } \\
\text { Education } \\
\text { Information }\end{array}$ \\
FC1 & 12805 & 8838 \\
FC2 & 208 & 134 \\
FC3 & 13286 & 9320 \\
FC4 & 12 & 5 \\
FC5 & 239 & 169 \\
FC6 & 5893 & 3682 \\
\hline
\end{tabular}


Figure 3

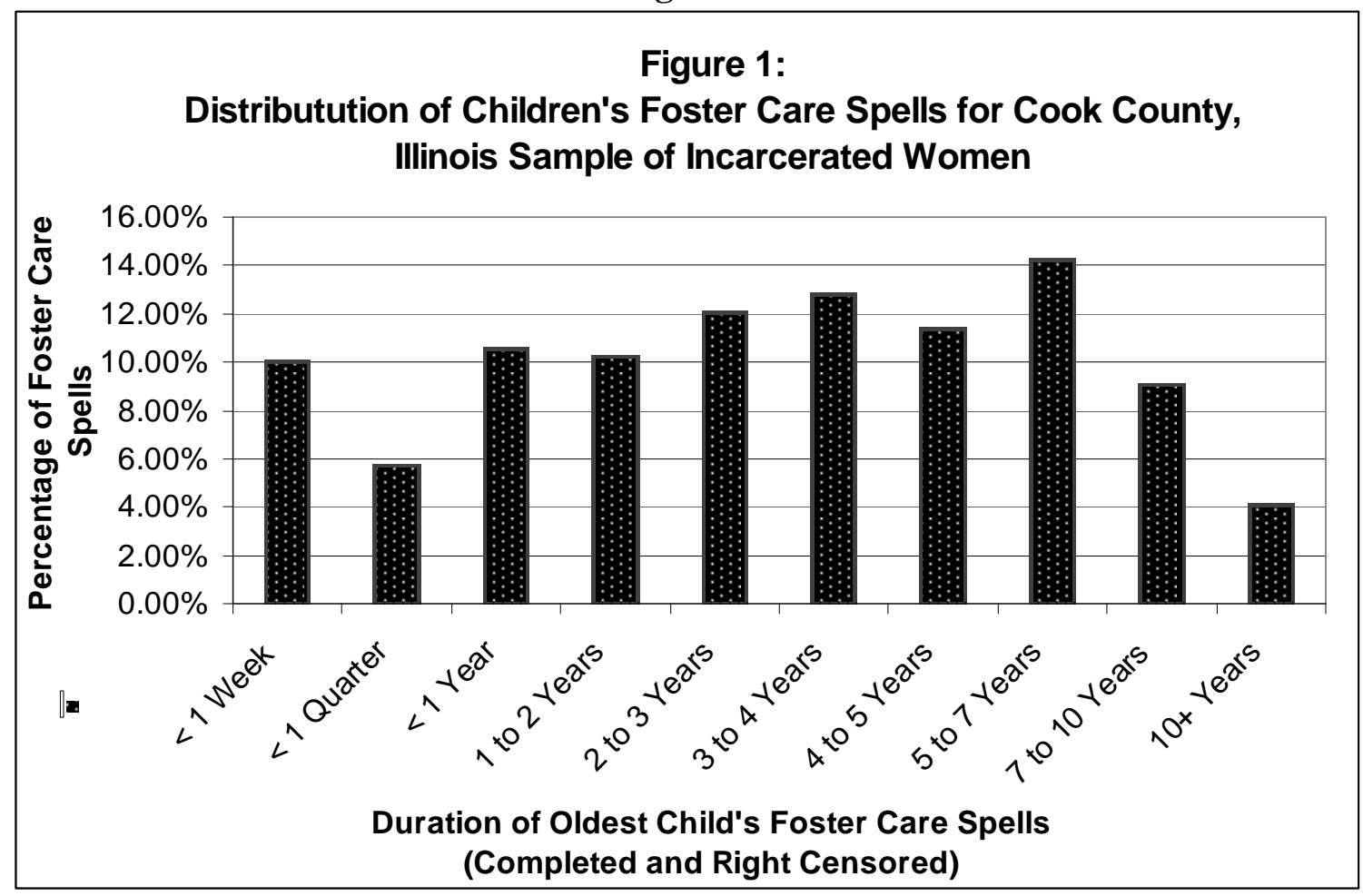


Figure 4

Empirical Probability Distribution of Completed Duration of Focal Child's Foster Care Spell (in days) When Spells Start Prior to First Prison Spell (End Prior to First Prison Spell: FC1; and Overlap First Prison Spell FC23)
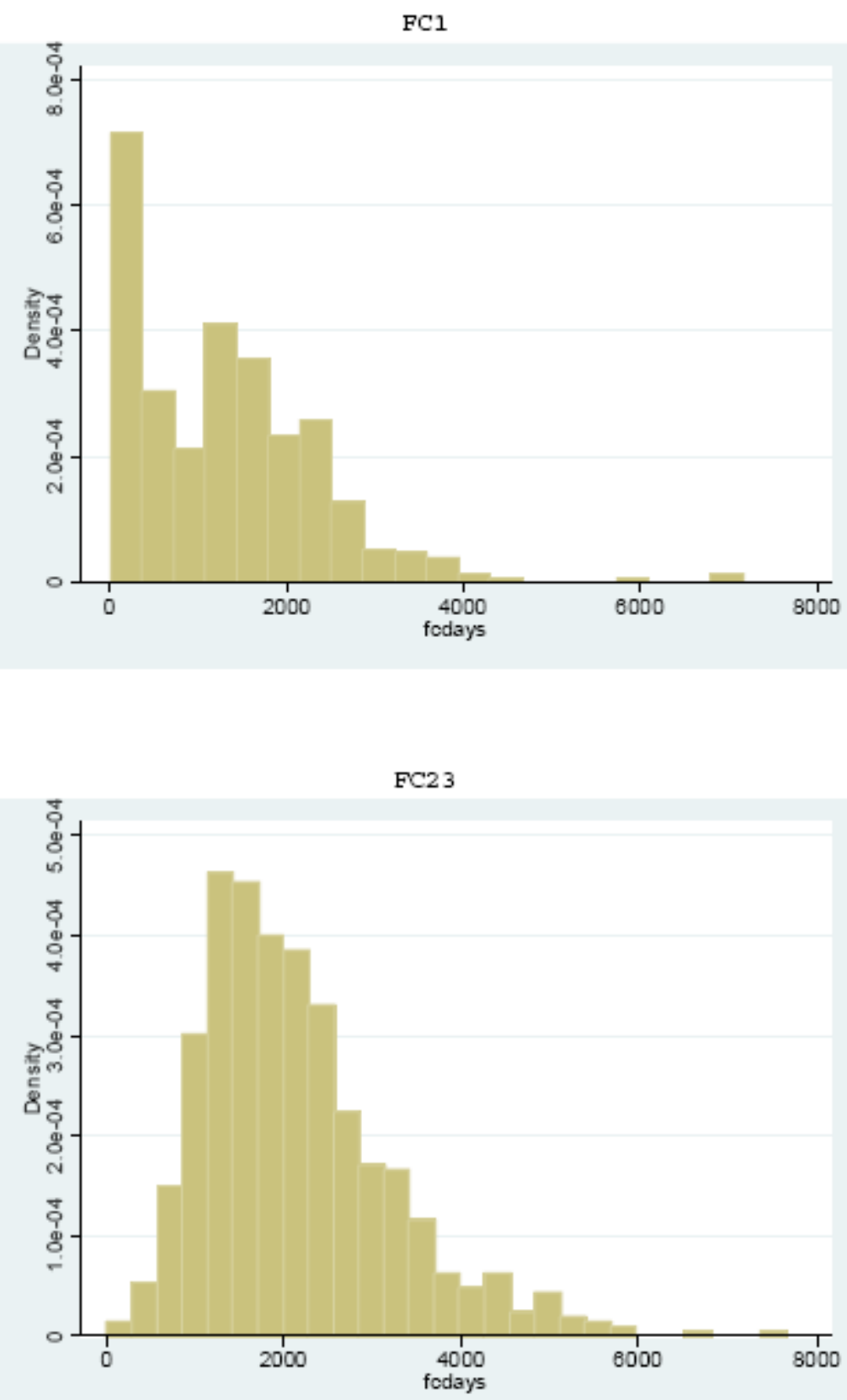


\section{Table A}

\section{Construction of Sample for Analysis}

Total Women Admitted to Cook County Jail

Between 10/92 and 11/02

52,896

Number of Incarcerated Women with a Child

Ever in Foster Care Prior to 12/02

Number of Own Children Ever in Foster Care:

1 child

2 children

$1,622(22.8 \%)$

3 children

$1,329(18.3 \%)$

4 children

$959(13.2 \%)$

5 or more children (19.1\%)

Incarceration Experience of Women With Children in Foster Care:

Ever in prison .........................

1,911

Only once in jail, no prison ......... $\quad 2,776$

More than once in jail, no prison .... $\quad 2,594$

Sample of Comparsion Group Members:

Only once in jail, no prison .......... 2,776

Incarcerated after $1 / 1 / 95 \ldots \ldots \ldots \ldots . . \quad 2,159$

Jail spell lasted less than one week .. $\quad 1,241$

Sample of Ex-State Prisoners:

Ever in prison ...................... 1,911

Incarcerated after 1/1/95 ........... $\quad 1,403$

Prison spell lasted at least 60 days ... $\quad 1,329$ 


\section{Table B}

\section{Estimates of the Effect of Time in Prison on the Probability of an Incarcerated Women Being Reunified With Here Child After Prison (Percentage Point Differences With Women in Short Jail Spells)}

\begin{tabular}{|c|c|c|c|c|c|c|c|}
\hline \multicolumn{8}{|c|}{ Timing of Foster Care and Short Jail Spells and The Probability of Reunification } \\
\hline Model & A & B & C & D & $\mathrm{E}$ & $\mathrm{F}$ & $\mathrm{F}$ \\
\hline Dependent Variable & Reunification & Reunification & Reunification & Reunification & Reunification & Reunification & Reunification \\
\hline \multicolumn{8}{|l|}{ Independent Variables } \\
\hline FC 1 & $\begin{array}{c}-0.033 \\
(0.026)\end{array}$ & $\begin{array}{c}-0.073 \\
(0.023)\end{array}$ & $\begin{array}{c}-0.059 \\
(0.027)\end{array}$ & $\begin{array}{l}-0.075 \\
(0.024)\end{array}$ & $\begin{array}{c}-0.071 \\
(0.030)\end{array}$ & $\begin{array}{l}-0.085 \\
(0.026)\end{array}$ & $\begin{array}{c}-0.080 \\
(0.025)\end{array}$ \\
\hline FC 23 & $\begin{array}{c}-0.300 \\
(0.018)\end{array}$ & $\begin{array}{c}-0.048 \\
(0.018)\end{array}$ & $\begin{array}{c}-0.227 \\
(0.018)\end{array}$ & $\begin{array}{c}-0.046 \\
(0.019)\end{array}$ & $\begin{array}{c}-0.221 \\
(0.022)\end{array}$ & $\begin{array}{c}-0.042 \\
(0.021)\end{array}$ & $\begin{array}{c}-0.053 \\
(0.020)\end{array}$ \\
\hline FC 6 & $\begin{array}{l}-0.087 \\
(0.028)\end{array}$ & $\begin{array}{l}-0.050 \\
(0.025)\end{array}$ & $\begin{array}{l}-0.125 \\
(0.028)\end{array}$ & $\begin{array}{l}-0.051 \\
(0.025)\end{array}$ & $\begin{array}{c}-0.129 \\
(0.029)\end{array}$ & $\begin{array}{l}-0.056 \\
(0.025)\end{array}$ & $\begin{array}{l}-0.054 \\
(0.025)\end{array}$ \\
\hline FC Ongoing (months) & & & $\begin{array}{l}-0.0448 \\
(0.0041)\end{array}$ & $\begin{array}{c}-0.0023 \\
(0.0045)\end{array}$ & $\begin{array}{c}-0.0449 \\
(0.0042)\end{array}$ & $\begin{array}{c}-0.0024 \\
(0.0046)\end{array}$ & $\begin{array}{c}-0.0022 \\
(0.0045)\end{array}$ \\
\hline Prison Spell $<2$ Years & & & & & $\begin{array}{c}\mathbf{0 . 0 1 7} \\
(0.031)\end{array}$ & $\begin{array}{c}0.018 \\
(0.027)\end{array}$ & $\begin{array}{c}0.010 \\
(0.019)\end{array}$ \\
\hline Prison Spell > 2 Years & & & & & $\begin{array}{c}0.073 \\
(0.052)\end{array}$ & $\begin{array}{c}0.045 \\
(0.045)\end{array}$ & $\begin{array}{c}0.027 \\
(0.035)\end{array}$ \\
\hline Interaction $\mathrm{PS}<2 \mathrm{Y}$ w FC23 & & & & & $\begin{array}{c}-0.018 \\
(0.041)\end{array}$ & $\begin{array}{c}-0.023 \\
(0.037)\end{array}$ & \\
\hline Interaction $\mathrm{PS}>2 \mathrm{Y}$ w FC23 & & & & & $\begin{array}{l}-0.103 \\
(0.072)\end{array}$ & $\begin{array}{c}-0.047 \\
(0.066)\end{array}$ & \\
\hline Controls & No & Yes & No & Yes & No & Yes & Yes \\
\hline \# of Observations & 2,472 & 2,472 & 2,472 & 2,472 & 2,472 & 2,472 & 2,472 \\
\hline R-Squared & 0.19 & 0.44 & 0.21 & 0.44 & 0.21 & 0.44 & 0.44 \\
\hline
\end{tabular}

Standard Errors in Parentheses 


\section{Table C}

Regression coefficients for other variables.

[To be supplied]

\section{Table D}

\section{The Distribution of Days in Jail for Mothers in the Short Jail Sample}

And the final distribution of them is:

\begin{tabular}{r|rrr} 
cjdays | & Freq. & Percent & Cum. \\
1 & 0 \\
2 & 93 & 7.49 & 7.49 \\
3 & 374 & 30.14 & 37.63 \\
4 & 248 & 19.98 & 57.61 \\
5 & 177 & 14.26 & 71.88 \\
6 & 120 & 9.67 & 81.55 \\
7 & 92 & 7.41 & 88.96 \\
-1 & 73 & 5.88 & 94.84 \\
Total & 1,241 & 100.00 & 100.00
\end{tabular}

